UMA COMPARAÇÃO DE REGRESSÃO LOGÍSTICA, ÁRVORES DE CLASSIFICAÇÃO

E REDES NEURAIS:

ANATISAYYDO DADOS DE CRÉDITO

Clavdia Ohtogh?

DISSERTAÇÃO APRESENT'ADA

$\mathrm{AO}$

INSTITUTO DE MATEMÁTICA E ESTATÍSTICA

DA

UNIVERSIDADE DE SÃO PAULO

PARA

OBTENÇǍO DO GRAU DE MESTRE

EM

ESTATÍSTICA

Área de Concentração: Estatística

Orientadora: Profa. Dra. Lúcia Pereira Barroso

- São Paulo, Abril de 2003 - 


\section{UMA COMPARAÇÃO DE REGRESSÃO LOGÍSTICA, ÁRVORES DE CLASSIFICAÇÃO \\ E REDES NEURAIS: ANALISANDO DADOS DE CRÉDITO}

Este exemplar corresponde à redação final da dissertação devidamente corrigida e defendida por Claudia Ohtoshi

e aprovada pela comissão julgadora.

São Paulo, Abril de 2003.

Banca examinadora:

- Profa. Dra. Lúcia Pereira Barroso (orientadora) - IME-USP

- Profa. Dra. Júlia Maria Pavan Soler - IME-USP

- Profa. Dra. Édina Shisue Miazaki - UnB 
A meus queridos pais, meu irmão Rodnei e meu marido Roberto 


\section{Agradecimentos}

Agradeço a todos que contribuíram para a elaboração deste trabalho, em especial:

- À Profa. Dra. Lúcia Pereira Barroso, por toda sua dedicação, paciência e imiensa disposição em me ajudar nos momentos difíceis que surgiram durante esta empreitada.

- A meus pais, Celso e Neusa, e a meu irmão Rodnei, que sempre carinhosamente me incentivaram e dos quais tenho muito orgulho.

- Ao meu marido Roberto, que com seu amor me apoiou durante os estudos e me suportou nos momentos de aflição.

- Aos meus superiores e demais colegas do Banco onde trabalho, que me apoiaram e me permitiram ausentar da empresa para me dedicar ao mestrado.

- Ao Departamento de Estatística do IME-USP, pela excelência dos professores, da estrutura oferecida aos alunos e dos programas de cursos existentes.

- À amiga de mestrado Cecília, pela qual tenho grande admiração por seu exemplo de força, coragem e determinação.

- Às amigas Cristina, Dulce, Hitomi e Neuci, que desde os tempos de faculdade até hoje continuam torcendo para que eu realize meus sonhos. 


\section{Resumo}

Este trabalho tem como finalidade comparar quatro técnicas: Redes Neurais Artificiais, Árvore de Classificação Binária, Real Attribute Learning Algorithm (REAL) e Regressão Logística, aplicadas para definir um modelo de classificação que permita avaliar o risco do cliente de uma dada instituição financeira se tornar inadimplente.

Para a construção desses modelos foram utilizadas variáveis cadastrais e de utilização, ou seja, são modelos baseados não somente nas características do cliente, mas também no seu perfil de comportamento quanto à utilização de conta-corrente e cheque especial.

Tais modelos têm sido utilizados por empresas que concedem crédito massificado, para classificar clientes quanto ao nível de risco e conceder novos créditos ou definir limites em função desse risco.

Como resultado do estudo, foi observado que as Redes Neurais Artificiais e a Regressão Logística tiveram acerto superior às demais técnicas. 


\section{Conteúdo}

1 Introdução 1

2 Descrição dos Dados $\quad 3$

$\begin{array}{lll}3 & \text { Regressão Logística } & 7\end{array}$

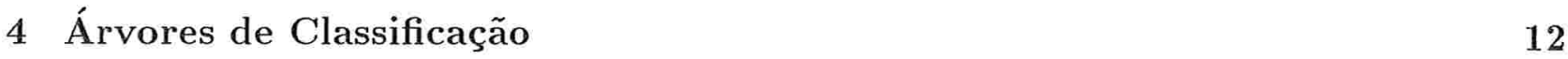

4.1 Árvore de Classificação Binária . . . . . . . . . . . . . . . . . . . 12

4.2 REAL : Real Attribute Learning Algorithm . . . . . . . . . . . . . . 18

4.2 .1 Construção da Árvore . . . . . . . . . . . . . . . . . . . . . . . 18

4.2 .2 Medida de Convicção e Função de Perda . . . . . . . . . . . . . . . 19

4.2 .3 Discretização das Variáveis Independentes . . . . . . . . . . . . . 20

4.2 .4 Ramificação e Agrupamento . . . . . . . . . . . . . . . . . . . 21

5 Redes Neurais Artificiais $\quad 22$ 
5.1 Definição. . . . . . . . . . . . . . . . . . . 22

5.2 Tipos de Arquitetura . . . . . . . . . . . . . . . . . . 24

5.2 .1 Redes com uma camada . . . . . . . . . . . . . 26

5.2 .2 Redes Multicamadas . . . . . . . . . . . . . . . . 28

5.3 Algoritmos de Treinamento . . . . . . . . . . . . . . . 28

5.4 Funções de Ativação . . . . . . . . . . . . . . . . . . . . 38

5.5 Redes Neurais em Problemas de Classificação . . . . . . . . . . . . . . . 39

6 Resultados

6.1 Seleção das Amostras . . . . . . . . . . . . . . . . . . . . . 45

6.2 Transformação das Variáveis . . . . . . . . . . . . . . . . . 47

6.3 Aplicação das Técnicas . . . . . . . . . . . . . . . . . 48

6.3 .1 Regressão Logística . . . . . . . . . . . . . . . . . . . . 48

6.3.2 Árvore de Classificação Binária . . . . . . . . . . . . . . . 51

6.3 .3 REAL ............................... 54

6.3 .4 Rede Neural Artificial . . . . . . . . . . . . . . . . . 56

6.4 Comparação dos modelos . . . . . . . . . . . . . . . . . 58

7 Conclusões 
A Variáveis Preditoras

B Valor de Informação ( $V I)$

68

C Escolha dos Parâmetros do REAL

Bibliografia 


\section{Capítulo 1}

\section{Introdução}

A atividade de concessão de crédito para uma grande quantidade de consumidores, executada por bancos, supermercados, lojas de varejo e várias outras organizações, tem crescido rapidamente nos últimos 30 anos. Métodos tradicionais de decisão, baseados na experiência passada de um analista de crédito, tornaram-se ultrapassados e ineficientes em razão do aumento na demanda por crédito, aliado a um ambiente de maior competição internacional e ao avanço computacional. Assim, cada dia mais, modelos estatísticos sofisticados, construídos a partir de dados históricos, têm sido utilizados tanto para auxiliar na decisão sobre a concessão de crédito a um novo cliente, quanto para lidar com clientes existentes, incluindo a decisão de aumentar ou reduzir seus limites de crédito. $\mathrm{O}$ conjunto de modelos de decisão e técnicas subjacentes que ajudam na primeira decisão é denominado de credit scoring, enquanto que para o segundo tipo de decisão é chamado de behavioral scoring.

Em ambos os casos utilizam-se métodos estatísticos usuais, como Análise Discriminante, Regressão Logística e Árvores de Classificação, para a construção de modelos que consigam discriminar entre clientes "bons" e "ruins" de crédito. Uma técnica mais recentemente desenvolvida, baseada no funcionamento do cérebro humano, é um sistema de processamento conhecido por Rede Neural Artificial. Trabalho recente de Rosa (2000) tratou da questão de avaliação de risco de crédito. Entretanto ele não considerou Redes Neurais para a solução 
de problemas de classificação, deixando-as como indicação para trabalhos futuros. Ferreira (1999) considerou Redes Neurais, comparando seus resultados com os da Regressão Logística e da Árvore de Classificação. Faltou entretanto fazer a comparação com o REAL (Real Attribute Learning Algorithm), algoritmo desenvolvido por Stern et al. (1996) que foi avaliado por Rosa (2000).

Neste trabalho, é feito um estudo comparativo entre Redes Neurais e o REAL em relação a duas técnicas estatísticas usuais: Regressão Logística e Árvores de Classificação Binária. Outra possibilidade seria fazer a comparação com Análise Discriminante (vide Oliveira (2000) e Desai et al. (1996)). Entretanto várias variáveis consideradas neste trabalho são categorizadas e o uso da transformação para variáveis binárias não levaria a bons resultados. Uma discussão sobre ganhos e perdas quando se categorizam variáveis quantitativas é dada em Rosa (2000). Neste trabalho, a comparação entre as técnicas é feita para um conjunto de dados reais de uma institutição financeira brasileira.

O trabalho é desenvolvido na seguinte seqüência: no Capítulo 2 são descritos os dados utilizados e nos Capítulos 3, 4 e 5, as técnicas de Regressão Logística, Árvores de Classificação (Binária e REAL) e Redes Neurais Artificiais, respectivamente. Maior ênfase foi dada a Redes Neurais e REAL por tratarem-se de técnicas mais recentes e menos usuais, sendo as outras mais exaustivamente estudadas, discutidas e aplicadas na literatura estatística. Os resultados da análise dos dados, a performance das técnicas são dadas no Capítulo 6 e as conclusões finais são dadas no Capítulo 7. 


\section{Capítulo 2}

\section{Descrição dos Dados}

O principal motivo que diferencia entre a abordagem de credit scoring e behavioral scoring é o fato de que na segunda há mais variáveis disponíveis para a construção do modelo. Além de dados cadastrais e informações de restrição de crédito provenientes de empresas que prestam esse serviço, há características que descrevem o comportamento de pagamento e utilização de produtos dos clientes. Esses dados são obtidos a partir do histórico dos clientes, conforme o fluxo descrito por Thomas et al. (2002). Um particular ponto no tempo é escolhido como o ponto de observação. Um período anterior a esse ponto, por exemplo, 6 ou 12 meses, é designado como o período de "performance" e as características relativas a este período são construídas para serem adicionadas aos dados cadastrais e restritivos dos clientes. Um outro período, por exemplo, 12 meses após o ponto de observação, é considerado para avaliação dos clientes em relação ao comportamento de pagamento de crédito. Ao final desse período, no ponto de avaliação, os clientes são classificados como "bons" ou "ruins" dependendo de seu status de inadimplência no momento da verificação.

Para a aplicação das técnicas que serão apresentadas nos próximos capítulos, foi utilizada uma base com 106.696 clientes que tomaram pelo menos um empréstimo antes de 31 de dezembro de 1999, em uma dada instituição financeira brasileira. Esta base é composta por 38 variáveis independentes, sendo 18 cadastrais e 20 de utilização. 
As variáveis cadastrais referem-se às características constantes no formulário que uma pessoa preenche ao abrir uma conta-corrente em um banco. Esses dados são geralmente armazenados em meio magnético e compõem o cadastro de clientes da instituição. Neste trabalho foram consideradas as informações existentes no cadastro em 31 de dezembro de 1999 (ponto de observação).

As variáveis de utilização referem-se às características que descrevem o comportamento do cliente na utilização de produtos e serviços bancários. Neste trabalho foram utilizadas as informações, mês a mês, da conta-corrente e das operações (empréstimos) do cliente, nos últimos seis meses do ano de 1999 (período de "performance").

Além dessas informações, foi usado o conceito do cliente quanto a seu comportamento de pagamento de empréstimos na instituição, avaliado em determinado período. Assim, no ponto de avaliação (31 de dezembro de 2000), o cliente foi classificado como "bom"(CONCEITO $=1$ ), quando não possuía anotações cadastrais restritivas ${ }^{1}$ e seus empréstimos não apresentaram pagamentos com atraso superior a 10 dias, ao longo do ano de 2000 e como "ruim" $($ CONCEITO $=0)$, quando seus empréstimos apresentaram pagamentos com atraso superior a 60 dias, ao longo do ano de 2.000. Os clientes, cujos empréstimos apresentaram pagamentos com atraso superior a 10 dias e inferior a 60 dias, foram excluídos da base de análise. Assim, a variável CONCEITO ficou com 98.327 clientes "bons" e 8.369 "ruins", uma relação de aproximadamente 12 clientes "bons" para 1 "ruim". Essa última variável é utilizada como variável dependente $(Y)$, a fim de se determinar uma regra de classificação.

Nas Tabelas A.1 e A.2 do Apêndice A estão listadas as variáveis cadastrais e de utilização, suas descrições e seus atributos de respostas.

Para cada variável foi calculado o valor da informação definido por Hand e Henley (1997)

\footnotetext{
${ }^{1}$ Anotação cadastral restritiva refere-se a um apontamento que o cliente tem no cadastro da própria instituição ou de empresas prestadoras de informações (SERASA, SPC, etc.), que restringe acesso a crédito, em função de algum problema de crédito no mercado.
} 
como

$$
V I=\sum_{j}\left(p b_{j}-p r_{j}\right) \cdot e_{j}
$$

em que

$p b_{j}$ é a freqüência relativa de clientes "bons" na categoria $j$ da variável considerada, em relação ao número total de clientes "bons";

$p r_{j}$ é a freqüênçia relativa de clientes "ruins" na categoria $j$ da variável considerada, em relação ao número total de clientes "ruins" e

$e_{j}=\ln \left(p b_{j} / p r_{j}\right)$ é denominado peso de evidência da categoria $j$ da variável considerada.

O peso de evidência de uma categoria de uma variável assumirá valor zero se a proporção de clientes "bons" e a proporção de clientes "ruins" nessa categoria forem iguais. Nesse caso a categoria não contribuirá para a discriminação dos clientes. Quanto mais distante de zero for o peso de evidência maior é o poder de discriminação da categoria. Se o valor é positivo a categoria discrimina clientes "bons"; se é negativo, clientes "ruins". Os pesos de evidência podem ser usados como valores das variáveis preditoras em lugar de suas categorias.

Se os valores observados de $p b_{j}$ e $p r_{j}$ forem iguais para todas as categorias de uma variável, o valor de informação dessa variável é zero, e esta nada contribui para a regra de classificação. Quanto maiores forem as diferenças entre $p b_{j}$ e $p r_{j}$ mais informação a variável conterá. Assim, o valor de informação é um indicativo de quais variáveis têm maior poder de explicação para o modelo.

As tabelas de freqüências e respectivos valores de informação das variáveis e pesos de evidência das categorias são apresentadas no Apêndice B.

Analisando essas tabelas, pode-se concluir que as variáveis (categorias das variáveis) que mais parecem contribuir para a discriminação de clientes "bons" e "ruins" são, na ordem: "Tem restrições SERASA" ( $\operatorname{sim})$, "Tem restrições" ( $\operatorname{sim})$, "Utilização média de cheque especial" $(<0,05)$, "Utilização máxima de cheque especial" $(<0,10)$, "Dias de excesso em cheque especial" (nenhum dia) e "Saldo médio em conta corrente e investimentos" ( $\geq$ R $\$$ 500). As duas primeiras variáveis discriminam clientes "ruins"; as 4 últimas, clientes "bons". 
As variáveis que menos contribuem para a discriminaçầo são: "Tem plano de previdência particular", "Número de meses desde o menor saldo em conta corrente", "Número de meses do menor saldo em conta corrente e investimentos", "Tem plano de saúde particular" e "Sexo". 


\section{Capítulo 3}

\section{Regressão Logística}

Neste capítulo é descrita a técnica mais usual utilizada para a construção de modelos de regressão quando a variável dependente é categorizada : Regressão Logística. Aqui é descrito somente o caso em que a variável categorizada é dicotômica, por ser a situação de interesse neste trabalho. Para uma extensão do caso em que a variável dependente possui mais do que duas categorias sugere-se a leitura de Hosmer e Lemeshow (1989).

Muitas funções de distribuição foram estudadas para serem usadas na análise de uma variável dependente dicotômica. Cox (1970) e Walker e Duncan (1967) propuseram o uso da distribuição logística, baseado na suposição de que o logaritmo da razão das probabilidades de duas categorias é linear.

Considere o caso em que observações podem ser classificadas em uma de duas categorias mutuamente exclusivas ( 1 ou 0 ). Como um exemplo, as categorias 1 e 0 poderiam representar, respectivamente, os eventos em que um indivíduo pode ser classificado como cliente "bom" (pagará todos os empréstimos contraídos no prazo de 10 dias) ou cliente "ruim" (deixará de pagar algum empréstimo ou está inadimplente há mais de 60 dias).

Então seja $Y$ a variável dependente binária que indica se um cliente pertence à categoria 
1, ou seja,

$$
Y_{i}= \begin{cases}1, & \text { se o } i \text {-ésimo indivíduo pertence à categoria dos clientes "bons" } \\ 0, & \text { se o } i \text {-ésimo indivíduo pertence à categoria dos clientes "ruins" }\end{cases}
$$

e seja $\mathbf{x}=\left(1, x_{1}, x_{2}, \ldots, x_{p}\right)^{\prime}$ o vetor, cujo primeiro elemento é 1 e os demais são os valores observados de $p$ variáveis explicativas ( $\mathrm{x}_{i}$ é o vetor associado ao $i$-ésimo indivíduo).

O modelo de Regressão Logística é um caso particular dos Modelos Lineares Generalizados (McCullagh e Nelder, 1989), cuja função de ligação é definida por

$$
\ln \left\{\frac{\pi(\mathrm{x})}{1-\pi(\mathrm{x})}\right\}=\beta^{\prime} \mathrm{x}
$$

em que

$\boldsymbol{\beta}^{\prime}=\left(\beta_{0}, \beta_{1}, \beta_{2}, \ldots, \beta_{p}\right)^{\prime}$ : vetor de parâmetros desconhecidos;

$\pi(\mathrm{x})=E(Y=1 \mid \mathrm{x})=P(Y=1 \mid \mathrm{x})$ : probabilidade de que o cliente esteja no grupo de "bons" clientes, dado o vetor de variáveis $\mathrm{x}$.

Esta probabilidade pode ser expressa como

$$
\pi(\mathrm{x})=\frac{\exp \left(\boldsymbol{\beta}^{\prime} \mathrm{x}\right)}{1+\exp \left(\boldsymbol{\beta}^{\prime} \mathbf{x}\right)}
$$

e o modelo pode ser escrito como

$$
Y=\pi(\mathrm{x})+\varepsilon
$$

em que $\varepsilon$ é o erro aleatório do modelo.

Como $Y$ pode assumir somente dois valores, o erro $\varepsilon$ também pode assumir somente dois valores, ou seja,

- se $Y=1$, então $\varepsilon=1-\pi(\mathrm{x})$, com probabilidade $\pi(\mathrm{x})$,

- se $Y=0$, então $\varepsilon=-\pi(\mathrm{x})$, com probabilidade $1-\pi(\mathrm{x})$,

isto é, $\varepsilon$ segue uma distribuição com média 0 e variância $\pi(\mathrm{x})(1-\pi(\mathrm{x}))$. A distribuição condicional de $Y$, dado o vetor $\mathrm{x}$, é Bernoulli com probabilidade de sucesso igual a $\pi(\mathrm{x})$. É possivel estimar $\pi(\mathrm{x})$ através da estimativa de $\beta^{\prime} \mathrm{x}$. 
$\mathrm{O}$ vetor de parâmetros $\beta$ é estimado maximizando-se a função de verossimilhança em relação aos $p+1$ elementos do vetor (Hosmer e Lemeshow, 1989). As soluções são obtidas por métodos iterativos, em especial o Método de Mínimos Quadrados Reponderados, tal que o passo $(m+1)$ do algoritmo leva a

$$
\boldsymbol{\beta}^{(m+1)}=\left(\mathbf{X}^{\prime} \mathbf{V}^{(m)} \mathbf{X}\right)^{-1} \mathbf{X}^{\prime} \mathbf{V}^{(m)} \mathbf{z}^{(m)},
$$

em que

$m=0,1, \ldots ;$

$\pi_{i}=P\left(Y_{i}=1 \mid \mathrm{x}_{i}\right)$ : probabilidade de que o $i$-ésimo cliente seja classificado como "bom";

$\mathbf{X}_{(n \times(p+1))}$ : matriz das variáveis explicativas dos $n$ indivíduos da amostra;

$\mathbf{V}=\operatorname{diag}\left[\pi_{1}\left(1-\pi_{1}\right), \pi_{2}\left(1-\pi_{2}\right), \ldots, \pi_{n}\left(1-\pi_{n}\right)\right]$

$\mathrm{z}=\left(z_{1}, z_{2}, \ldots, z_{n}\right)^{\prime}:$ vetor de variáveis dependentes modificadas como a seguir,

$z_{i}=\eta_{i}+\frac{\left(y_{i}-\pi_{i}\right)}{\left[\pi_{i}\left(1-\pi_{i}\right)\right]}$

$\eta_{i}=\ln \left\{\frac{\pi_{i}}{1-\pi_{i}}\right\}, i=1,2, \ldots, n$.

Para iniciar o algoritmo é necessário atribuir valores iniciais a $\pi_{i}, i=1,2, \ldots, n$. Para estimar as variâncias e covariâncias dos estimadores dos parâmetros, o caminho mais comum é utilizar a teoria da verossimilhança, ou seja, obter estimadores pela inversão da matriz de informação dada pelas segundas derivadas parciais do logaritmo na última iteração. Assintoticamente, a variância de $\hat{\beta}$ é dada por $\left(\mathbf{X}^{\prime} \mathbf{V X}\right)^{-1}$.

Na Regressão Logística há várias maneiras de avaliar o ajuste do modelo. Aqui destacamos algumas delas; entretanto, mais informações e detalhes podem ser encontrados em Pregibon (1981), Hosmer e Lemeshow (1989), Neter et al.(1996) e Paula (1997).

A adequacidade do modelo pode ser avaliada através do teste da razão de verossimilhanças. A estatística do teste, também conhecida como desvio do modelo, é

$$
D=-2 \sum_{i=1}^{n}\left[y_{\mathrm{i}} \ln \left(\frac{\hat{\pi}_{i}}{y_{i}}\right)+\left(1-y_{i}\right) \ln \left(1-\frac{\hat{\pi}_{i}}{y_{i}}\right)\right]
$$

em que $\hat{\pi}_{i}=\hat{\pi}\left(\mathbf{x}_{i}\right)$. Sob a hipótese nula, essa estatística segue aproximadamente uma distribuição Qui-Quadrado com $n-(p+1)$ graus de liberdade e valores altos da mesma indicam falta de ajuste. 
No caso do teste univariado sobre cada parâmetro $\left(H_{0}: \beta_{k}=0, k=0,1,2, \ldots, p\right)$ uma alternativa é a utilização do Teste de Wald (Rao, 1973), cuja estatística é dada por

$$
w_{k}=\frac{\hat{\beta}_{k}}{\hat{E P}\left(\hat{\beta}_{k}\right)} \text {, }
$$

em que $\hat{E P}\left(\hat{\beta}_{k}\right)$ é o estimador do erro padrão de $\hat{\beta}_{k}$. Sob a hipótese nula, essa estatística tem distribuição assintótica Normal Padrão.

Duas medidas baseadas na diferença entre os valores observados e os valores ajustados podem auxiliar na detecção de valores discrepantes; são o resíduo de Pearson e o desvio residual. Para definir esses resíduos considere a seguinte notação:

$L:$ número de valores observados distintos de $\mathrm{x}$;

$m_{l}$ : número de observações com $\mathrm{x}=\mathrm{x}_{l}, l=1,2, \ldots, L$;

$y_{l}$ : número de vezes que $Y$ assume o valor 1 dentre as observações que apresentam $\mathrm{x}=\mathrm{x}_{l}$; $\hat{\pi}_{l}$ : estimativa de $\pi\left(\mathrm{x}_{l}\right)$.

O resíduo de Pearson para o $l$-ésimo valor de $\mathrm{x}$ é dado por

$$
\chi_{l}=\frac{y_{l}-m_{l} \hat{\pi}_{l}}{\sqrt{m_{l} \hat{\pi}_{l}\left(1-\hat{\pi}_{l}\right)}}
$$

e o desvio residual por

$$
d_{l} \pm\left\{2\left[y_{l} \ln \left(\frac{y_{l}}{m_{l} \hat{\pi}_{l}}\right)+\left(m_{l}-y_{l}\right) \ln \left(\frac{m_{l}-y_{l}}{m_{l}\left(1-\hat{\pi}_{l}\right)}\right)\right]\right\}^{1 / 2}
$$

onde o sinal + ou - é o mesmo sinal de $\left(y_{l}-m_{l} \hat{\pi}_{l}\right)$.

Um gráfico desses resíduos versus o seu índice $l$ ou $\hat{\pi}_{l}$ podem indicar dados discrepantes. Além disso, os resíduos podem ser resumidos nas estatísticas $\chi^{2}=\sum_{l=1}^{L} \chi_{l}^{2}$ e $D=\sum_{l=1}^{L} d_{l}^{2}$. Sob a suposição de que o modelo é adequado, as distribuições de $\chi^{2}$ e $D$ são aproximadamente Qui-Quadrado com $L-(p+1)$ graus de liberdade. A indicação de não adequacidade do modelo é dada por valores altos de $\chi^{2}$ e $D$.

Outra maneira de avaliar o ajuste do modelo é a aplicação do teste desenvolvido por Hosmer e Lemeshow (1989). Esse teste é baseado em probabilidades estimadas, ordenadas de forma 
crescente e agrupadas em $g$ grupos. Esse agrupamento pode ser feito com base em percentis, ou seja, dividir as probabilidades estimadas em $g$ grupos com o mesmo número de observações por grupo $(n / g)$ ou em valores fixados; por exemplo, o primeiro grupo conteria as observações cujas probabilidades estimadas são menores do que 0,10 ; o segundo as que têm probabilidade entre 0,10 e 0,20 e assim por diante.

A estatística do teste é a estatística de Qui-Quadrado de Pearson aplicada a uma tabela de dimensão $2 \times g$, isto é,

$$
\hat{C}=\sum_{k=1}^{g} \frac{\left(o_{k}-n_{k} \bar{\pi}_{k}\right)^{2}}{n_{k} \bar{\pi}_{k}\left(1-\bar{\pi}_{k}\right)}
$$

em que

$n_{k}$ : número de observações no $k$-ésimo grupo;

$o_{k}$ : número de observações no $k$-ésimo grupo $\operatorname{com} Y=1$;

$\bar{\pi}_{k}$ : média das probabilidades estimadas das observações.

Segundo Hosmer e Lemeshow (1989), quando $L=n$ e o modelo é bem ajustado, $\hat{C}$ tem distribuição aproximadamente Qui-Quadrado com $g-2$ graus de liberdade. A falta de ajuste é indicada por valores altos de $\hat{C}$.

A regra de classificação em uma das populações consiste em estimar $\pi(\mathrm{x})$ para uma nova observação $\mathrm{x}_{c}$ : se $\hat{\pi}\left(\mathrm{x}_{c}\right) \geq 0,50$, classificar a observação no grupo dos clientes "bons"; caso contrário, no grupo dos "ruins". 


\section{Capítulo 4}

\section{Árvores de Classificação}

Neste capítulo é considerada a classificação em uma de $g$ populações e são descritos dois tipos de Árvores de Classificação : a binária e o REAL. Outros métodos não paramétricos são detalhados em Sanda (1990).

\section{1 Árvore de Classificação Binária}

A análise com Árvore de Classificação Binária é um método não paramétrico utilizado para explorar a estrutura de um conjunto de dados, podendo ser utilizado tanto em problemas de regressão como de classificação. Nestes problemas há um conjunto de variáveis explicativas $\mathrm{x}$ e uma única variável dependente $Y$. Foi primeiramente descrita no livro de Breiman et al.(1984) e é uma extensão do algoritmo AID (Automatic Interaction Detection) proposto por Morgan e Sonquist (1963). A apresentação de árvores de classificação descrita aqui segue a discussão desse livro.

A Árvore de Classificação Binária é um conjunto de regras, dispostas na forma de árvore, determinadas por um procedimento conhecido como particionamento recursivo. 
A idéia implícita na árvore de classificação é dividir a amostra de dados em grupos cada vez mais homogêneos em relação às categorias da variável dependente até que todos os subgrupos sejam suficientemente homogêneos e não possam mais ser divididos.

Assim, uma árvore de classificação $T$ para uma variável dependente categorizada $Y$ é construída por repetidamente dividir uma amostra em dois subconjuntos descendentes "mais puros", com elementos pertencentes à mesma categoria da variável dependente, do que o subconjunto matriz. O problema principal é como utilizar as variáveis explicativas para dividir a amostra de forma otimizada formando subconjuntos menores e mais puros. A regra denotada por $s$ para dividir a amostra em dois subgrupos usa as variáveis explicativas de acordo com o critério que será descrito a seguir. Os subgrupos são chamados de nós. A amostra inteira é denotada como nó raiz e é representado por $t_{1}$. Conseqüentemente, os nós descendentes são batizados por $t_{L}$ para a subamostra descendente à esquerda e por $t_{R}$ para a subamostra descendente à direita. Subgrupos que não são mais divididos são chamados de nós terminais. Graficamente, os nós e regras de partição, denotados respectivamente por $t$ e $s$, podem ser visto na Figura 4.1.

Figura 4.1: Um Exemplo de Árvore de Classificação

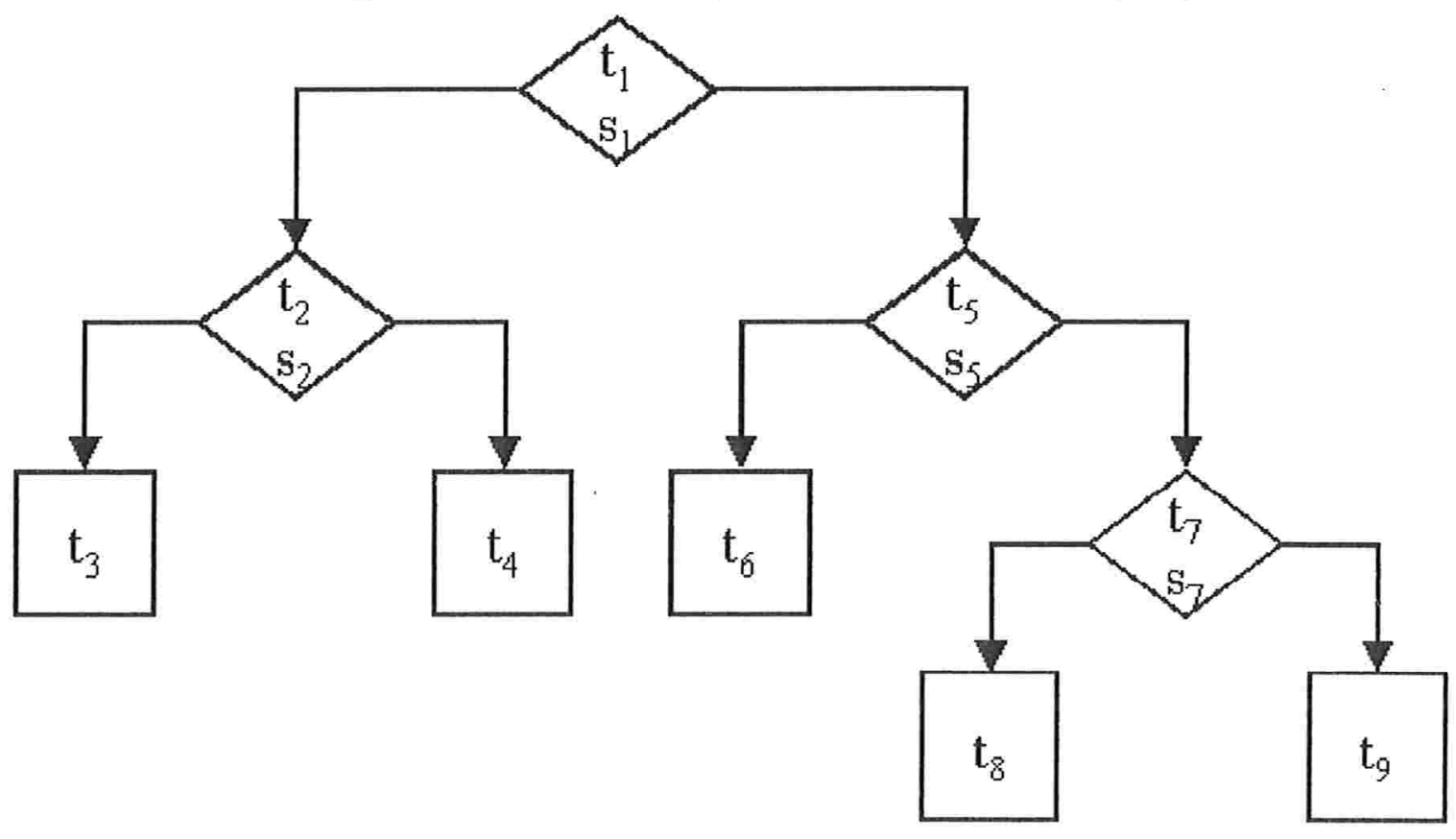


Neste exemplo, $t_{1}$ é o nó raiz que é dividido de acordo com a regra $s_{1}$ em dois subconjuntos descendentes $t_{2}$ e $t_{5}$, ou seja $t_{2}$ é o nó descendente à esquerda e $t_{5}$ é o nó descendente à direita do nó matriz $t_{1}$. Então $t_{2}$ é dividido de acordo com a regra $s_{2}$ em mais dois nós descendentes $t_{3}$ e $t_{4}$. Uma vez que esses nós não são mais divididos, eles são nós terminais. O nó $t_{5}$ é dividido de acordo com a regra $s_{5}$ em dois nós descendentes $t_{6}$ e $t_{7}$ dos quais $t_{6}$ é um nó terminal. Finalmente $t_{7}$ se divide de acordo com $s_{7}$ nos nós terminais $t_{8}$ e $t_{9}$.

Para determinar a partição de um nó qualquer $t$ em $t_{L}$ e $t_{R}$, considera-se inicialmente o conjunto $S(t)$ de todas as possíveis regras de partição $s$ em relação ao nó $t$. Cada regra de partição $s$ é definida em função de uma das variável $X_{j}(j=1, \ldots, p)$ do vetor $\mathbf{x}$.

No caso de variáveis explicativas quantitativas, um exemplo de regra poderia ser $s_{1}$ definida como

$$
s_{1}: t_{L}=\left\{\mathrm{x} \in t \mid x_{1} \leq 3\right\} \text { e } t_{R}=\left\{\mathrm{x} \in t \mid x_{1}>3\right\}
$$

No caso de variáveis explicativas categorizadas, um exemplo de regra poderia ser $s_{2}$ definida como

$$
s_{2}: t_{L}=\left\{\mathrm{x} \in t \mid x_{2} \in\{1,2\}\right\} \quad \text { e } t_{R}=\left\{\mathrm{x} \in t \mid x_{2} \in\{3\}\right\},
$$

em que $X_{2}$ é uma variável categorizada que assume os valores $\{1,2,3\}$.

Em seguida, é necessário determinar a regra de partição $s \in S$ que melhor separa as populações subjacentes da variável dependente, denominada de regra de partição ótima e denotada por $s^{*}$. Uma vez determinada essa regra, $t$ é particionado em $t_{R}$ e $t_{L}$ de acordo com $s^{*}$. O processo se repete sucessivamente, considerando os nós subjacentes $t_{R}$ e $t_{L}$ criados, até que o nó subjacente criado se torne "puro", ou seja, as observações provenham da mesma população ou tenha poucas observações de outras populações (usualmente, em torno de 5). O nó puro é o que denominamos anteriormente de nó terminal.

Um dos critérios utilizados para determinar a regra de partição ótima s* é o critério de Gini, que se baseia no somatório das variâncias das observações em um determinado nó. Denotando a $i$-ésima população por $\tau_{i}, i=1,2, \ldots, g$ e redefinindo as observações no nó $t$ como 1 se a 
observação provier de $\tau_{i}$ e 0 , caso contrário, a variância amostral destas observações será estimada por $\hat{P}\left(\tau_{i} \mid t\right)\left(1-\hat{P}\left(\tau_{i} \mid t\right)\right)$, onde

$$
\hat{P}\left(\tau_{i} \mid t\right)=\frac{\hat{p}_{i} n_{i}(t)}{n_{i} \hat{P}(t)},
$$

$p_{i}$ é a probabilidade a priori da $i$-ésima população, que geralmente é estimada por $\frac{n_{i}}{n}$ ou é considerada igual para todas as populações, isto é, $\frac{1}{g}, n_{i}(t)$ é o número de casos da população $i$ no nó $t, n_{i}$ é o número de casos na população $i$ e $\hat{P}(t)$ é a probabilidade estimada de que uma observação esteja no nó $t$, dada por

$$
\hat{P}(t)=\sum_{j=1}^{g} \frac{\hat{p}_{j} n_{j}(t)}{n_{j}} .
$$

Somando-se essas variâncias para todas as populações obtemos a medida de impureza de Gini, dada por

$$
i(t)=\sum_{i=1}^{g} \hat{P}\left(\tau_{i} \mid t\right)\left(1-\hat{P}\left(\tau_{i} \mid t\right)\right),
$$

que indica o grau de heterogeneidade das observações no nó em questão, ou seja, quanto menor essa medida, mais homogêneas são as observações no nó.

A medida de Gini pode ser reescrita como

$$
i(t)=1-\sum_{i=1}^{g} \hat{P}^{2}\left(\tau_{i} \mid t\right)
$$

uma vez que $\sum_{i=1}^{g} \hat{P}\left(\tau_{i} \mid t\right)=1$.

Essa medida atinge o valor máximo quando $\hat{P}^{2}\left(\tau_{i} \mid t\right)=1 / g$ para $i=1, \ldots, g$ e valor mínimo quando o nó $t$ for "puro", ou seja, quando $\hat{P}^{2}\left(\tau_{i} \mid t\right)=1$, para algum $i$ e $\hat{P}^{2}\left(\tau_{h} \mid t\right)=0$, para todo $h \neq i$. Por isso, $i(t)$ é denominado medida de impureza do nó $t$.

A melhor partição de um nó $t$ em $t_{R}$ e $t_{L}$ é dada pela regra ótima $s^{*}$ que maximiza

$$
\Delta i(s, t)=i(t)-P_{L} i\left(t_{L}\right)-P_{R} i\left(t_{R}\right),
$$

em que $P_{L}$ é a probabilidade de uma observação ser classificada como membro do nó descendente esquerdo e $P_{R}$ é a probabilidade de uma observação ser classificada como membro do 
nó descendente direito. A partição ótima é aquela que maximiza o descréscimo na impureza da árvore inicial $i(t)$.

A função $\Delta i(s, t)$ é maximizada em uma rotina de dois passos. Primeiro, para cada variável explicativa qualitativa encontra-se a categoria ou subconjunto de categorias $A$ que maximiza $\Delta i(s, t)$, ou seja, se uma observação do nó original pertence à categoria $A$ então ela é alocada no nó descendente esquerdo; caso contrário, no nó descendente direito. Se a variável explicativa é quantitativa, um valor $c$ é escolhido de modo a maximizar $\Delta i(s, t)$, ou seja, se uma observação é menor ou igual a $c$ então ela é alocada no nó descendente esquerdo; caso contrário, no nó descendente direito. Segundo, escolhe-se a variável que conduz ao maior valor de $\Delta i(s, t)$ em relação a todas as variáveis explicativas. O processo de partição segue nos nós descendentes até que a árvore não possa ser mais particionada, ou seja, quando atinge o nó completamente puro $(i(t)=0)$ ou quando o número de observações em um nó fica abaixo de um número pré especificado (já mencionado anteriormente ser usualmente 5). Esta árvore final é denominada árvore máxima e é denotada por $T_{\max }$. No entanto, essa árvore pode não produzir uma regra de classificação boa para novas observações, pois depende da amostra utilizada.

Portanto, o próximo objetivo é encontrar a árvore de tamanho correto (árvore ótima) $T^{*}$, através do corte (ou poda) da árvore $T_{\max }$.

A regra de classificação para um nó $t$ é feita classificando-se todas as observações deste nó na população cuja probabilidade a posteriori estimada $\hat{P}\left(\tau_{i} \mid t\right)$ for maior $(i=1, \ldots, g)$. A taxa de erro aparente no nó $t$ é então definida como

$$
e_{a p}(t)=1-\max _{i=1, \ldots, g} \hat{P}\left(\tau_{i} \mid t\right)
$$

Conseqüentemente, a taxa de erro aparente de uma árvore é dada por

$$
e_{a p}(T)=\sum_{t \in \tilde{T}} e_{a p}(t) \hat{P}(t)
$$

em que $\tilde{T}$ é o conjunto de nós terminais de $T$. Define-se uma sub-árvore $T_{t}$ da árvore T como a árvore formada pelo nó $t$ e todas as ramificações de $t$ em $T$. Assim, analogamente, a taxa 
de erro aparente devido à sub-árvore $T_{t}$ é dada por

$$
e_{a p}\left(T_{t}\right)=\sum_{t^{\prime} \in \tilde{\widetilde{T}}_{t}} e_{a p}\left(t^{\prime}\right) \hat{P}\left(t^{\prime}\right)
$$

em que $\widetilde{T_{t}}$ é o conjunto de nós terminais de $T_{t}$.

O primeiro passo para determinar a árvore ótima é construir uma seqüência de árvores $T_{0}=T_{\text {max }}, T_{1}, T_{2}, \ldots, T_{N}=t_{1}$ candidatas a $T^{*}$. Partindo-se de $T_{\text {max }}$ o objetivo é definir como as podas devem ser feitas até se chegar a $t_{1}$. Para qualquer nó, sub-árvore, árvore T, o critério de poda está baseado na seguinte medida

$$
R_{\alpha}(T)=e_{a p}+\alpha n(T)
$$

em que

$\alpha \geq 0, \alpha \in \Re$ é denominado parâmetro de complexidade;

$e_{a p}(T)$ é a taxa de erro aparente e

$n(T)$ é o número de nós terminais da árvore $T$.

Então, o procedimento consiste em:

(i) seja $i=0$ e $T_{0}=T_{m a x}$;

(ii) calcule $\alpha_{i+1}=\frac{e_{a p}(t)-e_{a p}\left(T_{t}\right)}{n\left(T_{t}\right)-1}$ para cada nó não terminal de $T_{i}$;

(iii) considere o menor valor de $\alpha_{i+1}$ e corte da árvore $T_{i}$, todas as partições feitas a partir de $t$ transformando-o em nó terminal. Denote a árvore resultante em $T_{i+1}$;

(iv) incremente o índice i em uma unidade e retorne ao passo (ii) até que $T_{i}$ seja igual ao nó inicial $t_{1}$.

Uma vez obtidas as candidatas a $T^{*}: T_{1}, T_{2}, \ldots, t_{1}$ escolhe-se como árvore ótima aquela que minimiza a taxa de erro real, que usualmente refere-se a taxa de erro da amostra teste. 


\subsection{REAL : Real Attribute Learning Algorithm}

O REAL é um algoritmo desenvolvido por Stern et al. (1996) para construir árvores de classificação utilizando variáveis independentes contínuas e que também pode ser aplicado quando as variáveis são categorizadas ordinais. Suas principais vantagens são:

(i) em geral, as árvores de classificação desenvolvidas apresentam menores taxas de erros;

(ii) uma medida de convicção (ou confiança) é utilizada para se definir o desenvolvimento da árvore;

(iii) não há necessidade de um critério externo para se definir a árvore ótima (critério de "poda" da árvore).

\subsubsection{Construção da Árvore}

Cada iteração do algoritmo corresponde a uma ramificação de um nó terminal na árvore. Os dados naquele nó são classificados de acordo com um valor do atributo selecionado e novos ramos são associados a um intervalo de valores específicos. O processo de particionamento dos valores da variável independente em intervalos subjacentes que não se sobrepõem é denominado processo de discretização. Cada iteração inclui:

(i) a discretização de cada variável e sua avaliação por uma função de perda;

(ii) a seleção do melhor atributo (variável) e sua adequada partição;

(iii) a junção de intervalos adjacentes que não alcançam o limite mínimo de conviç̧ão. 


\subsubsection{Medida de Convicção e Função de Perda}

Dado um nó $t$ com $n(t)$ clientes, $k$ dos quais classificados incorretamente e $(n(t)-k)$ classificados corretamente, é necessário definir um parâmetro escalar simples para medir a probabilidade de má classificação e seu respectivo nível de confiança.

Seja $q$ a probabilidade de classificar incorretamente um cliente em um dado nó, então, $p=(1-q)$ é a probabilidade de se classificar corretamente um cliente. Seja $D(c)$ a distribuição acumulada a priori de $q$, ou seja,

$$
D(c)=P(q \leq c)=P(p \geq 1-c) .
$$

A medida de convicção é definida como:

$$
m c=\min c \mid P(q \leq c) \geq 1-g(c),
$$

em que $g(c)$ é uma função bijetora monotonicamente crescente no intervalo $[0,1]$.

A função convexa $g(c)$ atende aos requisitos anteriores e é dada por:

$$
g(c)=c^{r}, r \geq 1
$$

em que $r$ é denominado parâmetro de convexidade e é um valor a ser definido pelo usuário.

Com as suposições anteriores e assumindo que a distribuição a priori de $q$ é uma Uniforme $(0,1)$, a distribuição a posteriori $D(c, n, k)$ é dada por

$$
D(c, n, k)=\frac{\int_{q=0}^{c} B(n, k, q)}{\int_{q=0}^{1} B(n, k, q)},
$$

onde

$$
B(n, k, q)=\left(\begin{array}{c}
n(t) \\
k
\end{array}\right) q^{k} p^{n(t)-k}
$$

Desta forma, a distribuição a posteriori é dada pela função beta incompleta e mc é a raiz da função monotonicamente decrescente:

$$
m c(n, k, r)=c \mid f(c)=0
$$




$$
\begin{gathered}
f(c)=1-g(c)-D(c, n, k) \\
f(c)=1-c^{r}-\operatorname{betainc}(c, k+1, n(t)-k+1) .
\end{gathered}
$$

As variáveis independentes são discretizadas em intervalos e a discretização escolhida é aquela que minimiza a função de perda dada por

$$
\text { loss }=\sum_{j} n_{j} m c_{j}
$$

ou seja, é a soma das medidas de convicção dos intervalos multiplicadas pelo número de observações em cada intervalo. O valor da função de perda é uma estimativa do número de casos classificados incorretamente nas populações definidas pela variável resposta, fixadas as classes das variáveis independentes.

\subsubsection{Discretização das Variáveis Independentes}

Dada uma variável preditora, o primeiro passo do procedimento de discretização é ordenar as observações em relação a essa variável e agrupá-las segundo intervalos de valores.

Depois disso agrupam-se os intervalos adjacentes de forma a diminuir a função de perda total da discretização. Em cada passo realiza-se a operação de agrupar intervalos que apresentam ganho máximo.

O ganho em se agrupar $J$ intervalos adjacentes é o decréscimo relativo na função de perda, ou seja, é a diferença entre o valor da função de perda obtido com a discretização da variável em questão nos $J$ intervalos e o valor da função de perda obtido se todos os $J$ intervalos forem agrupados em um só. Esse ganho é dado por

$$
\operatorname{gain}(J, 1)=\operatorname{loss}_{J}-\operatorname{loss}_{1}
$$

em que $\operatorname{loss}_{J}$ é a função de perda com $J$ intervalos e $l o s s_{1}$ é a função de perda com 1 intervalo.

O procedimento de discretização é interrompido quando não há mais agrupamento de intervalos com ganho positivo. 


\subsubsection{Ramificação e Agrupamento}

Para cada nó terminal na árvore:

(1) realiza-se o procedimento de discretização para cada variável independente;

(2) mede-se a função de perda no final da discretização;

(3) seleciona-se a variável com perda mínima;

(4) ramifica-se o nó de acordo com a discretização da variável.

Se nenhuma discretização de variável diminui a função de perda por um valor limitante de $\epsilon>0$ então nenhuma ramificação acontece.

Uma discretização prematura pelo parâmetro selecionado em um dado nível pode inibir a melhoria adicional da árvore de classificação pelo processo de ramificação. Por esta razão, o usuário deve estabelecer um valor limiar de convicção, $c l$, de modo a agrupar todos os intervalos adjacentes que não alcancem $m c \leq c l$. Para prevenir um loop infinito, o valor da função de perda associado ao intervalo resultante do agrupamento é a soma dos valores da função de perda dos intervalos agrupados. Nos ramos finais, este agrupamento não é feito. $\mathrm{O}$ limite de conviç̧ão interrompe naturalmente o processo de ramificação e não há necessidade de um procedimento de podagem externo como na Árvore de Classificação Binária. 


\section{Capítulo 5}

\section{Redes Neurais Artificiais}

Neste capítulo é apresentado um resumo sobre Redes Neurais Artificiais. O assunto é muito amplo e maiores detalhes podem ser encontrados em Bishop (1995).

\subsection{Definição}

A Rede Neural Artificial (RNA) é um sistema de processamento de informações inspirado no funcionamento do cérebro humano. Redes Neurais Artificiais são baseadas nas seguintes suposições:

1. a transmissão das informações ou sinais ocorrem através de elementos de processamento simples chamados de neurônios, nós ou unidades;

2. os sinais são passados para outros neurônios através de conexões (sinapses);

3. cada conexão tem um peso associado que é multiplicado pelo sinal transmitido;

4. a cada neurônio se aplica uma função de ativação (usualmente não linear). A função é aplicada ao seu correspondente valor de entrada. 
Assim, uma rede neural consiste de um conjunto de neurônios interligados entre si através de conexões, que têm um peso associado. Cada neurônio tem um estado interno, chamado de ativação, que é uma função das entradas recebidas.

Por exemplo, considere um neurônio artificial simples $Y$, conforme a Figura 5.1, que recebe as informações das unidades de entrada $X_{1}, X_{2}$ e $X_{3}$. Os valores dessas unidades são respectivamente $x_{1}, x_{2}$ e $x_{3}$. Os pesos das conexões de $X_{1}, X_{2}$ e $X_{3}$ ao neurônio $Y$ são $w_{1}, w_{2}$ e $w_{3}$, respectivamente. A entrada da rede, $y^{\prime}$, para o neurônio $Y$ é a soma ponderada dos valores de entradas $x_{1}, x_{2}$ e $x_{3}$, ou seja

$$
y^{\prime}=w_{1} x_{1}+w_{2} x_{2}+w_{3} x_{3}
$$

Figura 5.1: Um neurônio artificial simples

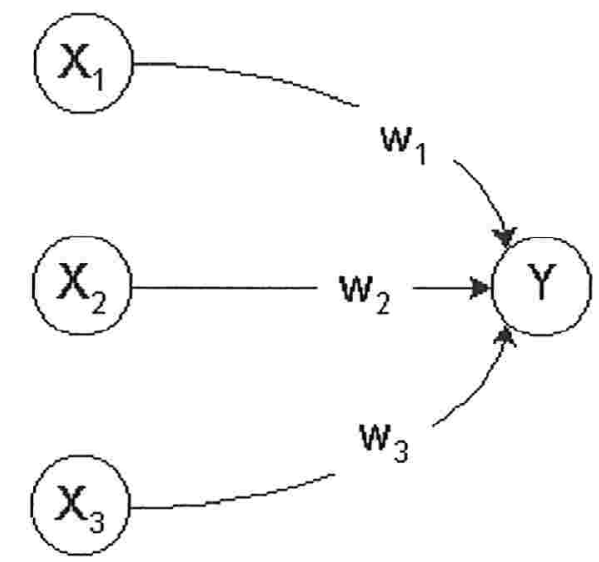

A ativação do neurônio Y é dada por alguma função da entrada da rede, $y=\varphi\left(y^{\prime}\right)$, onde $\varphi$ é em geral uma função não linear como, por exemplo, a função logística

$$
\varphi\left(y^{\prime}\right)=\frac{1}{1+\exp \left(-y^{\prime}\right)}
$$

Tipicamente, uma RNA é formada por unidades de entrada, unidades escondidas ou intermediárias e unidades de saída, ponderadas por camadas de pesos, chamados pesos adaptativos ou sinápticos. Como exemplo, veja a Figura 5.2 a seguir, referente a uma rede neural com duas camadas de pesos adaptativos. 
Figura 5.2: Rede neural com duas camadas de pesos adaptativos

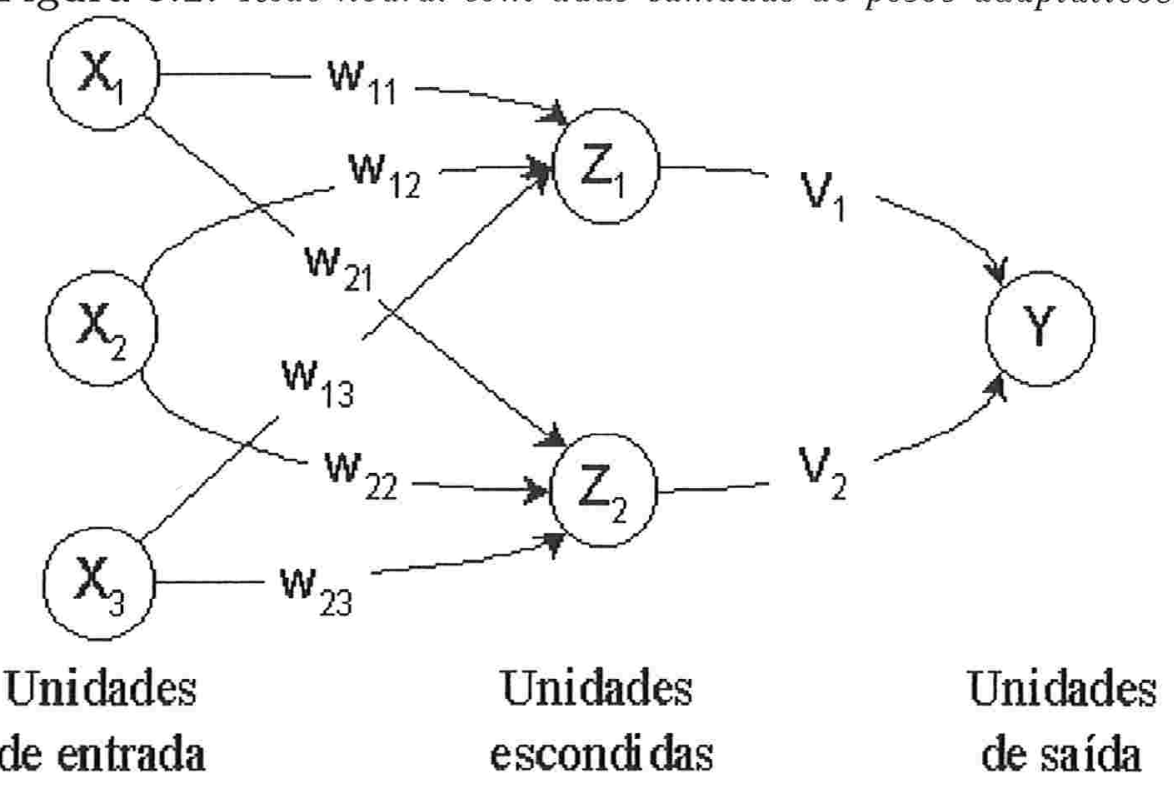

Uma RNA é caracterizada principalmente pelos seguintes fatores:

1. a arquitetura da rede - a forma como estão conectados os neurônios na rede;

2. o algoritmo de treinamento (ou aprendizado) - método utilizado para determinar os pesos nas conexões da rede;

3. a função de ativação - função que produz a ativação do neurônio, que é função dos sinais de entrada recebidos pelo neurônio.

\subsection{Tipos de Arquitetura}

É conveniente tratar os neurônios numa rede arranjados em camadas. Geralmente, os neurônios de uma mesma camada possuem a mesma função de ativação e estão conectados aos mesmos conjuntos de neurônios.

A arquitetura da rede consiste na forma como estão arranjadas as camadas de neurônios e os tipos de conexões permitidas entre eles. Em geral, a ativação de cada unidade da camada 
de entrada é igual ao próprio valor de entrada externo (ou seja, da informação da amostra), que poderia ser considerado como o valor resultante da função identidade aplicada ao valor de entrada externo.

As redes neurais com alimentação para frente, em que os sinais fluem das unidades de entrada para as unidades de saída em uma direção para frente, são chamadas feedforward. Exemplos são dados nas Figuras 5.1 e 5.2.

Um outro tipo de rede é a rede recorrente que permite que os neurônios dependam não somente dos valores de entrada, mas também dos seus próprios valores defasados. Este tipo de rede é semelhante ao processo utilizado em regressão com médias móveis e envolvem análise de séries de tempo. Um exemplo é a rede de Hopfield (Hopfield, 1984), em que um caso particular é o da Figura 5.3.

Figura 5.3: Rede neural recorrente

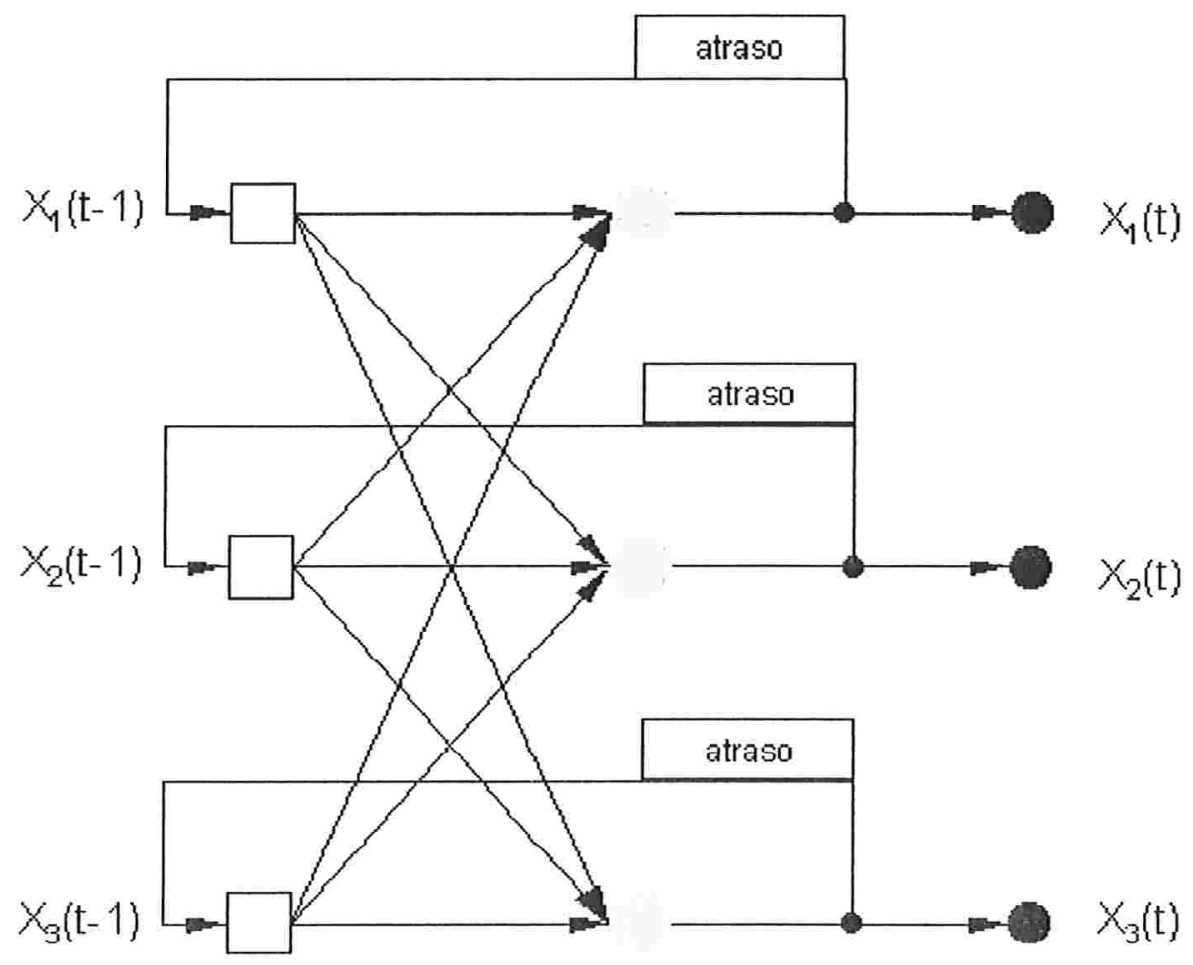

Redes Neurais Artificiais são freqüentemente classificadas como de uma camada ou multicamada, conforme a quantidade de camadas de pesos adaptativos. 


\subsubsection{Redes com uma camada}

Uma RNA com uma única camada é aquela que tem apenas uma camada de pesos adaptativos. Como um exemplo veja a Figura 5.1.

Note que uma rede neural simples, como a da Figura 5.1, com uma única camada e função de ativação identidade $\left(y=w_{1} x_{1}+w_{2} x_{2}+w_{3} x_{3}\right)$ é equivalente a um modelo de regressão múltipla. Os círculos à esquerda equivalem às variáveis explicativas, os pesos adaptativos aos coeficientes de regressão e o círculo à direita à variável resposta.

A seguir serão apresentadas duas redes neurais típicas com uma camada que fornecem a base para o conceito de redes multicamadas.

\section{Neurônio de McCulloch-Pitts}

O modelo de McCulloch-Pitts (McCulloch e Pitts, 1943) é considerado como a primeira Rede Neural Artificial. Neste modelo, o neurônio recebe a soma ponderada dos valores provenientes das unidades de entrada e tem como saída o valor 1, se a soma for maior do que determinado valor limiar ou 0 , se a soma for menor ou igual a este valor limiar.

Matematicamente, o $k$-ésimo neurônio deste modelo pode ser representado como

$$
y_{k}=\varphi\left(\sum_{j=1}^{p} w_{k j} x_{j}\right)
$$

em que $y_{k}$ é o valor de saída do neurônio $k, w_{k j}$ é o peso associado à entrada $j$ e ao neurônio $k, x_{j}$ é o valor da $j$-ésima unidade de entrada e $\varphi$ é a função de ativação definida como

$$
\varphi\left(y^{\prime}\right)=\left\{\begin{array}{c}
1, \quad \text { se } y^{\prime}>\theta \\
0, \quad \text { se } y^{\prime} \leq \theta
\end{array}\right.
$$

em que $\theta$ é o valor limiar. 


\section{Perceptron de Rosenblatt}

Rosenblatt e outros autores desenvolveram uma classe de RNA chamada perceptron (Rosenblatt, 1958). A mais típica dessas redes tem uma única camada de pesos fixos, com função de ativação limiar.

A Figura 5.4 apresenta uma rede Perceptron com uma camada de pesos adaptativos.

Figura 5.4: Perceptron

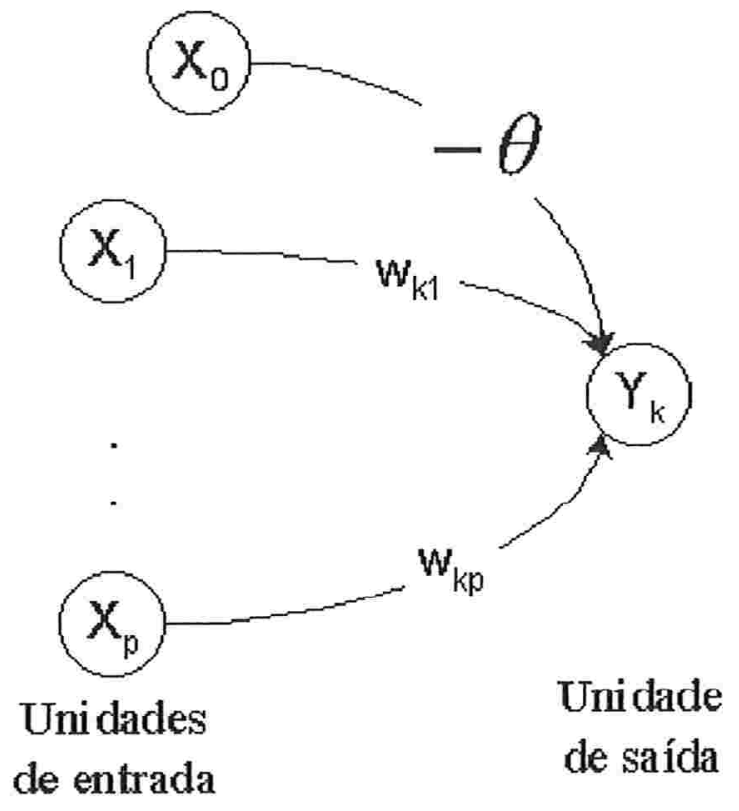

O Perceptron é equivalente a uma análise discriminante linear, em que a função discriminante é dada por

$$
y_{k}=\varphi\left(\sum_{j=0}^{p} w_{k j} x_{j}\right)
$$

em que $w_{k 0}=-\theta$ e $x_{0}=1$. Se a análise discriminante é aplicada a duas populações, $\varphi$ é definida como

$$
\varphi\left(y^{\prime}\right)=\left\{\begin{array}{rl}
1, & \text { se } y^{\prime}>0 \\
-1, & \text { se } y^{\prime} \leq 0
\end{array} .\right.
$$

A constante $w_{k 0}=-\theta$ é referida como limiar ou viés, fazendo uma referência a que a soma 
ponderada das entradas deve exceder $\theta$.

\subsubsection{Redes Multicamadas}

Uma rede multicamada é aquela com mais de uma camada de pesos adaptativos. É uma rede com uma ou mais camadas de unidades escondidas entre as unidades de entrada e de saída.

A utilização de redes multicamadas permite resolver problemas mais complexos não abrangidos pelas redes com uma camada. Entretanto, seu treinamento é mais difícil.

O perceptron multicamada (PML) é talvez a arquitetura de rede multicamada mais comumente utilizada; foi originariamente criada por Rumelhart e McClelland (1986) e é amplamente discutida na maioria dos livros sobre redes neurais (por exemplo, Bishop, 1995). É uma rede formada de unidades perceptrons arranjadas em camadas, onde a função de ativação é limiar (0 - 1) ou sigmoidal. Conseqüentemente a rede tem uma interpretação simples como uma forma de modelo de entradas e saídas, com os pesos e valores limiares (viéses) sendo os parâmetros livres do modelo.

Outra característica de uma rede PML é seu algoritmo de aprendizado, conhecido como algoritmo de retropropagação ou ainda "regra delta generalizada", que será descrito na Seção 5.3 .

\subsection{Algoritmos de Treinamento}

O treinamento da rede consiste em ajustar os pesos com o objetivo de otimizar o desempenho da mesma, por exemplo, minimizando uma função de erros. Do ponto de vista estatístico, o treinamento seria correspondente à fase de estimação dos parâmetros de um modelo com uma amostra de dados. 
O treinamento pode ser classificado de duas formas:

- Supervisionado - é aquele em que para cada vetor de entrada se conhece a saída, podendo-se então modificar os pesos adaptativos da rede de forma ordenada a fim de atingir o objetivo desejado. $\mathrm{Na}$ área estatística poderia por exemplo corresponder à análise discriminante ou à regressão logística em que o vetor de entradas é composto pelas variáveis explicativas e a saída é a variável que classifica as unidades em cada grupo.

- Não-supervisionado - difere do anterior pelo fato de não se conhecer a saída para cada vetor de entrada. O treinamento não-supervisionado poderia corresponder aos métodos estatísticos de análise de conglomerados e de componentes principais.

Em relação aos diferentes algoritmos utilizados nos treinamentos supervisionados destacamos os seguintes:

a) Back-propagation;

b) Gradiente Descendente Conjugado;

c) Levenberg-Marquardt;

d) Delta-bar-Delta;

e) Quick-propagation.

\section{Algoritmo Back-propagation}

O algoritmo mais conhecido e utilizado para treinamento de redes neurais é o Back-propagation (Fausett, 1994). Algoritmos mais avançados considerando a abordagem de redução do gradiente são o Gradiente Descendente Conjugado (Bishop, 1995) e Levenberg-Marquardt (Shepherd, 1997), que são substancialmente mais rápidos do que o Back-propagation em muitos problemas. 
Os algoritmos Delta-bar-Delta (Jacobs, 1988) e Quick-Propagation (Fahlman, 1988) são variações do algoritmo Back-propagation.

No Back-propagation, o vetor gradiente da superfície de erros é calculada. Este vetor aponta na direção da inclinação mais íngrime a partir do ponto atual; então movendo-se uma curta distância nesta linha, obtém-se uma diminuição do erro. Com uma seqüência de tais movimentos, eventualmente se chegará a um mínimo de algum tipo. A parte difícil é decidir qual o tamanho da distância (passo) a se mover.

Passos grandes podem convergir mais rapidamente, mas podem também passar da solução ou apontar para a direção errada. Em contrapartida, passos muito pequenos, podem levar à direção correta, mas um número excessivo de iterações poderá ser necessário. Na prática, o tamanho do passo é proporcional à inclinação e a uma constante especial, chamada de taxa de aprendizagem, que é escolhida experimentalmente. A escolha dos pesos iniciais influenciará a chegada a um mínimo global ou local. Um procedimento comum é iniciar com pesos e viéses com valores entre $-0,5$ e 0,5 e taxa de aprendizagem $\alpha$ com valor entre 0 e 1 .

Como ilustração, os passos de um algoritmo Back-propagation para uma rede com uma camada escondida são dados a seguir. O treinamento por Back-propagation tem três estágios: o Feedforward das unidades de entrada, o Back-propagation do erro associado e o ajustamento dos pesos e viéses. Os pesos e viéses $\left(v_{j h}\right.$ e $\left.w_{h k}\right)$ e a taxa de aprendizagem $(\alpha)$ são fixados no passo inicial. Os passos restantes são os seguintes:

\section{- Feedforward}

Para cada unidade da amostra de treinamento, execute os passos 1 a 7 :

1) cada unidade de entrada $\left(x_{j}, j=1,2, \ldots, p\right)$ transmite seu valor para as unidades da camada escondida;

2) calcula-se o valor para a camada escondida $\left(z_{h}, h=1,2, \ldots, q\right)$

$$
z_{h}^{*}=v_{0 h}+\sum_{j=1}^{p} x_{j} v_{j h}
$$


e aplica-se a função de ativação

$$
z_{h}=\varphi\left(z_{h}^{*}\right)
$$

3) repete-se esse procedimento para as unidades de saída $\left(y_{k} ; k=1,2, \ldots, m\right)$, ou seja,

$$
y_{k}^{*}=w_{0 k}+\sum_{h=1}^{q} z_{h} w_{h k} \quad \text { e } \quad y_{k}=\varphi\left(y_{k}^{*}\right)
$$

\section{- Back-propagation}

4) para cada unidade de saída, calcula-se o erro

$$
e_{k}=\left(t_{k}-y_{k}\right)
$$

em que $t_{k}$ é o valor alvo de saída (por exemplo, no caso da regressão, $t_{k}$ é o valor da variável resposta, conhecida na amostra) e multiplica-se pela primeira derivada da função de ativação

$$
\delta_{k}^{(2)}=e_{k} \varphi^{\prime}\left(y_{k}^{*}\right)
$$

Os termos para correção dos pesos e viéses das conexões posteriores à camada escondida são

$$
\Delta w_{0 k}=\alpha \delta_{k}^{(2)} \quad \text { e } \quad \Delta w_{h k}=\alpha \delta_{k}^{(2)} z_{h}
$$

respectivamente;

5) para as unidades da camada escondida, calcula-se

$$
\delta_{h}^{(1)}=\sum_{k=1}^{m} \delta_{k}^{(2)} w_{h k} \varphi^{\prime}\left(z_{h}^{*}\right) .
$$

Os termos para correção dos pesos e viéses das conexões anteriores à camada escondida são

$$
\Delta v_{0 h}=\alpha \delta_{h}^{(1)} \quad \text { e } \quad \Delta v_{j h}=\alpha \delta_{h}^{(1)} x_{j}
$$

- Ajustamento dos pesos e viéses

6) para $h=0,1, \ldots, q$ e $k=1,2, \ldots, m$

$$
w_{h k}(\text { atual })=w_{h k}(\text { anterior })+\Delta w_{h k} ;
$$


7) para $j=0,1, \ldots, p$ e $h=1,2, \ldots, q$

$$
v_{j h}(\text { atual })=v_{j h}(\text { anterior })+\Delta v_{j h} .
$$

Em cada iteração do algoritmo, todos os casos de treinamento (unidades amostrais) são submetidos um a um à rede e os valores de saída real e previsto são comparados através dos erros calculados. Estes erros, juntamente com o gradiente da superfície de erros, são usados para ajustar os pesos e então o processo se repete. Ao final de cada iteração é verificado se um número estipulado de iterações foi atingido ou se o erro total alcançou um nível aceitável. Caso positivo, o algoritmo é interrompido.

A base matemática para o algoritmo Back-propagation é a técnica de otimização conhecida como gradiente descendente. O gradiente de uma função (neste caso, a função é a função de erros e as variáveis são os pesos da rede), quando assume valor positivo, dá a direção em que a função cresce mais rapidamente; o valor negativo do gradiente dá a direção em que a função decresce mais rapidamente.

O algoritmo foi desenvolvido com o objetivo de obter os pesos que minimizem a função de erros, dada por

$$
E=0,5 \sum_{j=1}^{m}\left(t_{j}-y_{j}\right)^{2} .
$$

Para isso é necessário calcular as derivadas de E com relação aos pesos e viéses ou gradiente da superfície de erros, de onde vêm os $\delta$ 's.

Pela regra da cadeia, temos que

$$
\begin{gathered}
\frac{\partial E}{\partial w_{h k}}=\frac{\partial}{\partial w_{h k}} 0,5 \sum_{j=1}^{m}\left[t_{j}-y_{j}\right]^{2} \\
=\frac{\partial}{\partial w_{h k}} 0,5\left[t_{k}-\varphi\left(y_{k}^{*}\right)\right]^{2} \\
=-\left[t_{k}-y_{k}\right] \frac{\partial}{\partial w_{h k}} \varphi\left(y_{k}^{*}\right)
\end{gathered}
$$




$$
\begin{gathered}
=-\left[t_{k}-y_{k}\right] \varphi^{\prime}\left(y_{k}^{*}\right) \frac{\partial}{\partial w_{h k}}\left(y_{k}^{*}\right) \\
=-\left[t_{k}-y_{k}\right] \varphi^{\prime}\left(y_{k}^{*}\right) z_{h}=-e_{k} \varphi^{\prime}\left(y_{k}^{*}\right) z_{h} .
\end{gathered}
$$

Por definição, seja $\delta_{k}^{(2)}=\left[t_{k}-y_{k}\right] \varphi^{\prime}\left(y_{k}^{*}\right)$.

Em relação aos pesos das camadas escondidas, temos

$$
\begin{gathered}
\frac{\partial E}{\partial v_{j h}}=-\sum_{k=1}^{m}\left[t_{k}-y_{k}\right] \frac{\partial}{\partial v_{j h}} y_{k} \\
=-\sum_{k=1}^{m}\left[t_{k}-y_{k}\right] \varphi^{\prime}\left(y_{k}^{*}\right) \frac{\partial}{\partial v_{j h}} y_{k}^{*} \\
=-\sum_{k=1}^{m} \delta_{k}^{(2)} \frac{\partial}{\partial v_{j h}} y_{k}^{*} \\
=-\sum_{k=1}^{m} \delta_{k}^{(2)} w_{h k} \frac{\partial}{\partial v_{j h}} z_{h} \\
=-\sum_{k=1}^{m} \delta_{k}^{(2)} w_{h k} \varphi^{\prime}\left(z_{h}^{*}\right) x_{j} .
\end{gathered}
$$

Por definição, seja $\delta_{h}^{(1)}=\sum_{k=1}^{m} \delta_{k}^{(2)} w_{h k} \varphi^{\prime}\left(z_{h}^{*}\right)$.

Consequentemente, as atualizações para os pesos das unidades de saída são dadas por

$$
\begin{gathered}
\Delta w_{h k}=-\alpha \frac{\partial E}{\partial w_{h k}} \\
=\alpha\left[t_{k}-y_{k}\right] \varphi^{\prime}\left(y_{k}^{*}\right) z_{h} \\
=\alpha \delta_{k}^{(2)} z_{h}
\end{gathered}
$$

e para os pesos das camadas escondidas temos

$$
\begin{gathered}
\Delta v_{j h}=-\alpha \frac{\partial E}{\partial v_{j h}} \\
=\alpha \sum_{k=1}^{m} \delta_{k}^{(2)} w_{h k} \varphi^{\prime}\left(z_{h}^{*}\right) x_{j}
\end{gathered}
$$




$$
=\alpha \delta_{h}^{(1)} x_{j}
$$

Note também que, para o desenvolvimento acima, a função de ativação deve ser contínua, diferenciável e monotonicamente não descrescente. Além disso, para eficiência computacional, é desejável que as derivadas sejam fáceis de calcular.

O algoritmo também pode ser modificado pela inclusão de um termo de momento, o qual reforça o movimento em uma determinada direção, de modo que se muitos passos são tomados numa mesma direção, o algoritmo aumenta a velocidade para se mover rapidamente sobre platôs.

Exemplo de Back-propagation: considere uma rede com duas unidades de entrada, duas unidades escondidas em uma única camada e uma unidade de saída, com função de ativação binária sigmoidal conforme ilustra a Figura 5.5.

Figura 5.5: Perceptron

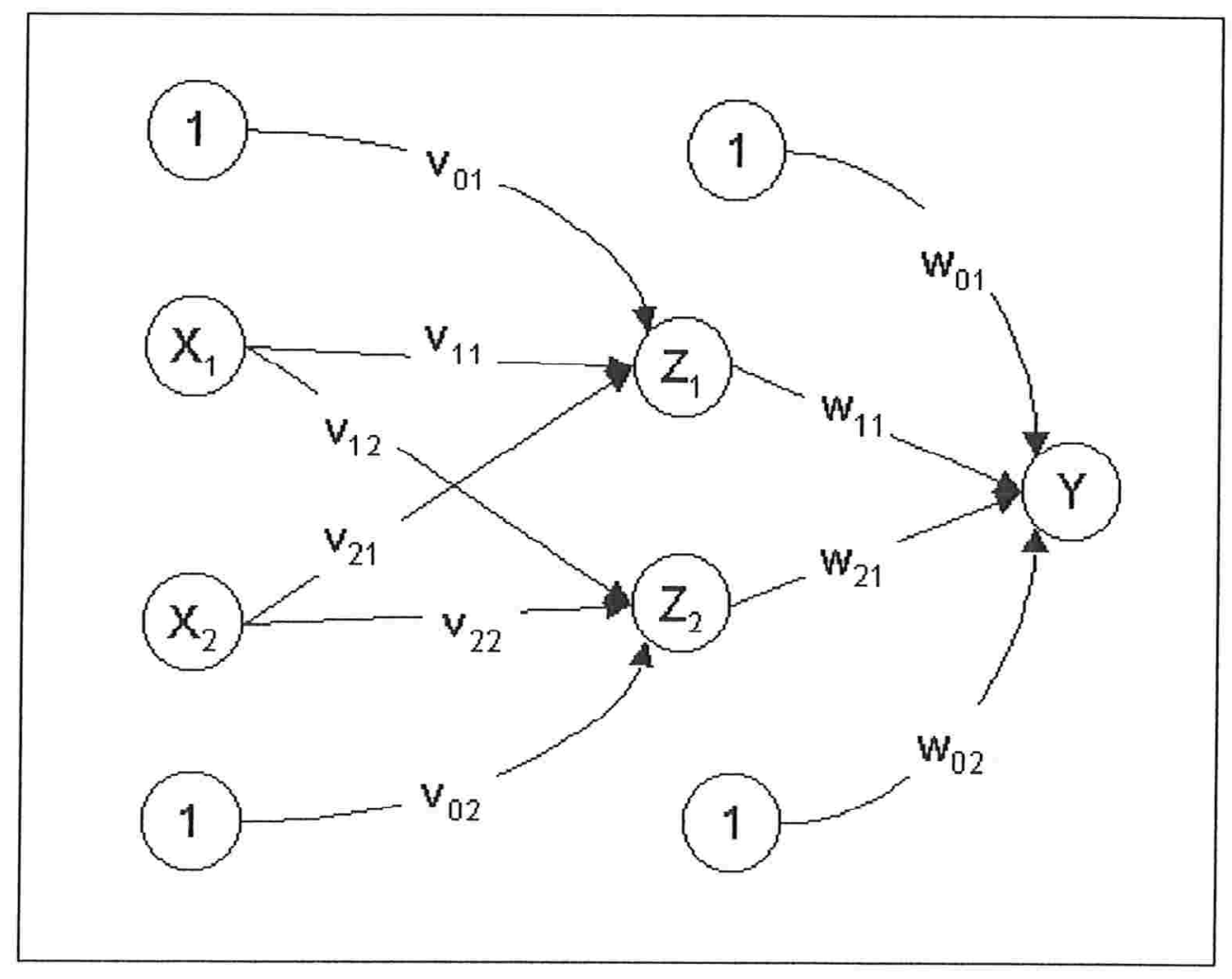

Como em muitos modelos, os valores 1 na Figura 5.5 estão associados a constantes. No 
caso da regressão, por exemplo, estariam associados a interceptos. O conjunto de dados de treinamento é dado a seguir:

$$
\begin{aligned}
& \left(\begin{array}{llll}
x_{0} & x_{1} & x_{2} & t_{1}
\end{array}\right) \\
& \left(\begin{array}{llll}
1 & 1 & 1 & 0
\end{array}\right) \\
& \left(\begin{array}{llll}
1 & 1 & 0 & -1
\end{array}\right) \\
& \left(\begin{array}{llll}
1 & 0 & 1 & -1
\end{array}\right)
\end{aligned}
$$

Os pesos e viéses iniciais das unidades de entrada para as unidades escondidas são:

$$
\begin{array}{rrl}
-0,3 & 0,3 & \text { (viéses relacionados às duas unidades escondidas) } \\
0,2 & 0,3 & \text { (pesos referentes à primeira unidade de entrada) } \\
-0,1 & -0,1 & \text { (pesos referentes à segunda unidade de entrada) }
\end{array}
$$

Os pesos e viéses iniciais das unidades escondidas para a unidade de saída são:

$$
\begin{array}{rr}
-0,3 & \text { (viés relacionado à unidade de saída) } \\
0,2 & \text { (peso da primeira unidade escondida) } \\
0,3 & \text { (peso da segunda unidade escondida) }
\end{array}
$$

A função de ativação binária sigmoidal varia no intervalo $(0,1)$ e é definida como

$$
\varphi(x)=\frac{1}{1+\exp (-x)} .
$$

Sua derivada é dada por

$$
\varphi^{\prime}(x)=\varphi(x)[1-\varphi(x)]
$$

Assim, aplicando o algoritmo Back-propagation, para os dados acima e $\alpha=1$, temos que os resultados para a primeira iteração são: 


\begin{tabular}{|c|rrr|}
\hline$x_{0}$ & 1 & 1 & 1 \\
$x_{1}$ & 1 & 1 & 0 \\
$x_{2}$ & 1 & 0 & 0 \\
$t_{1}$ & 0 & -1 & -1 \\
$v_{01}$ & $-0,300$ & $-0,300$ & $-0,300$ \\
$v_{11}$ & 0,200 & 0,200 & 0,198 \\
$v_{21}$ & $-0,100$ & $-0,100$ & $-0,100$ \\
$v_{02}$ & 0,300 & 0,300 & 0,300 \\
$v_{12}$ & 0,300 & 0,300 & 0,274 \\
$v_{22}$ & $-0,100$ & $-0,100$ & $-0,100$ \\
$y_{1}$ & 0,544 & 0,546 & 0,534 \\
\hline$\left(t_{1}-y_{1}\right)^{2}$ & 0,296 & 2,392 & 2,354 \\
\hline$\sqrt{\sum\left(t_{1}-y_{1}\right)^{2}}$ & 2,245 & & \\
\hline
\end{tabular}

Ao considerar o valor da raiz quadrada da soma dos erros quadráticos em cada iteração como referência para o critério de parada, o algoritmo é interrompido após 695 iterações. Os resultados finais são:

\begin{tabular}{|c|rrr|}
\hline$x_{0}$ & 1 & 1 & 1 \\
$x_{1}$ & 1 & 1 & 0 \\
$x_{2}$ & 1 & 0 & 0 \\
$t_{1}$ & 0 & -1 & -1 \\
$v_{01}$ & $-0,183$ & $-0,183$ & $-0,183$ \\
$v_{11}$ & 0,421 & 0,421 & 0,421 \\
$v_{21}$ & $-0,035$ & $-0,035$ & $-0,035$ \\
$v_{02}$ & 0,389 & 0,389 & 0,389 \\
$v_{12}$ & 2,542 & 2,542 & 2,543 \\
$v_{22}$ & $-0,034$ & $-0,034$ & $-0,034$ \\
$y_{1}$ & 0,035 & 0,035 & 0,051 \\
\hline$\left(t_{1}-y_{1}\right)^{2}$ & 0,001 & 1,071 & 1,104 \\
\hline$\sqrt{\sum\left(t_{1}-y_{1}\right)^{2}}$ & 1,475 & & \\
\hline
\end{tabular}

\section{Outros Algoritmos de Treinamento}

Além do Back-propagation, outros algoritmos de treinamento mais sofisticados para oti- 
mização da função não linear são utilizados. O algoritmo Gradiente Descendente Conjugado e Levenberg-Marquardt são duas outras formas de algoritmo e se baseiam nas abordagens da procura da linha e da região de confiança do modelo.

O algoritmo da procura da linha é o seguinte : tome uma direção sensível para se mover no espaço multidimensional. Então projete uma linha naquela direção, localize o ponto mínimo junto a esta linha. O que é uma direção sensível neste contexto? Uma escolha óbvia é a direção da inclinação descendente (a mesma direção que seria escolhida pelo Back-propagation). Entretanto, esta escolha intuitivamente óbvia prova ser um tanto pobre. Para obter o mínimo junto a uma direção, mesmo em uma superfície simples como uma parábola, um grande número de procuras de linhas pode ser necessário. Uma melhor abordagem é selecionar direções "sem interferências" ou conjugadas - daí temos o Gradiente Descendente Conjugado. A idéia implícita é que o algoritmo encontra o valor mínimo junto a uma direção particular e a segunda derivada junto a essa direção deve ser mantida zero. Direções conjugadas são selecionadas para manter esta derivada de segunda ordem igual a zero, sob a suposição de que a superfície é parabólica. Se esta condição vale, o número de iterações $N$ para alcançar um ponto mínimo é menor do que no Back-propagation. Na realidade, em uma superfície de erros complexa as direções conjugadas desaparecem, mas essa propriedade continua valendo.

A abordagem da região de confiança do modelo funciona como segue : ao invés de seguir a procura em uma dada direção, é assumido que a superfície tem uma forma simples, tal que o ponto de mínimo possa ser localizado facilmente. O modelo tipicamente assume que a superfície tem uma forma bem comportada (por exemplo, uma parábola), que será verdadeiro se estiver suficientemente perto do ponto de mínimo. De qualquer forma, a suposição pode ser violada grosseiramente e o modelo poderia escolher pontos muito inadequados para se mover. O modelo pode somente ser confiável dentro da região em torno do ponto atual, mesmo que o tamanho desta região não seja conhecido. Portanto, é importante escolher novos pontos para testar o comprometimento entre aquilo sugerido pelo modelo e aquilo sugerido pelo Gradiente Descendente Conjugado. Se o novo ponto é bom, então move-se para ele e reforça-se o papel do modelo em selecionar um novo ponto; se o novo ponto é ruim, permanece-se onde está e reforça-se o papel do passo do Gradiente Descendente Conjugado em selecionar um novo 
ponto (e tomar passos menores).

O algoritmo de Levenberg-Marquardt usa um modelo que assume que a função subjacente é localmente linear. É tipicamente o mais rápido dos algoritmos de treinamento, embora tenha algumas limitações. Especificamente, ele pode somente ser usado em redes com saída simples, com a função soma dos erros quadráticos e exige memória de processamento da ordem de $W^{2}$, em que W é o número de pesos na rede. O algoritmo do Gradiente Descendente Conjugado é quase tão rápido e não sofre estas restrições.

O Back-propagation pode ser útil, apesar de não oferecer uma solução tão rápida. É também uma boa escolha se o conjunto de dados é muito grande e contém uma grande quantidade de dados redundantes. Em contraste, os algoritmos do Gradiente Descendente Conjugado e o de Levenberg-Marquardt realizam ambos os cálculos usando todo o banco de dados. Assim, aumentar o número de casos pode reduzir significantemente a velocidade em cada iteração, mas não necessariamente fornece melhoria naquela iteração. Se os dados são esparsos, então adicionar dados fará cada iteração melhor. O Back-propagation pode também ser igualmente bom se o conjunto de dados for muito pequeno.

Duas variações do Back-propagation, que são o Delta-bar-Delta e o Quick-propagation, foram projetadas para lidar com algumas das limitações desta técnica. Em muitos casos, eles não são significantemente melhores do que o Back-propagation e às vezes são piores. Eles também requerem mais controle dos parâmetros do que qualquer dos outros algoritmos descritos anteriormente, o que torna-os mais difíceis de usar.

\subsection{Funções de Ativação}

A função de ativação é aquela aplicada à entrada de um neurônio. Esta entrada pode ser uma soma ponderada para o caso dos neurônios localizados nas camadas escondidas ou um valor de dado externo (dados da amostra). Assim, para as unidades de entrada, a função de ativação é a função identidade. A mesma função é utilizada para todos os neurônios em uma 
camada da rede, podendo ser diferente para camadas distintas. As funções mais comuns são:

1. Função identidade (rampa)

$$
\varphi\left(y^{\prime}\right)=y^{\prime}
$$

2. Função indicadora (degrau)

$$
\varphi\left(y^{\prime}\right)=\left\{\begin{array}{l}
1, \quad y^{\prime} \geq \theta \\
0, \quad y^{\prime}<\theta
\end{array},\right.
$$

em que $\theta$ é um valor limiar;

3. Função logística (sigmóide binária)

$$
\varphi\left(y^{\prime}\right)=\frac{1}{1+\exp \left(-y^{\prime}\right)}, y^{\prime} \in(0,1)
$$

4. Função tangente hiperbólica (sigmóide bipolar)

$$
\varphi\left(y^{\prime}\right)=\tanh \left(\frac{y^{\prime}}{2}\right)=\frac{1-\exp \left(-y^{\prime}\right)}{1+\exp \left(-y^{\prime}\right)}, y^{\prime} \in(-1,1)
$$

5. Função normal (probit)

$$
\varphi\left(y^{\prime}\right)=\phi\left(y^{\prime}\right)
$$

em que $\phi$ é a função de distribuição acumulada da Normal padrão.

\subsection{Redes Neurais em Problemas de Classificação}

Em problemas de classificação, o propósito da rede é associar cada caso a uma das possíveis classes (ou, mais genericamente, estimar a probabilidade do caso pertencer a uma classe). No aplicativo STATISTICA Neural Network, usado neste trabalho, um problema de classificação pode ser resolvido através dos seguintes tipos de redes:

- Perceptrons Multicamadas (PML);

- Redes com funções de bases radiais (RBF); 
- Redes de Kohonen;

- Redes Neurais Probabilísticas (RNP);

- Redes Lineares.

\section{Perceptrons Multicamadas (PML)}

As redes do tipo PML mencionadas na. Seção 5.2.2. utilizam uma função de ativação identidade para as unidades de entrada e uma função de ativação não linear para as demais unidades da rede.

A função de ativação padrão é a função logística para todas as camadas. Uma boa alternativa é a função tangente hiperbólica (tanh), que é uma versão simétrica da função logística. Esta pode produzir uma melhor "performance" do que a função logística em muitos casos.

As redes PML podem ser treinadas utilizando-se os seguintes algoritmos: Gradiente Descendente Conjugado, Levenberg-Marquardt, Back-propagation, Quick-propagation ou Deltabar-Delta. Essas redes são relativamente compactas e amplamente aplicáveis. No entanto, o processo de treinamento pode ser prolongado.

\section{Redes com Funções de Bases Radiais (RBF)}

A maioria das redes PML utilizam como argumento ao qual a função de ativação é aplicada, o produto escalar do vetor de entrada e do vetor de pesos relacionado a um neurônio. Os neurônios das camadas intermediárias das redes tipo PML utilizam, geralmente, funções de bases sigmoidais. No entanto, existem redes como a de funções de bases radiais cuja ativação de um neurônio é função da distância entre seus vetores de entradas e de pesos. A rede portanto foi batizada com tal nome, em virtude dos neurônios da camada intermediária utilizarem funções de bases radiais.

As redes com funções de bases radiais geralmente possuem uma camada de entrada, uma camada escondida de unidades radiais e uma camada de saída de unidades lineares. Foram 
introduzidas por Broomhead e Lowe (1988) e Moody e Darken (1989) e foram também estudadas por Bishop (1995) e Haykin (1994).

A camada radial tem funções de ativação exponenciais e a camada de saída tem funções de ativação lineares.

É às vezes útil alterar a função de ativação da camada de saída para a logística e usar o algoritmo de treinamento Gradiente Descendente Conjugado, uma vez que a otimização linear é mais propensa a erro. Gradientes Descendentes Conjugados podem também ser alterados na camada de saída linear, embora sejam mais lentos.

Redes com função de bases radiais são treinadas em três etapas:

- Avaliação do centro: os centros da camada escondida radial são otimizados primeiro, usando treinamento não supervisionado. Os centros podem ser avaliados por diversos algoritmos: por amostragem, K-médias ou Kohonen. Esses algoritmos substituem os centros por grupos associados. O objetivo neste passo é particionar o espaço dos padrões em $K$ conjuntos $S_{j}$ disjuntos e posicionar os centros no ponto médio de cada conjunto $S_{j}$

- Avaliação dos desvios: a dispersão dos dados é refletida nos desvios radiais. Esses podem ser avaliados por diversos algoritmos: explícito, isotrópico, k-vizinhos mais próximos, por exemplo. Neste passo, a finalidade é minimizar a soma dos quadrados das distâncias entre os vetores de entrada e o centro do conjunto $S_{j}$ ao qual eles pertencem.

- Otimização linear: a função da camada intermediária da rede RBF é transformar um conjunto de exemplos não linearmente separável em um conjunto linearmente separável. Assim, uma vez que os centros foram associados, o problema agora se reduz a ajustar os pesos da camada de saída linear, através por exemplo da técnica de otimização da pseudo-inversa. Esta garante rapidamente a minimização do erro quando os desvios não são muito grandes. No entanto, pode-se também utilizar o Gradiente Descendente Conjugado ou outros algoritmos iterativos de treinamento. 
Os treinamentos das redes RBF são relativamente rápidos. No entanto, tendem a ser maiores do que os das PML's.

\section{Redes de Kohonen}

As redes Kohonen têm um camada de entrada e uma camada de saída de unidades radiais. Inventadas por Kohonen (1982), elas são também descritas em muitos outros livros de redes neurais (por exemplo: Haykin, 1994; Patterson, 1996; Fausett, 1994).

A raiz quadrada da função de ativação é usada posteriormente, de modo que a saída representa a distância do caso de entrada a partir do vetor de pesos da unidade. Isto pode ser mudado, se desejado (por exemplo, para linear, quando se quer distância quadrada ou uma execução rápida).

As redes de Kohonen têm tipicamente uma camada de saída bidimensional e são usadas para classificação, executando isso de uma forma incomum. A definição do pós processamento sempre inclue uma variável de saída nominal simples, com um valor nominal para cada classe. As unidades da camada de saída são rotuladas para corresponder às classes. Quando a rede é executada, o nó vencedor (ou seja, um nó com a mais baixa ativação, indicando maior proximidade ao padrão de entrada) é selecionado e seu rótulo é usado para associar o nó à classe. Como uma conseqüência desta estrutura incomum, a camada de saída da rede de Kohonen é definida pelo usuário e pode ter qualquer número de unidades.

As redes de Kohonen são treinadas usando um algoritmo de aprendizado não supervisionado, que não requer variáveis de saída nos dados de treinamento. Este algoritmo pode também ser usado para atribuir centros a qualquer outra rede onde a primeira camada escondida é radial, incluindo as redes com funções radiais.

\section{Redes Neurais Probabilísticas (RNP)}

As redes probabilísticas (Bayesianas) são usadas somente para classificações. Elas têm três ou quatro camadas. Há uma camada de entrada, uma camada de unidades radiais e 
uma camada de unidades de classificação lineares. Opcionalmente, pode haver uma quarta camada, também linear, que contém uma matriz de perda. Se uma matriz de perda é incluída, ela pode ser quadrada, ou seja, a terceira e quarta camadas podem ter o mesmo número de unidades. Proposta por Specht (1990), elas contemplam o método de aproximação das funções pela estimação kernel (Parzen, 1962) na forma de uma rede neural. (Leia também Patterson (1996 e Bishop (1995)).

As unidades radiais em redes probabilísticas são usadas para armazenar os exemplares padrões, tomados diretamente dos casos de treinamento. Tipicamente, todo o conjunto de dados de treinamento é utilizado e então o número de unidades na primeira camada escondida deve ser igual ao número de casos de treinamento.

Cada uma das unidades da camada de classificação é somada às saídas dos exemplares padrões para cada classe, conseqüentemente construindo uma estimativa da probabilidade do membro pertencer àquela classe. Seus pesos são ajustados para levar em conta a representação de cada classe e as probabilidades a priori conhecidas de cada classe.

Se definida, a matriz de perda é usada para probabilidades ponderadas pelo custo de má classificação, a fim de chegar a um custo mínimo de decisão.

A função de normalização de soma unitária é usada, de modo que as saídas podem ser interpretadas diretamente como probabilidades (se uma matriz de perda foi definida).

Os treinamentos de redes probabilísticas são estremamente rápidos, mas são em geral muito grandes.

\section{Redes Lineares}

As redes lineares têm somente duas camadas: uma de entrada e uma de saída.

Muitos problemas não podem ser resolvidos (ou bem resolvidos) por técnicas lineares. No entanto, muitos outros podem. Quando isto ocorre, deve-se sempre treinar uma rede linear, como um padrão de comparação em relação às demais não lineares, mais complexas. 
Redes lineares são melhor treinadas usando uma técnica da pseudo-inversa. Esta técnica otimiza a última camada em qualquer rede assumindo que ela é uma camada linear. A técnica da pseudo-inversa é rápida e garante que se descubra uma solução ótima.

Pode-se também usar o Gradient Descendente Conjugado ou outros algoritmos de treinamento iterativos, para otimizar uma rede linear. 


\section{Capítulo 6}

\section{Resultados}

\subsection{Seleção das Amostras}

A partir da base de dados descrita no Capítulo 2, contendo 106.696 casos (98.327 clientes "bons" e 8.369 clientes "ruins"), foram selecionadas 3 amostras (de treinamento, de validação e de teste) a serem utilizadas para aplicação das técnicas mencionadas nos capítulos anteriores. Para a construção das amostras foram utilizados todos os casos de clientes "ruins", selecionando-se aleatoriamente metade da base de clientes "ruins" (4.185 casos) para compor a amostra de treinamento, sendo o restante dos casos divididos aleatoriamente para compor as amostras restantes (2.092 casos em cada amostra). Para que as amostras tivessem a mesma quantidade de clientes "bons" e "ruins", foram selecionados aleatoriamente 4.185 clientes "bons" para compor a primeira amostra e 2.092 casos para as demais. A amostra de treinamento, com 8.370 casos, foi utilizada para estimar os pesos (parâmetros) do modelo. A amostra de teste, com 4.184 casos, foi utilizada para checar o poder preditivo do modelo construído. E a amostra de validação, também com 4.184 casos, foi utilizada para evitar o superajuste do modelo, ao se aplicar a Rede Neural Artificial na sua construção. Note que a amostra de validação não é necessária para o ajuste do modelo nas demais técnicas e portanto pode ser utilizada como uma amostra adicional para testar o modelo. 
O motivo para não se utilizar uma amostra refletindo a mesma razão de "bons" e "ruins" da população na construção do modelo é que esta é tão fortemente orientada para os clientes "bons" (na base utilizada, 12 "bons" para 1 "ruim") que poderia interferir na identificação das características da subpopulação de "ruins", gerando uma regra de classificação que favorece o acerto dos clientes que são "bons".

Para explicar o termo "superajuste" do modelo, mencionado no primeiro parágrafo deste capítulo, na aplicação da técnica de Redes Neurais, será utilizada a analogia que é feita para o ajustamento da curva polinomial a um conjunto de pontos, cujo conceito implícito pode ser estendido para redes neurais.

Um polinômio é uma equação com termos contendo somente constantes e potência das variáveis. Por exemplo

$$
\begin{gathered}
y=2 x+3 \text { ou } \\
y=3 x^{2}+4 x+1 .
\end{gathered}
$$

Polinômios diferentes têm diferentes formatos de curva; para potências maiores (e portanto maior número de termos) apresentam formas mais excêntricas. Dado um conjunto de dados, pode-se ajustar uma curva polinomial (ou seja, um modelo) para explicar os dados, que provavelmente apresentará ruídos. Polinômios que apresentam potências menores podem não ser suficientemente flexíveis para se ajustarem a todos os pontos, ao passo que polinômios de potências maiores são mais flexíveis, ajustando os dados exatamente pela adoção de uma forma altamente excêntrica.

Redes Neurais apresentam precisamente o mesmo problema. Uma rede com mais pesos ou com função mais complexa está sujeita a "superajuste". Uma rede com menos pesos pode não ser suficientemente poderosa para modelar a função subjacente. Por exemplo, uma rede com nenhuma camada intermediária modela, de fato, uma função linear simples.

Desta forma, como é possível então escolher a complexidade da rede? Uma rede grande invariavelmente alcança uma taxa de erro menor, mas isso não necessariamente indica um 
bom modelo, ao contrário, pode estar indicando um "superajuste" do modelo.

Uma solução para se evitar o "superajuste" é a utilização de uma amostra de validação no processo de implementação do modelo. Quando o treinamento progride, o erro no treinamento naturalmente cai e a função de erro do modelo diminui. De fato, se o erro na amostra de validação pára de cair, isto indica que a rede está começando a iniciar um "superajuste". Quando o "superajuste" ocorre na amostra de treinamento é aconselhável diminuir o número de camadas escondidas ou de unidades da rede. Em contrapartida, se a rede não é suficientemente poderosa para modelar a função subjacente, o "superajuste" não é provável acontecer e nem o erro com a amostra de treinamento nem o erro com a amostra de validação diminuirá para um nível satisfatório.

\subsection{Transformação das Variáveis}

Os dados ausentes (missing) das variáveis preditoras foram tratados como uma categoria separada pois a omissão de resposta nas variáveis cadastrais pode indicar algum problema de crédito e a falta de resposta nas variáveis de utilização o encerramento da conta corrente, por exemplo.

Para a aplicação da Regressão Logística, as respostas das variáveis contínuas das amostras foram primeiramente divididas em classes, conforme apresentado no Apêndice B. Após essa transformação, as variáveis contínuas foram categorizadas e finalmente, todas as variáveis categorizadas, originalmente ou por transformação, foram transformadas em variáveis dummy.

Para a aplicação da Árvore de Classificação Binária, foi utilizada a mesma transformação de variáveis mencionada anteriormente. No entanto, não foram criadas variáveis dummy a partir das respostas ou classes de respostas. As variáveis categorizadas, originalmente ou por transformação, foram utilizadas diretamente na construção da árvore de classificação.

Para aplicação do REAL e da Rede Neural Artificial, as variáveis contínuas também foram 
divididas em classes, como mencionado no parágrafo anterior. No entanto, ao invés de criar variáveis dummy a partir de variáveis categorizadas, optou-se por substituir a resposta da variável pelo respectivo peso de evidência da classe a qual pertence. Essa transformação é necessária pois o REAL trabalha com variáveis ordenadas, agrupando categorias vizinhas ou valores próximos. Ao usar a transformação do peso de evidência, as categorias das variáveis ficam ordenadas em relação à variável resposta. Quanto à Rede Neural, os pesos de evidência foram utilizados no lugar das variáveis dummy pois estas fariam aumentar muito o número de variáveis para treinar a rede.

\subsection{Aplicação das Técnicas}

\subsubsection{Regressão Logística}

Para a construção do modelo foi utilizado o procedimento de Regressão Logística do aplicativo SAS, o algoritmo stepwise e a opção LOGIT como função de ligação. Esse algoritmo verifica a importância das variáveis que são incluídas ou excluídas do modelo com base em uma medida de significância estatística do coeficiente da variável, fixada em 0,05.

Após a definição do modelo foi verificado se havia multicolinearidade entre as variáveis através da opção TOL e VIF da regressão linear entre a variável dependente e as variáveis independentes do modelo avaliado. Valores de TOL abaixo de 0,40 indicam a existência de multicolinearidade.

Na Tabela 6.1 a seguir são apresentadas as estimativas dos parâmetros das variáveis selecionadas para o modelo final, bem como, os erros padrões das estimativas, as estatísticas de Wald, os graus de liberdade e os níveis descritivos do teste de Wald. As estimativas com valor igual a zero referem-se aos atributos das variáveis que representam a categoria de referência na construção da variável dummy. 
Tabela 6.1: $\quad$ Modelo Final da Regressão Logística

\begin{tabular}{|c|c|c|c|c|c|}
\hline Variável & Estimativa & Erro-Padrão & Wald & g.l. & $\mathrm{p}$-value \\
\hline Intercepto & 3,717 & 0,4912 & 57,2548 & 1 & $<, 0001$ \\
\hline \multicolumn{6}{|l|}{ Estado civil } \\
\hline solteiro $(a)$ & - & - & - & 1 & - \\
\hline casado(a)-comunhão universal & $-0,2864$ & 0,0858 & 11,1343 & 1 & 0,0008 \\
\hline casado(a)-comunhão parcial & $-0,2554$ & 0,0931 & 7,528 & 1 & 0,0061 \\
\hline casado(a)-separação de bens & $-0,0369$ & 0,3189 & 0,0134 & 1 & 0,9078 \\
\hline viúvo(a) & $-0,2579$ & 0,2301 & 1,2563 & 1 & 0,2623 \\
\hline separado(a)judicialmente & 0,2612 & 0,1706 & 2,3464 & 1 & 0,1256 \\
\hline divorciado(a) & 0,3854 & 0,1764 & 4,7717 & 1 & 0,0289 \\
\hline \multicolumn{6}{|l|}{ Escolaridade } \\
\hline analfabeto (a) & - & - & - & 1 & - \\
\hline superior completo & $-0,7509$ & 0,4497 & 2,7878 & 1 & 0,0950 \\
\hline primeiro grau & $-0,1697$ & 0,4451 & 0,01453 & 1 & 0,7031 \\
\hline segundo grau & $-0,3072$ & 0,4451 & 0,04763 & 1 & 0,4901 \\
\hline superior incompleto & $-0,4169$ & 0,4856 & 0,07369 & 1 & 0,3907 \\
\hline pós-graduado(a) & $-1,2885$ & 0,5674 & 5,1574 & 1 & 0,0231 \\
\hline mestrado & $-0,944$ & 0,689 & 1,8769 & 1 & 0,1707 \\
\hline doutorado & $-3,1991$ & 1,3384 & 5,7129 & 1 & 0,0168 \\
\hline superior em andamento & $-1,2526$ & 0,5256 & 5,6807 & 1 & 0,0172 \\
\hline \multicolumn{6}{|l|}{ Tipo de residência } \\
\hline própria quitada & - & - & - & 1 & - \\
\hline própria financiada & 0,1981 & 0,1428 & 1,9238 & 1 & 0,1654 \\
\hline alugada & 0,2331 & 0,0948 & 6,0465 & 1 & 0,0139 \\
\hline familiar & 0,0877 & 0,0925 & 0,08976 & 1 & 0,3434 \\
\hline cedida & 0,5343 & 0,1839 & 8,4447 & 1 & 0,0037 \\
\hline \multicolumn{6}{|l|}{ Sexo } \\
\hline feminino & - & - & - & 1 & - \\
\hline masculino & 0,3692 & 0,0725 & 25,9576 & 1 & $<, 0001$ \\
\hline \multicolumn{6}{|l|}{ Tem restrições SERASA } \\
\hline não tem restrições & - & - & - & 1 & - \\
\hline tem restrições & 4,5924 & 0,2353 & 381,0543 & 1 & $<, 0001$ \\
\hline
\end{tabular}


Tabela 6.1: $\quad$ Modelo Final da Regressão Logística (continuação)

\begin{tabular}{|c|c|c|c|c|c|}
\hline Variável & Estimativa & Erro-Padrão & Wald & g.l. & p-value \\
\hline \multicolumn{6}{|l|}{ Natureza da ocupação } \\
\hline trabalhador sem vínc.empregatício & - & - & - & 1 & - \\
\hline empregado em empresa privada & $-0,2923$ & 0,2067 & 2,0001 & 1 & 0,1573 \\
\hline profissional liberal & $-0,3219$ & 0,1147 & 7,8702 & 1 & 0,0050 \\
\hline proprietário de empresa & 0,0741 & 0,0919 & 0,06505 & 1 & 0,4199 \\
\hline funcionário público & $-0,0734$ & 0,1081 & 0,04609 & 1 & 0,4972 \\
\hline demais naturezas & 0,0356 & 0,1798 & 0,00392 & 1 & 0,8431 \\
\hline aposentado ou pensionista & $-0,405$ & 0,3998 & 1,026 & 1 & 0,3111 \\
\hline \multicolumn{6}{|l|}{ Recebe proventos pelo banco } \\
\hline não recebe proventos & - & - & - & 1 & - \\
\hline recebe proventos & $-1,2493$ & 0,0829 & 227,1754 & 1 & $<, 0001$ \\
\hline \multicolumn{6}{|l|}{ Região } \\
\hline norte & - & - & - & 1 & - \\
\hline nordeste & $-0,164$ & 0,1403 & 1,3655 & 1 & 0,2426 \\
\hline centro-oeste & 0,0603 & 0,1544 & 0,01526 & 1 & 0,6961 \\
\hline sudeste & $-0,4047$ & 0,1364 & 8,8088 & 1 & 0,0030 \\
\hline sul & $-0,6605$ & 0,1492 & 19,5903 & 1 & $<, 0001$ \\
\hline \multicolumn{6}{|l|}{ Tempo de conta } \\
\hline$(\geq 0 e<6$ meses $)$ & - & - & - & 1 & - \\
\hline$(\geq 6 e<12$ meses $)$ & 0,0879 & 0,1668 & 0,02776 & 1 & 0,5983 \\
\hline$(\geq 1 e<3$ anos $)$ & $-0,3788$ & 0,1312 & 8,3356 & 1 & 0,0039 \\
\hline$(\geq 3 e<7$ anos $)$ & $-0,6586$ & 0,1418 & 21,5743 & 1 & $<, 0001$ \\
\hline$(\geq 7$ anos $)$ & $-0,6965$ & 0,142 & 24,0733 & 1 & $<, 0001$ \\
\hline \multicolumn{6}{|l|}{$\begin{array}{l}\text { Variação do saldo médio em } \mathrm{c} / \mathrm{c} e \\
\text { investimentos }\end{array}$} \\
\hline missing ou $(<0,30)$ & - & - & - & 1 & - \\
\hline$(\geq 0,30 e<0,75)$ ou $(\geq 2,85)$ & $-0,1912$ & 0,0877 & 4,7501 & 1 & 0,0293 \\
\hline $\begin{array}{l}\geq 0,75 \text { e }<1,05) \text { ou }(\geq 1,35 e< \\
2,85)\end{array}$ & $-0,4011$ & 0,0884 & 20,5971 & 1 & $<, 0001$ \\
\hline$(\geq 1,05 e<1,35)$ & $-0,7295$ & 0,1301 & 31,4395 & 1 & $<, 0001$ \\
\hline
\end{tabular}


Tabela 6.1: $\quad$ Modelo Final da Regressão Logística (continuação)

\begin{tabular}{|l||c|c|c|c|c|}
\hline \hline Variável & Estimativa & Erro-Padrão & Wald & g.l. & p-value \\
\hline \hline Entradas mais saídas dividido pelo & & & & & \\
saldo médio em c/c & & & & & \\
\hline ( $\geq$ 21,25) & - & - & - & 1 & - \\
missing ou $(\geq 13,75$ e $<1,25)$ & $-0,2229$ & 0,0989 & 5,0746 & 1 & 0,0243 \\
$(<1,25)$ ou $(\geq 10,00$ e $<13,75)$ & $-0,4842$ & 0,1318 & 13,498 & 1 & 0,0002 \\
$(\geq 6,25$ e $<10,00)$ & $-0,6798$ & 0,1097 & 38,365 & 1 & $<, 0001$ \\
$(\geq 3,75$ e $<6,25)$ & $-0,8139$ & 0,1335 & 37,1787 & 1 & $<, 0001$ \\
( $\geq 1,25$ e $<3,75)$ & $-1,2188$ & 0,1375 & 78,5642 & 1 & $<, 0001$ \\
\hline \hline Cheques devolvidos & & & & & \\
\hline mais que 5 cheques & - & - & - & 1 & - \\
missing & $-2,029$ & 0,1803 & 126,6159 & 1 & $<, 0001$ \\
3, 4 ou 5 cheques & $-0,8429$ & 0,1596 & 27,8957 & 1 & $<, 0001$ \\
1 ou 2 cheques & $-1,1456$ & 0,1383 & 68,6629 & 1 & $<, 0001$ \\
nenhum cheque & $-1,7682$ & 0,1188 & 221,4148 & 1 & $<, 0001$ \\
\hline \hline Utilização média de cheque especial & & & & & \\
\hline missing ou $(\geq 0,70)$ & - & - & - & 1 & - \\
$(\geq 0,50$ e $<0,70)$ & $-0,7704$ & 0,1159 & 44,2057 & 1 & $<, 0001$ \\
$(\geq 0,30$ e $<0,50)$ & $-0,8436$ & 0,1119 & 56,8775 & 1 & $<, 0001$ \\
$(\geq 0,15$ e $<0,30)$ & $-1,1909$ & 0,124 & 92,2646 & 1 & $<, 0001$ \\
$(\geq 0,05$ e $<0,15)$ & $-1,52$ & 0,1526 & 99,2798 & 1 & $<, 0001$ \\
(<0,05) & $-2,0409$ & 0,1334 & 234,2207 & 1 & $<, 0001$ \\
\hline \hline
\end{tabular}

A taxa de acerto do modelo pode ser vista na seção "Comparação dos Modelos".

\subsection{2 Árvore de Classificação Binária}

Utilizando o aplicativo ANSWER TREE, foi obtida uma Árvore de Classificação Binária com 8 níveis e 13 nós terminais. As regras de classificação para cada nó podem ser vistas na Figura 6.1 e Tabela 6.2 a seguir. 
Figura 6.1: Árvore de Classificação Final

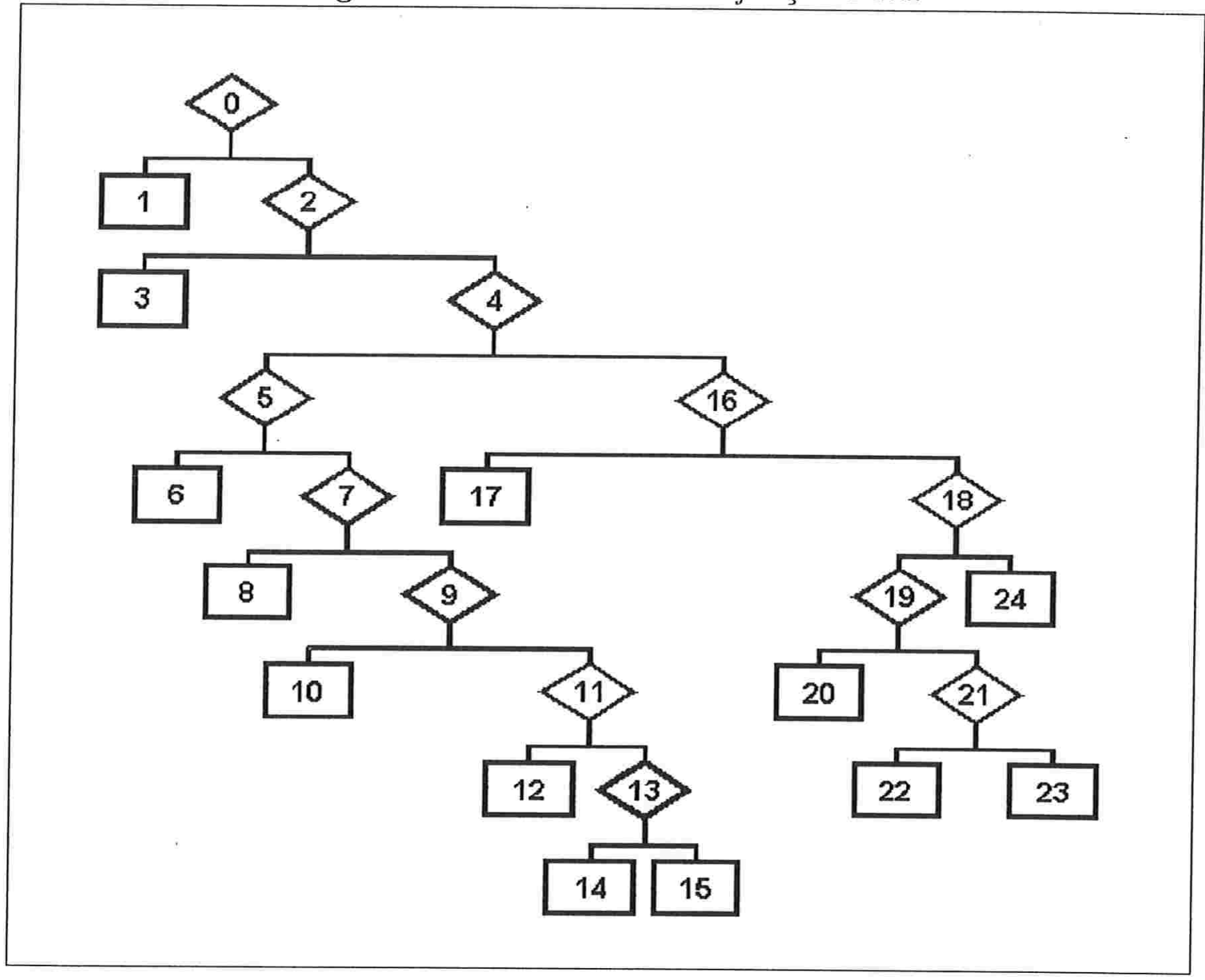


Tabela 6.2: Árvore de Classificação Binária

\begin{tabular}{|c|l|l|}
\hline Nó & Regra à Esquerda & Regra à Direita \\
\hline \hline 0 & "Tem restrições SERASA" $=\{\operatorname{sim}\}$ & "Tem restrições SERASA" $=\{$ não $\}$ \\
\hline 2 & "Dias de excesso em cheque especial" $=0$ & "Dias de excesso em cheque especial" $>0$ \\
\hline 4 & "Recebe proventos pelo banco" $=\{\operatorname{sim}\}$ & "Recebe proventos pelo banco" $=\{$ não $\}$ \\
\hline 5 & "Entradas mais saídas dividido pelo saldo médio & "Entradas mais saídas dividido pelo saldo médio \\
em c/c" $\leq 13,75$ & em c $>13,75$ \\
\hline 7 & "Cheques devolvidos" $>5$ & "Cheques devolvidos" $\leq 5$ \\
\hline 9 & "Escolaridade" $\in\{$ superior completo, pós- & "Escolaridade" $\in\{$ analfabeto, primeiro grau, se- \\
& $\begin{array}{l}\text { graduado, mestrado, doutorado }\} \\
\text { gundo grau, superior incompleto, superior em an- } \\
\text { damento }\}\end{array}$ \\
\hline 13 & "Dias de excesso em cheque especial" $\leq 7$ & "Dias de excesso em cheque especial" $>7$ \\
\hline 16 & "Chegião" $\in\{$ sul, sudeste $\}$ & "Região" $\in\{$ centro-oeste, nordeste, norte $\}$ \\
\hline 18 & "Tempo de conta" $\geq 3$ & "Cheques devolvidos" $\leq 5$ \\
\hline 19 & $\begin{array}{l}\text { (Valor de empréstimos dividido pela renda" } \leq \\
0,55) \text { ou (missing) }\end{array}$ & "Valor de empréstimos dividido pela renda" $>$ \\
\hline 21 & $\begin{array}{l}\text { (Utilização máxima de cheque especial" } \geq 0,85) \\
\text { ou (missing) }\end{array}$ & "Utilização máxima de cheque especial" < $<0,85$ \\
\hline
\end{tabular}

A Tabela 6.3 apresenta a descrição dos nós terminais a partir da aplicação das regras da árvore de classificação final na amostra de treinamento. A primeira coluna contém o código correspondente a cada nó terminal desenhado na Figura 6.1. A segunda coluna contém a quantidade de casos que foram associados a cada nó específico. A terceira coluna contém a quantidade de clientes "bons" em cada nó. A quarta coluna contém o percentual de clientes classificados como "bons" em cada nó. E a última coluna contém a classe da variável dependente que foi associada a cada nó terminal. 
Tabela 6.3: $\quad$ Nós Terminais da Árvore de Classificação Binária

\begin{tabular}{|r|r|r|r|r|}
\hline \hline Nó & Qtde. casos & Qtde. bons & $\%$ bons & Classe \\
\hline \hline 1 & 1.890 & 21 & 1,11 & 0 \\
\hline 3 & 2.634 & 2.356 & 89,45 & 1 \\
\hline 6 & 441 & 359 & 81,41 & 1 \\
\hline 8 & 148 & 47 & 31,76 & 0 \\
\hline 10 & 223 & 169 & 75,78 & 1 \\
\hline 12 & 61 & 51 & 83,61 & 1 \\
\hline 14 & 287 & 175 & 60,98 & 1 \\
\hline 15 & 374 & 166 & 44,39 & 0 \\
\hline 17 & 448 & 73 & 16,29 & 0 \\
\hline 20 & 477 & 294 & 61,64 & 1 \\
\hline 22 & 223 & 64 & 28,70 & 0 \\
\hline 23 & 70 & 43 & 61,43 & 1 \\
\hline 24 & 1.094 & 367 & 13,07 & 0 \\
\hline
\end{tabular}

\subsubsection{REAL}

Para desenvolvimento da árvore de classificação utilizando o REAL, foram primeiramente construídas 10 amostras, com o objetivo de escolher quais parâmetros do REAL conduzem à melhor regra de classificação. Os valores considerados para o parâmetro de convexidade $(r)$ e para a medida de convicção $(c l)$ foram respectivamente $r=(2,0 ; 3,0 ; 4,0$ e 5,0$)$ e $c l=(0,10 ; 0,30$ e 0,50$)$.

Para a aplicação da versão disponível do REAL é necessário especificar o percentual mínimo de casos de um nó interno em relação ao conjunto de dados de treinamento. As simulações foram feitas fixados os valores $0 \%, 2 \%, 6 \%$ e $8 \%$. Observou-se que quanto maior essa porcentagem menor é o número de níveis e de variáveis que compõem a árvore. Ao utilizar $0 \%$, a árvore incluiu 37 variáveis independentes, isto é, praticamente todas as variáveis disponíveis. Com o valor fixado em $2 \%$, a árvore foi reduzida para 18 variáveis, sem grande comprometimento da taxa de acerto e por isso esse foi o valor escolhido.

No Apêndice C são apresentados o tamanho das amostras (Tabela C.1) e as taxas de acerto na classificação de clientes "ruins" (TAR), "bons" (TAB) e total (TAT), para cada grupo de 
parâmetros utilizados (Tabelas C.2 a C.13).

Comparando-se as taxas médias de acerto obtidas com as 10 amostras, verificou-se que os valores $r=2$ e $c l=0,5$ (Tabela C.4) conduzem à melhor classificação, especialmente para a taxa de acertos de clientes "ruins" (TAR), que é a mais importante.

A árvore de classificação final obtida ao se aplicar o REAL na amostra de treinamento, com os parâmetros escolhidos acima, apresenta 13 camadas e as 18 variáveis relacionadas abaixo:

1. Escolaridade;

2. Tem plano de previdência particular;

3. Tem restrições;

4. Tem restrições SERASA;

5. Recebe proventos pelo banco;

6. Idade;

7. Saldo médio em c/c e investimentos;

8. Saldo médio em c/c dividido pela renda;

9. Variação do saldo médio em c/c;

10. Entradas mais saídas dividido pelo saldo médio em c/c;

11. Dias de excesso em c/c;

12. Cheques devolvidos;

13. Dias de excesso em cheque especial;

14. Utilização máxima de cheque especial;

15. Utilização média de cheque especial; 
16. Valor médio de empréstimos;

17. Valor de empréstimos dividido pela renda;

18. Menor valor de saldo médio em c/c divivido por empréstimos.

Não serão apresentadas as regras de classificação de cada nó como na seção anterior, em virtude da grande quantidade de nós formados pela árvore. As taxas de acerto do modelo nas amostras de treinamento, validação e teste são apresentadas na Tabela 6.5.

\subsubsection{Rede Neural Artificial}

Utilizando o aplicativo STATISTICA, a rede neural final apresentou 23 variáveis de entrada e 8 nós na camada intermediária, conforme Figura 6.2. As variáveis que compõem o modelo de rede neural são:

1. Estado civil;

2. Escolaridade;

3. Tem restrições SERASA;

4. Recebe proventos pelo banco;

5. Região;

6. Tempo na ocupação;

7. Renda;

8. Tempo de conta;

9. Saldo médio em c/c dividido pela renda;

10. Saldo médio em c/c e investimentos divivido pela renda; 
11. Variação do saldo médio em c/c;

12. Variação do saldo médio em c/c e investimentos;

13. Entradas mais saídas dividido pelo saldo médio em c/c;

14. Número de meses desde o menor saldo em $\mathrm{c} / \mathrm{c}$;

15. Dias de excesso em c/c;

16. Cheques devolvidos;

17. Dias de excesso em cheque especial;

18. Utilização máxima de cheque especial;

19. Utilização média de cheque especial;

20. Número de meses da utilização de cheque;

21. Valor médio de empréstimos;

22. Menor valor de saldo médio em $\mathrm{c} / \mathrm{c}$ dividido por empréstimos;

23. Menor valor de saldo médio em c/c e investimentos dividido por empréstimos.

As taxas de acerto do modelo nas amostras de treinamento, validação e teste são apresentadas na Tabela 6.5. 
Figura 6.2: Rede Neural Final, contendo 23 variáves de entrada e 8 nós na camada intermediária

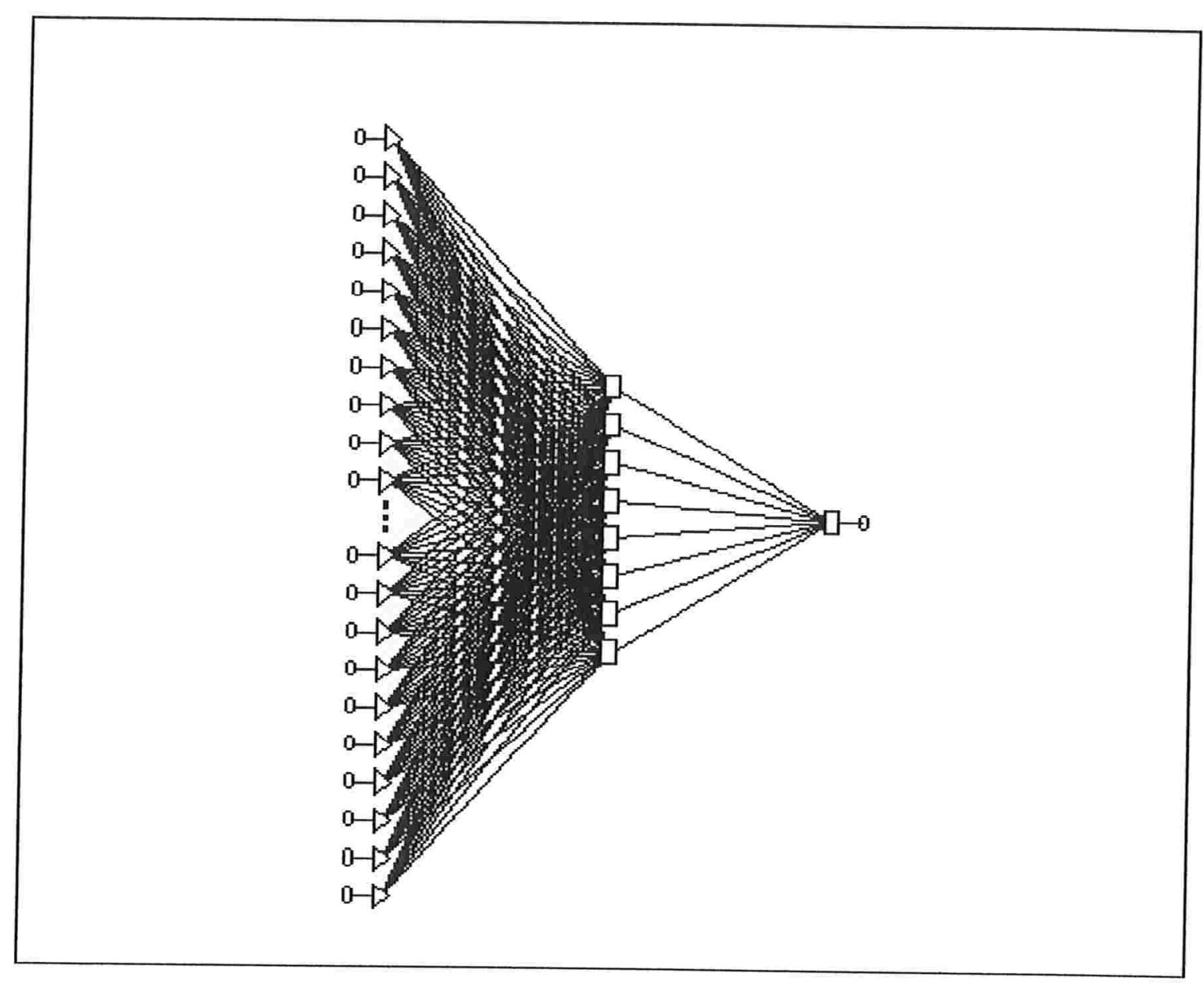

\subsection{Comparação dos modelos}

A Tabela 6.4 apresenta um quadro comparativo da composição de cada um dos modelos obtidos com as técnicas descritas anteriormente.

As variáveis "Escolaridade", "Tem restrições SERASA", "Recebe proventos pelo banco", "Entradas mais saídas dividido pelo saldo médio em c/c" e "Cheques devolvidos" estão presentes em todos os modelos ajustados. As variáveis "Região", "Tempo de conta", "Dias de excesso em cheque especial", "Utilização máxima de cheque especial" e "Utilização média 
de cheque especial" estão em três dos quatro modelos e todas no modelo de Redes Neurais. Os modelos que apresentam mais variáveis em comum são os do REAL e de Redes Neurais; 13 das variáveis preditoras estão presentes nos dois. Algumas variáveis foram incluídas em algum modelo mesmo apresentando baixo valor de informação. Isso pode ser explicado pelo fato de que uma variável pode ter maior poder de discriminação na presença de outra do que isoladamente.

A Tabela 6.5 contém as porcentagens de clientes "bons", "ruins" e totais classificados corretamente para os quatro modelos ajustados.

Observa-se que, com relação ao acerto global, o pior desempenho foi da Árvore de Classificação Binária e os melhores da Rede Neural Artificial e da Regressão Logística, com ligeira superioridade para a Rede Neural Artificial.

Já para a taxa de acerto dos clientes "ruins", que é a principal delas, os comentários são análogos uma vez que a Árvore de Classificação Binária teve o pior desempenho e a Rede Neural Artificial o melhor. Nesse caso, a superioridade da Rede Neural Artificial sobre a Regressão Logística foi um pouco mais acentuada.

Em termos gerais, espera-se que a taxa de acerto na amostra de treinamento seja maior do que nas amostras de validação e teste pois na primeira as mesmas unidades amostrais são utilizadas tanto para a estimação dos parâmetros como para a classificação das unidades. Isso em geral aconteceu com algumas exceções como, por exemplo, a taxa de acerto de clientes "ruins" da Regressão Logística na amostra de treinamento é de 0,8172 enquanto que na amostra teste é de 0,8231. Entretanto esses valores são bem próximos.

É interessante notar que a maior diferença está nas taxas de acerto de clientes "ruins" na Árvore de Classificação Binária; enquanto a taxa da amostra de treinamento é de 0,8217, as taxas das amostras de validação e teste são respectivamente 0,6689 e 0,6785, bem mais baixas. 
Tabela 6.4: Quadro comparativo das variáveis nos modelos finais

I=Regressão Logística; II=Árvore de Classificação Binária; III=REAL; IV=Rede Neural Artificial.

\begin{tabular}{|r|l|c|c|c|c|}
\hline \hline \multicolumn{2}{|c|}{ Variável } & I & II & III & IV \\
\hline \hline V1 & Estado civil & $*$ & & & $*$ \\
\hline V2 & Escolaridade & $*$ & $*$ & $*$ & $*$ \\
\hline V3 & Tipo de residência & $*$ & & & \\
\hline V4 & Sexo & $*$ & & & \\
\hline V8 & Tem plano de previdência particular & & & $*$ & \\
\hline V9 & Tem restrições & & & $*$ & \\
\hline V10 & Tem restrições SERASA & $*$ & $*$ & $*$ & $*$ \\
\hline V11 & Natureza da ocupação & $*$ & & & \\
\hline V12 & Recebe proventos pelo banco & $*$ & $*$ & $*$ & $*$ \\
\hline V13 & Região & $*$ & $*$ & & $*$ \\
\hline V14 & Tempo na ocupação & & & & $*$ \\
\hline V16 & Idade & & & $*$ & \\
\hline V18 & Renda & & & & $*$ \\
\hline V19 & Tempo de conta & $*$ & $*$ & & $*$ \\
\hline V21 & Saldo médio em c/c e investimentos & & & $*$ & \\
\hline V22 & Saldo médio em c/c dividido pela renda & & & $*$ & $*$ \\
\hline V23 & Saldo médio em c/c e investimentos dividido pela renda & & & & $*$ \\
\hline V24 & Variação do saldo médio em c/c & & & $*$ & $*$ \\
\hline V25 & Variação do saldo médio em c/c e investimentos & $*$ & & & $*$ \\
\hline V26 & Entradas mais saídas dividido pelo saldo médio em c/c & $*$ & $*$ & $*$ & $*$ \\
\hline V27 & Número de meses desde o menor saldo em c/c & & & & $*$ \\
\hline V29 & Dias de excesso em c/c & & & $*$ & $*$ \\
\hline V30 & Cheques devolvidos & $*$ & $*$ & $*$ & $*$ \\
\hline V31 & Dias de excesso em cheque especial & & $*$ & $*$ & $*$ \\
\hline V32 & Utilização máxima de cheque especial & & & $*$ & $*$ \\
\hline V33 & Utilização média de cheque especial & & & $*$ \\
\hline V34 & Número de meses da utilização de cheque & & & $*$ \\
\hline V35 & Valor médio de empréstimos & & & $*$ \\
\hline V36 & Valor de empréstimos dividido pela renda & & \\
\hline V37 & Menor valor de saldo médio em c/c dividido por empréstimos & & \\
\hline V38 & Menor valor de saldo médio em c/c e investimentos dividido por em- & & \\
\hline \hline & préstimos & & & \\
\hline \hline
\end{tabular}


Tabela 6.5: Quadro comparativo do acerto dos modelos

\begin{tabular}{|c|c|c|c|c|c|c|c|c|c|c|c|}
\hline \multicolumn{12}{|c|}{ Regressão Logística } \\
\hline \multicolumn{4}{|c|}{ Amostra de Treinamento } & \multicolumn{4}{|c|}{ Amostra de Validação } & \multicolumn{4}{|c|}{ Amostra Teste } \\
\hline & \multicolumn{2}{|c|}{ predito } & \multirow[b]{2}{*}{$p_{\text {acerto }}$} & \multirow[b]{2}{*}{ obs. } & \multicolumn{2}{|c|}{ predito } & \multirow[b]{2}{*}{$p_{\text {acerto }}$} & \multirow[b]{2}{*}{ obs. } & \multicolumn{2}{|c|}{ predito } & \multirow[b]{2}{*}{$p_{\text {acerto }}$} \\
\hline obs. & ruim & bom & & & ruim & bom & & & ruim & bom & \\
\hline ruim & 3.420 & 765 & 0,8172 & ruim & 1.718 & 374 & 0,8212 & ruim & 1.722 & 370 & 0,8231 \\
\hline bom & 617 & 3.568 & 0,8526 & bom & 330 & 1.762 & 0,8423 & bom & 729 & 1.986 & 0,8509 \\
\hline total & 4.037 & 4.333 & 0,8349 & total & 2.048 & 2.136 & 0,8314 & total & 2.034 & 2.150 & 0,8370 \\
\hline
\end{tabular}

\begin{tabular}{|c|c|c|c|c|c|c|c|c|c|c|c|}
\hline \multicolumn{12}{|c|}{ Árvore de Classificação Binária } \\
\hline \multicolumn{4}{|c|}{ Amostra de Treinamento } & \multicolumn{4}{|c|}{ Amostra de Validação } & \multicolumn{4}{|c|}{ Amostra Teste } \\
\hline & \multicolumn{2}{|c|}{ predito } & \multirow[b]{2}{*}{$p_{\text {acerto }}$} & \multirow[b]{2}{*}{ obs. } & \multicolumn{2}{|c|}{ predito } & \multirow[b]{2}{*}{$p_{\text {acerto }}$} & \multirow[b]{2}{*}{ obs. } & \multicolumn{2}{|c|}{ predito } & \multirow[b]{2}{*}{$p_{\text {acerto }}$} \\
\hline obs. & ruim & bom & & & ruim & bom & & & ruim & bom & \\
\hline ruim & 3.439 & 746 & 0,8217 & ruim & 1.816 & 899 & 0,6689 & ruim & 1.842 & 873 & 0,6785 \\
\hline bom & 658 & 2.058 & 0,7577 & bom & 744 & 1.971 & 0,7260 & bom & 718 & 1.997 & 0,7355 \\
\hline total & 2.613 & 2.819 & 0,7390 & total & 2.560 & 2.870 & 0,6970 & total & 2.560 & 2.870 & 0,7070 \\
\hline
\end{tabular}

\begin{tabular}{|c|c|c|c|c|c|c|c|c|c|c|c|}
\hline \multicolumn{12}{|c|}{ REAL-Real Attribute Learning Algorithm } \\
\hline \multicolumn{4}{|c|}{ Amostra de Treinamento } & \multicolumn{4}{|c|}{ Amostra de Validação } & \multicolumn{4}{|c|}{ Amostra Teste } \\
\hline & \multicolumn{2}{|c|}{ predito } & \multirow[b]{2}{*}{$p_{\text {acerto }}$} & \multirow[b]{2}{*}{ obs. } & \multicolumn{2}{|c|}{ predito } & \multirow[b]{2}{*}{$p_{\text {acerto }}$} & \multirow[b]{2}{*}{ obs. } & \multicolumn{2}{|c|}{ predito } & \multirow[b]{2}{*}{$p_{\text {acerto }}$} \\
\hline obs. & ruim & bom & & & ruim & bom & & & ruim & bom & \\
\hline ruim & 3.446 & 739 & 0,8234 & ruim & 1.707 & 385 & 0,8160 & ruim & 1.701 & 391 & 0,8131 \\
\hline bom & 671 & 3.514 & 0,8397 & bom & 409 & 1.683 & 0,8045 & bom & 350 & 1.742 & 0,8327 \\
\hline total & 4.117 & 4.253 & 0,8315 & total & 2.116 & 2.068 & 0,8102 & total & 2.051 & 2.133 & 0,8229 \\
\hline
\end{tabular}

\begin{tabular}{|c|c|c|c|c|c|c|c|c|c|c|c|}
\hline \multicolumn{12}{|c|}{ Rede Neural Multicamada } \\
\hline \multicolumn{4}{|c|}{ Amostra de Treinamento } & \multicolumn{4}{|c|}{ Amostra de Validação } & \multicolumn{4}{|c|}{ Amostra Teste } \\
\hline & \multicolumn{2}{|c|}{ predito } & \multirow[b]{2}{*}{$p_{\text {acerto }}$} & \multirow[b]{2}{*}{ obs. } & \multicolumn{2}{|c|}{ predito } & \multirow[b]{2}{*}{$p_{\text {acerto }}$} & \multirow[b]{2}{*}{ obs. } & \multicolumn{2}{|c|}{ predito } & \multirow[b]{2}{*}{$p_{\text {acerto }}$} \\
\hline obs. & ruim & bom & & & ruim & bom & & & ruim & bom & \\
\hline ruim & 3.545 & 640 & 0,8471 & ruim & 1.754 & 338 & 0,8384 & ruim & 1.763 & 329 & 0,8427 \\
\hline bom & 616 & 3.569 & 0,8528 & bom & 339 & 1.753 & 0,8380 & bom & 352 & 1.740 & 0,8317 \\
\hline total & 4.161 & 4.209 & 0,8499 & total & 2.093 & 2.091 & 0,8382 & total & 2.115 & 2.069 & 0,8372 \\
\hline
\end{tabular}




\section{Capítulo 7}

\section{Conclusões}

Neste trabalho foram desenvolvidos modelos de behavioral scoring com base em variáveis cadastrais e de utilização de clientes de uma instituição financeira, a fim de classificá-los como "bons" ou "ruins" de crédito. Esses modelos foram ajustados por meio de quatro técnicas: Regressão Logística, Árvore de Classificação Binária, Real Attribute Learning Algorithm e Redes Neurais Artificiais, com o objetivo de fazer uma comparação entre elas.

Tomando como critério de comparação a porcentagem de clientes classificados corretamente como "bons" ou "ruins" de crédito, a técnica que apresentou o pior desempenho foi a Árvore de Classificação Binária. Os melhores resultados foram obtidos com a Regressão Logística e com as Redes Neurais Artificiais, com ligeira superioridade para a última, especialmente com relação à taxa de acerto na classificação de clientes "ruins", que é a principal delas.

Como sugestão para trabalhos futuros destacamos:

1. consideração de um terceiro grupo de clientes (nem "bons" e nem "ruins") - aqueles que estão inadimplentes entre 10 e 60 dias;

2. verificação da eficácia dos modelos no decorrer do tempo, uma vez que envolvem variáveis comportamentais de clientes, sujeitas a mudanças. 
Apêndice A

Variáveis Preditoras 
Tabela A.1: Variáveis Cadastrais

\begin{tabular}{|c|c|c|c|c|}
\hline & Nome & Descrição & Tipo & Atributos \\
\hline 1 & Estado Civil & estado civil do cliente & categorizada & $\begin{array}{l}\text { solteiro(a), divorciado(a), sepa- } \\
\text { rado(a) judicialmente, casado(a)- } \\
\text { separação de bens, casado(a)- } \\
\text { comunhão parcial, casado(a)- } \\
\text { comunhão universal, viúvo(a) }\end{array}$ \\
\hline 2 & Escolaridade & $\begin{array}{l}\text { nível de escolaridade } \\
\text { do cliente }\end{array}$ & categorizada & $\begin{array}{l}\text { analfabeto(a), primeiro grau, segun- } \\
\text { do grau, superior incompleto, supe- } \\
\text { rior em andamento, superior com- } \\
\text { pleto, pós-graduado(a), mestrado, } \\
\text { doutorado }\end{array}$ \\
\hline 3 & Tipo de residência & $\begin{array}{l}\text { tipo de residência do } \\
\text { cliente }\end{array}$ & categorizada & $\begin{array}{l}\text { alugada, cedida ou familiar, própria } \\
\text { financiada, própria quitada }\end{array}$ \\
\hline 4 & Sexo & sexo do cliente & binária & $1=$ masculino $0=$ feminino \\
\hline 5 & $\begin{array}{l}\text { Tem plano de saúde } \\
\text { do empregador }\end{array}$ & $\begin{array}{l}\text { indicadora se o cliente } \\
\text { tem plano de saúde pa- } \\
\text { go pelo empregador }\end{array}$ & binária & $1=\operatorname{sim} ; 0=$ não \\
\hline 6 & $\begin{array}{l}\text { Tem plano de pre- } \\
\text { vidência do empre- } \\
\text { gador }\end{array}$ & $\begin{array}{l}\text { indicadora se o cliente } \\
\text { tem plano de previdên- } \\
\text { cia pago pelo empre- } \\
\text { gador }\end{array}$ & binária & $1=\operatorname{sim} ; 0=$ não \\
\hline 7 & $\begin{array}{l}\text { Tem plano de saúde } \\
\text { particular }\end{array}$ & $\begin{array}{l}\text { indicadora se o cliente } \\
\text { tem plano de saúde } \\
\text { particular }\end{array}$ & binária & $1=\operatorname{sim} ; 0=$ não \\
\hline 8 & $\begin{array}{l}\text { Tem plano de previ- } \\
\text { dência particular }\end{array}$ & $\begin{array}{l}\text { indicadora se o cliente } \\
\text { tem plano de previdên- } \\
\text { cia particular }\end{array}$ & binária & $1=\operatorname{sim} ; 0=$ não \\
\hline
\end{tabular}




\section{Tabela A.1: Variáveis Cadastrais (continuação)}

\begin{tabular}{|c|c|c|c|c|}
\hline & Nome & Descrição & Tipo & Atributos \\
\hline 9 & Tem restrições & $\begin{array}{l}\text { indicadora se o cliente } \\
\text { tem anotações restri- } \\
\text { tivas no cadastro do } \\
\text { banco }\end{array}$ & binária & $1=\operatorname{sim} ; 0=$ não \\
\hline 10 & $\begin{array}{l}\text { Tem restrições } \\
\text { SERASA }\end{array}$ & $\begin{array}{l}\text { indicadora se o cliente } \\
\text { tem anotações restri- } \\
\text { tivas no cadastro da } \\
\text { SERASA }\end{array}$ & binária & $1=\operatorname{sim} ; 0=$ não \\
\hline 11 & $\begin{array}{l}\text { Natureza da ocu- } \\
\text { pação }\end{array}$ & $\begin{array}{l}\text { natureza da ocupação } \\
\text { principal do cliente }\end{array}$ & categorizada & $\begin{array}{l}\text { trabalhador sem vínculo empre- } \\
\text { gatício, empregado em empresa do } \\
\text { setor privado, profissional liberal, } \\
\text { proprietário de empresa, servidor } \\
\text { público ou funcionário de empre- } \\
\text { sa pública ou de economia mista, } \\
\text { aposentado ou pensionista, outras }\end{array}$ \\
\hline 12 & $\begin{array}{l}\text { Recebe proventos } \\
\text { pelo banco }\end{array}$ & $\begin{array}{l}\text { indicadora se o cliente } \\
\text { recebe pagamento de } \\
\text { salário via banco }\end{array}$ & binária & $1=\operatorname{sim} ; 0=$ não \\
\hline 13 & Região & $\begin{array}{l}\text { região geográfica em } \\
\text { que o cliente mora }\end{array}$ & categorizada & $\begin{array}{l}\text { Norte, Nordeste, Centro-Oeste, Sul, } \\
\text { Sudeste }\end{array}$ \\
\hline & Nome & \multicolumn{2}{|c|}{ Descrição } & Tipo \\
\hline 14 & Tempo na ocupação & \multicolumn{2}{|c|}{ tempo que exerce a ocupação (em anos) } & discreta \\
\hline 15 & $\begin{array}{l}\text { Tempo de } \\
\text { residência }\end{array}$ & \multicolumn{2}{|c|}{ tempo que mora na residência (em anos) } & discreta \\
\hline 16 & Idade & \multicolumn{2}{|l|}{ idade do cliente (em anos) } & discreta \\
\hline 17 & $\begin{array}{l}\text { Número de depen- } \\
\text { dentes }\end{array}$ & \multicolumn{2}{|c|}{ quantidade de dependentes +1} & discreta \\
\hline 18 & Renda & \multicolumn{2}{|c|}{ valor da renda bruta mensal } & contínua \\
\hline
\end{tabular}


Tabela A.2: Variáveis de Utilização

\begin{tabular}{|c|c|c|c|}
\hline & Nome & Descrição & Tipo \\
\hline 19 & Tempo de conta & tempo que o cliente possui c/c no banco (em anos) & discreta \\
\hline 20 & $\begin{array}{lr}\text { Saldo médio em } \\
\text { conta } & \text { corrente } \\
(\mathrm{c} / \mathrm{c}) & \\
\end{array}$ & $\begin{array}{l}\text { valor do saldo médio em c/c nos últimos } 6 \text { meses } \\
\text { de } 1.999\end{array}$ & contínua \\
\hline 21 & $\begin{array}{l}\text { Saldo médio em } c / c \\
\text { e investimentos }\end{array}$ & $\begin{array}{l}\text { valor do saldo médio em c/c e investimentos nos } \\
\text { últimos } 6 \text { meses do ano de } 1.999\end{array}$ & contínua \\
\hline 22 & $\begin{array}{l}\text { Saldo médio em } \mathrm{c} / \mathrm{c} \\
\text { dividido pela renda }\end{array}$ & $\begin{array}{l}\text { valor do saldo médio em conta corrente nos } \\
\text { últimos } 6 \text { meses de } 1.999 \text { dividido pela renda }\end{array}$ & contínua \\
\hline 23 & $\begin{array}{l}\text { Saldo médio em } c / c \\
\text { e investimentos di- } \\
\text { vidido pela renda }\end{array}$ & $\begin{array}{l}\text { valor do saldo médio em conta corrente e investi- } \\
\text { mentos nos últimos } 6 \text { meses do ano de } 1.999 \text { divi- } \\
\text { dido pela renda }\end{array}$ & contínua \\
\hline 24 & $\begin{array}{l}\text { Variação do saldo } \\
\text { médio em } \mathrm{c} / \mathrm{c}\end{array}$ & $\begin{array}{l}\text { saldo médio em c/c no último trimestre de } 1.999 \\
\text { dividido pelo saldo médio em } \mathrm{c} / \mathrm{c} \text { no penúltimo } \\
\text { trimestre de } 1.999\end{array}$ & contínua \\
\hline 25 & $\begin{array}{l}\text { Variação do saldo } \\
\text { médio em c/c e in- } \\
\text { vestimentos }\end{array}$ & $\begin{array}{l}\text { saldo médio em } \mathrm{c} / \mathrm{c} \text { e investimentos no último } \\
\text { trimestre de } 1.999 \text { dividido pelo saldo médio em } \\
\mathrm{c} / \mathrm{c} \text { e investimentos no penúltimo trimestre de } \\
1.999\end{array}$ & contínua \\
\hline 26 & $\begin{array}{l}\text { Entradas mais } \\
\text { saídas dividido pelo } \\
\text { saldo médio } \mathrm{em} \mathrm{c} / \mathrm{c}\end{array}$ & $\begin{array}{l}\text { soma das entradas e saídas dividida pelo saldo } \\
\text { médio em c/c nos últimos } 6 \text { meses de } 1.999\end{array}$ & contínua \\
\hline 27 & $\begin{array}{l}\text { Número de meses } \\
\text { desde o menor sal- } \\
\text { do em } \mathrm{c} / \mathrm{c}\end{array}$ & $\begin{array}{l}\text { número de meses desde a ocorrência do menor } \\
\text { saldo em c/c nos últimos } 6 \text { meses de } 1.999\end{array}$ & discreta \\
\hline 28 & $\begin{array}{l}\text { Número de meses } \\
\text { do menor saldo em } \\
c / c \text { e investimentos }\end{array}$ & $\begin{array}{l}\text { número de meses desde a ocorrência do menor } \\
\text { saldo em } \mathrm{c} / \mathrm{c} \text { e investimentos nos últimos } 6 \text { meses } \\
\text { de } 1.999\end{array}$ & discreta \\
\hline 29 & $\begin{array}{l}\text { Dias de excesso em } \\
\mathrm{c} / \mathrm{c}\end{array}$ & $\begin{array}{l}\text { quantidade de dias em que o cliente excedeu o } \\
\text { saldo em c/c nos últimos } 6 \text { meses de } 1.999\end{array}$ & discreta \\
\hline 30 & Cheques devolvidos & $\begin{array}{l}\text { quantidade de cheques devolvidos nos últimos } 6 \\
\text { meses de } 1.999\end{array}$ & discreta \\
\hline
\end{tabular}




\section{Tabela A.2: Variáveis de Utilização (continuação)}

\begin{tabular}{|c|c|c|c|}
\hline & Nome & Descrição & Tipo \\
\hline 31 & $\begin{array}{l}\text { Dias de excesso em } \\
\text { cheque especial }\end{array}$ & $\begin{array}{l}\text { quantidade de dias em que o cliente excedeu o } \\
\text { limite de cheque especial nos últimos } 6 \text { meses de } \\
1.999\end{array}$ & discreta \\
\hline 32 & $\begin{array}{l}\text { Utilização máxima } \\
\text { de cheque especial }\end{array}$ & $\begin{array}{l}\text { valor da máxima utilização do limite de cheque } \\
\text { especial nos últimos } 6 \text { meses de } 1.999\end{array}$ & contínua \\
\hline 33 & $\begin{array}{l}\text { Utilização média de } \\
\text { cheque especial }\end{array}$ & $\begin{array}{l}\text { valor da utilização média do limite de cheque es- } \\
\text { pecial nos últimos } 6 \text { meses de } 1.999\end{array}$ & contínua \\
\hline 34 & $\begin{array}{l}\text { Número de meses } \\
\text { da utilização de } \\
\text { cheque }\end{array}$ & $\begin{array}{l}\text { número de meses desde a última utilização do } \\
\text { limite de cheque especial nos últimos } 6 \text { meses de } \\
1.999\end{array}$ & discreta \\
\hline 35 & $\begin{array}{l}\text { Valor médio de em- } \\
\text { préstimos }\end{array}$ & $\begin{array}{l}\text { valor médio dos empréstimos do cliente nos } \\
\text { últimos } 6 \text { meses de } 1.999\end{array}$ & contínua \\
\hline 36 & $\begin{array}{l}\text { Valor de em- } \\
\text { préstimos dividido } \\
\text { pela renda }\end{array}$ & $\begin{array}{l}\text { valor dos empréstimos dividido pela renda do } \\
\text { cliente nos últimos } 6 \text { meses de } 1.999\end{array}$ & contínua \\
\hline 37 & $\begin{array}{l}\text { Menor valor de } \\
\text { saldo médio } \mathrm{em} \\
\mathrm{c} / \mathrm{c} \text { dividido por } \\
\text { empréstimos }\end{array}$ & $\begin{array}{l}\text { menor valor do saldo médio em } \mathrm{c} / \mathrm{c} \text { dividido pe- } \\
\text { lo total de empréstimos que o cliente tem com o } \\
\text { banco nos últimos } 6 \text { meses de } 1.999\end{array}$ & contínua \\
\hline 38 & $\begin{array}{l}\text { Menor valor de } \\
\text { saldo médio em } \\
c / c \text { e investimen- } \\
\text { tos dividido por } \\
\text { empréstimos }\end{array}$ & $\begin{array}{l}\text { menor valor do saldo médio em } \mathrm{c} / \mathrm{c} \text { e investi- } \\
\text { mentos dividido pelo total de empréstimos que } \\
\text { o cliente tem com o banco nos últimos } 6 \text { meses de } \\
1.999\end{array}$ & contínua \\
\hline
\end{tabular}




\section{Apêndice B}

\section{Valor de Informação (VI)}

\section{Variável 1 - Estado civil}

\begin{tabular}{l||r|r|r|r|r|c}
\hline & \multicolumn{1}{|c|}{ Bons } & Ruins & \multicolumn{1}{c|}{ Total } & $p b / p r$ & $\ln (p b / p r)$ & $\boldsymbol{V} \boldsymbol{I}$ \\
\hline Solteiro(a) & 26.702 & 3.154 & 29.856 & 0,7206 & $-0,3277$ & 0,0345 \\
Separado(a) judicialmente & 3.768 & 400 & 4.168 & 0,8018 & $-0,2209$ & 0,0021 \\
Divorciado(a) & 3.382 & 342 & 3.724 & 0,8417 & $-0,1724$ & 0,0011 \\
Casado(a)-separação de bens & 1.208 & 103 & 1.311 & 0,9982 & $-0,0018$ & 0,0000 \\
Casado(a)-comunhão parcial & 20.953 & 1.623 & 22.576 & 1,0988 & 0,0942 & 0,0018 \\
Casado(a)-comunhão universal & 39.271 & 2.599 & 41.870 & 1,2861 & 0,2516 & 0,0224 \\
Viúvo(a) & 3.043 & 148 & 3.191 & 1,7500 & 0,5596 & 0,0074 \\
\hline TOTAL & 98.327 & 8.369 & 106.696 & & & $\mathbf{0 , 0 6 9 3}$ \\
\hline
\end{tabular}

Variável 2 - Escolaridade

\begin{tabular}{l||r|r|r|r|r|c}
\hline & Bons & Ruins & Total & $p b / p r$ & $\ln (p b / p r)$ & $\boldsymbol{V I}$ \\
\hline Analfabeto(a) & 491 & 62 & 553 & 0,6740 & $-0,3945$ & 0,0010 \\
Primeiro grau & 26.825 & 3.105 & 29.930 & 0,7353 & $-0,3074$ & 0,0302 \\
Segundo grau & 33.648 & 3.570 & 37.218 & 0,8022 & $-0,2204$ & 0,0186 \\
Superior incompleto & 2.549 & 213 & 2.762 & 1,0186 & 0,0184 & 0,0000 \\
Superior em andamento & 1.525 & 82 & 1.607 & 1,5829 & 0,4593 & 0,0026 \\
Superior completo & 29.884 & 1.246 & 31.130 & 2,0414 & 0,7136 & 0,1106 \\
Pós-graduado(a) & 2.232 & 69 & 2.301 & 2,7533 & 1,0128 & 0,0146 \\
Mestrado & 735 & 18 & 753 & 3,4755 & 1,2457 & 0,0066 \\
Doutorado & 438 & 4 & 442 & 9,3200 & 2,2322 & 0,0089 \\
\hline TOTAL & 98.327 & 8.369 & 106.696 & & & 0,1932 \\
\hline
\end{tabular}


Variável 3 - Tipo de residência

\begin{tabular}{l||r|r|r|r|r|c}
\hline & \multicolumn{1}{|c|}{ Bons } & Ruins & \multicolumn{1}{c|}{ Total } & $p b / p r$ & $\ln (p b / p r)$ & $V \boldsymbol{I}$ \\
\hline Alugada & 12.445 & 1.714 & 14.159 & 0,6180 & $-0,4813$ & 0,0377 \\
Cedida ou familiar & 18.420 & 1.924 & 20.344 & 0,8149 & $-0,2047$ & 0,0087 \\
Própria financiada & 6.000 & 467 & 6.467 & 1,0935 & 0,0894 & 0,0005 \\
Própria quitada & 61.462 & 4.264 & 65.726 & 1,2268 & 0,2044 & 0,0236 \\
\hline TOTAL & 98.327 & 8.369 & 106.696 & & & $\mathbf{0 , 0 7 0 5}$ \\
\hline
\end{tabular}

Variável 4 - Sexo

\begin{tabular}{l||c|r|r|r|r|r}
\hline & Bons & Ruins & \multicolumn{1}{c|}{ Total } & $p b / p r$ & $\ln (p b / p r)$ & $\boldsymbol{V} \boldsymbol{I}$ \\
\hline Masculino & 61.108 & 5.840 & 66.948 & 0,8906 & $-0,1159$ & 0,0088 \\
Feminino & 37.440 & 2.529 & 39.748 & 1,2526 & 0,2252 & 0,0172 \\
\hline TOTAL & 98.327 & 8.369 & 106.696 & & & $\mathbf{0 , 0 2 6 0}$ \\
\hline
\end{tabular}

Variável 5 - Tem plano de saúde do empregador

\begin{tabular}{l||c|r|r|r|r|r}
\hline & Bons & Ruins & Total & $p b / p r$ & $\ln (p b / p r)$ & \multicolumn{1}{|c}{$\boldsymbol{I}$} \\
\hline Não possui & 80.765 & 7.586 & 88.351 & 0,9062 & $-0,0985$ & 0,0084 \\
Possui & 17.562 & 783 & 18.345 & 1,9090 & 0,6466 & 0,0550 \\
\hline TOTAL & 98.327 & 8.369 & 106.696 & & & $\mathbf{0 , 0 6 3 4}$ \\
\hline
\end{tabular}

Variável 6 - Tem plano de previdência do empregador

\begin{tabular}{l||c|r|r|r|r|r}
\hline & Bons & Ruins & Total & $p b / p r$ & $\ln (p b / p r)$ & \multicolumn{1}{|c}{} \\
\hline Não possui & 82.973 & 7.676 & 90.649 & 0,9200 & $-0,0833$ & 0,0061 \\
Possui & 15.354 & 693 & 16.047 & 1,8858 & 0,6343 & 0,0465 \\
\hline TOTAL & 98.327 & 8.369 & 106.696 & & & $\mathbf{0 , 0 5 2 6}$ \\
\hline
\end{tabular}

Variável 7 - Tem plano de saúde particular

\begin{tabular}{l||c|r|r|r|r|r}
\hline & Bons & Ruins & \multicolumn{1}{c|}{ Total } & $p b / p r$ & $\ln (p b / p r)$ & $\boldsymbol{V I}$ \\
\hline Não possui & 84.639 & 7.614 & 92.253 & 0,9461 & $-0,0554$ & 0,0027 \\
Possui & 13.688 & 755 & 14.443 & 1,5431 & 0,4338 & 0,0213 \\
\hline TO'TAL & 98.327 & 8.369 & 106.696 & & & $\mathbf{0 , 0 2 4 0}$ \\
\hline
\end{tabular}


Variável 8 - Tem plano de previdência particular

\begin{tabular}{l||r|r|r|c|r|c}
\hline & Bons & Ruins & \multicolumn{1}{c|}{ Total } & $p b / p r$ & $\ln (p b / p r)$ & $\boldsymbol{V} \boldsymbol{I}$ \\
\hline Não possui & 93.887 & 8.053 & 101.940 & 0,9923 & $-0,0077$ & 0,0001 \\
Possui & 4.440 & 316 & 4.756 & 1,1959 & 0,1789 & 0,0013 \\
\hline TOTAL & 98.327 & 8.369 & 106.696 & & & $\mathbf{0 , 0 0 1 4}$ \\
\hline
\end{tabular}

Variável 9 - Tem restrições

\begin{tabular}{l||r|r|r|r|r|r}
\hline & \multicolumn{1}{|c|}{ Bons } & Ruins & \multicolumn{1}{c|}{ Total } & $p b / p r$ & $\ln (p b / p r)$ & \multicolumn{1}{c}{$\boldsymbol{V I}$} \\
\hline Sim & 1.413 & 4.147 & 5.560 & 0,0290 & $-3,5404$ & 1,7035 \\
Não & 96.914 & 4.222 & 101.136 & 1,9538 & 0,3222 & 0,2204 \\
\hline TOTAL & 98.327 & 8.369 & 106.696 & & & $\mathbf{2 , 0 2 5 7}$ \\
\hline
\end{tabular}

Variável 10 - Tem restrições SERASA

\begin{tabular}{l||r|r|r|r|r|c}
\hline & \multicolumn{1}{||}{ Bons } & Ruins & \multicolumn{1}{c|}{ Total } & $p b / p r$ & $\ln (p b / p r)$ & $\boldsymbol{V I}$ \\
\hline Sim & 491 & 3.729 & 4.220 & 0,0112 & $-4,4912$ & 1,9787 \\
Não & 97.836 & 4.640 & 102.476 & 1,7947 & 0,5848 & 0,2577 \\
\hline TOTAL & 98.327 & 8.369 & 106.696 & & & $\mathbf{2 , 2 3 6 4}$ \\
\hline
\end{tabular}

Variável 11 - Natureza da ocupação

\begin{tabular}{l||r|r|r|r|r|c}
\hline & \multicolumn{1}{|c|}{ Bons } & Ruins & \multicolumn{1}{c|}{ Total } & $p b / p r$ & $\ln (p b / p r)$ & $V I$ \\
\hline Trabalhador sem vínculo empregatício & 26.702 & 3.154 & 29.856 & 0,7206 & $-0,3277$ & 0,0345 \\
Empregado em empresa do setor privado & 3.768 & 400 & 4.168 & 0,8018 & $-0,2209$ & 0,0021 \\
Profissional liberal & 3.382 & 342 & 3.724 & 0,8417 & $-0,1724$ & 0,0011 \\
Proprietário de empresa & 1.208 & 103 & 1.311 & 0,9982 & $-0,0018$ & 0,0000 \\
Funcionário público & 20.953 & 1.623 & 22.576 & 1,0988 & 0,0942 & 0,0018 \\
Demais naturezas & 39.271 & 2.599 & 41.870 & 1,2861 & 0,2516 & 0,0224 \\
Aposentado ou pensionista & 3.043 & 148 & 3.191 & 1,7500 & 0,5596 & 0,0074 \\
\hline TOTAL & 98.327 & 8.369 & 106.696 & & & $\mathbf{0 , 0 6 9 3}$ \\
\hline
\end{tabular}

Variável 12 - Recebe proventos pelo banco

\begin{tabular}{l||c|r|r|c|r|c}
\hline & Bons & Ruins & Total & $p b / p r$ & $\ln (p b / p r)$ & $\boldsymbol{V I}$ \\
\hline Não & 48.172 & 6.553 & 54.725 & 0,6257 & $-0,4689$ & 0,1374 \\
Sim & 50.155 & 1.816 & 51.971 & 2,3507 & 0,8547 & 0,2505 \\
\hline TOTAL & 98.327 & 8.369 & 106.696 & & & $\mathbf{0 , 3 8 7 9}$ \\
\hline
\end{tabular}


Variável 13 - Região

\begin{tabular}{l||r|r|r|r|r|c}
\hline & \multicolumn{1}{|c|}{ Bons } & Ruins & \multicolumn{1}{c|}{ Total } & $p b / p r$ & $\ln (p b / p r)$ & $\boldsymbol{V I}$ \\
\hline Nordeste & 20.118 & 2.271 & 22.389 & 0,7540 & $-0,2824$ & 0,0188 \\
Norte & 5.423 & 563 & 5.986 & 0,8198 & $-0,1986$ & 0,0024 \\
Centro-Oeste & 11.364 & 1.129 & 12.493 & 0,8567 & $-0,1546$ & 0,0030 \\
Sudeste & 43.578 & 3.190 & 46.768 & 1,1627 & 0,1508 & 0,0094 \\
Sul & 17.844 & 1.216 & 19.060 & 1,2490 & 0,2223 & 0,0080 \\
\hline TOTAL & 98.327 & 8.369 & 106.696 & & & $\mathbf{0 , 0 4 1 6}$ \\
\hline
\end{tabular}

Variável 14 - Tempo na ocupação

\begin{tabular}{l||r|r|r|r|r|c}
\hline & \multicolumn{1}{|c|}{ Bons } & Ruins & Total & $p b / p r$ & $\ln (p b / p r)$ & $\boldsymbol{V I}$ \\
\hline$(\geq 0$ e $<2$ anos $)$ & 11.147 & 1.491 & 12.638 & 0,6363 & $-0,4521$ & 0,0293 \\
$(\geq 2$ e $<12$ anos $)$ & 52.324 & 5.064 & 57.388 & 0,8794 & $-0,1285$ & 0,0094 \\
$(\geq 12$ e $<28$ anos $)$ & 28.935 & 1.584 & 30.519 & 1,5548 & 0,4413 & 0,0463 \\
$(\geq 28$ anos $)$ & 5.921 & 230 & 6.151 & 2,1911 & 0,7844 & 0,0257 \\
\hline TOTAL & 98.327 & 8.369 & 106.696 & & & $\mathbf{0 , 1 1 0 7}$ \\
\hline
\end{tabular}

Variável 15 - Tempo de residência

\begin{tabular}{l||r|r|r|r|r|c}
\hline & \multicolumn{1}{|c|}{ Bons } & Ruins & \multicolumn{1}{c|}{ Total } & $p b / p r$ & $\ln (p b / p r)$ & $\boldsymbol{V I}$ \\
\hline ( $\geq 0$ e $<6$ anos $)$ & 35.557 & 3.743 & 39.300 & 0,8085 & $-0,2126$ & 0,0182 \\
$(\geq 6$ e $<14$ anos $)$ & 31.998 & 2.681 & 34.679 & 1,0158 & 0,0157 & 0,0001 \\
$(\geq 14$ e $<28$ anos $)$ & 23.753 & 1.625 & 25.378 & 1,2441 & 0,2184 & 0,0104 \\
$(\geq 28$ anos $)$ & 7.019 & 320 & 7.339 & 1,8669 & 0,6243 & 0,0207 \\
\hline TOTAL & 98.327 & 8.369 & 106.696 & & & $\mathbf{0 , 0 4 9 3}$ \\
\hline
\end{tabular}

Variável 16 - Idade

\begin{tabular}{l||r|r|r|r|r|r}
\hline & \multicolumn{1}{|c|}{ Bons } & Ruins & \multicolumn{1}{c}{ Total } & $p b / p r$ & $\ln (p b / p r)$ & $\boldsymbol{V I}$ \\
\hline$(<25$ anos $)$ & 5.306 & 904 & 6.210 & 0,4996 & $-0,6939$ & 0,0375 \\
$(\geq 25$ e $<40$ anos $)$ & 37.555 & 4.092 & 41.647 & 0,7811 & $-0,2471$ & 0,0264 \\
$(\geq 40$ e $<58$ anos $)$ & 42.392 & 2.871 & 45.263 & 1,2568 & 0,2286 & 0,0201 \\
$(\geq 58$ anos $)$ & 13.074 & 0.502 & 13.576 & 2,2167 & 0,7960 & 0,0581 \\
\hline TOTAL & 98.327 & 8.369 & 106.696 & & & $\mathbf{0 , 1 4 2 2}$ \\
\hline
\end{tabular}


Variável 17 - Número de dependentes +1

\begin{tabular}{l||c|c|c|c|r|r}
\hline & Bons & Ruins & Total & $p b / p r$ & $\ln (p b / p r)$ & \multicolumn{1}{|c}{$\boldsymbol{V I}$} \\
\hline (=1 dependente) & 29.308 & 3.301 & 32.609 & 0,7557 & $-0,2801$ & 0,027 \\
(>1 dependente) & 69.019 & 5.068 & 74.087 & 1,1591 & 0,1476 & 0,0142 \\
\hline TOTAL & 98.327 & 8.369 & 10.6696 & & & $\mathbf{0 , 0 4 1 2}$ \\
\hline
\end{tabular}

Variável 18 - Renda

\begin{tabular}{l||c|r|r|r|r|c}
\hline & Bons & Ruins & Total & $p b / p r$ & $\ln (p b / p r)$ & $V I$ \\
\hline$(<\mathrm{R} \$ 500)$ & 15.354 & 2.297 & 17.651 & 0,5689 & $-0,5641$ & 0,0667 \\
$(\geq \mathrm{R} \$ 500 \mathrm{e}<\mathrm{R} \$ 1.000)$ & 24.257 & 2.359 & 26.616 & 0,8752 & $-0,1333$ & 0,0047 \\
$(\geq \mathrm{R} \$ 1.000 \mathrm{e}<\mathrm{R} \$ 2.000)$ & 27.301 & 2.011 & 29.312 & 1,1555 & 0,1445 & 0,0054 \\
$(\geq \mathrm{R} \$ 2.000 \mathrm{e}<\mathrm{R} \$ 4.000)$ & 18.713 & 1.186 & 19.899 & 1,3429 & 0,2948 & 0,0143 \\
$(\geq \mathrm{R} \$ 4.000)$ & 12.702 & 516 & 13.218 & 2,0952 & 0,7396 & 0,0499 \\
\hline TOTAL & 98.327 & 8.369 & 10.6696 & & & $\mathbf{0 , 0 4 1 2}$ \\
\hline
\end{tabular}

Variável 19 - Tempo de conta

\begin{tabular}{l||r|r|r|r|r|c}
\hline & \multicolumn{1}{|c|}{ Bons } & Ruins & \multicolumn{1}{c}{ Total } & $p b / p r$ & $\ln (p b / p r)$ & $\boldsymbol{V I}$ \\
\hline ( $\geq 0$ e $<6$ meses $)$ & 3.712 & 692 & 4.404 & 0,4566 & $-0,7839$ & 0,0352 \\
$(\geq 6$ e $<12$ meses $)$ & 3.810 & 596 & 4.406 & 0,5441 & $-0,6086$ & 0,0198 \\
$(\geq 1$ e $<3$ anos $)$ & 28.640 & 3.530 & 32.170 & 0,6906 & $-0,3702$ & 0,0483 \\
$(\geq 3$ e $<7$ anos $)$ & 21.109 & 1.707 & 22.816 & 1,0525 & 0,0512 & 0,0005 \\
$(\geq 7$ anos $)$ & 41.056 & 1.844 & 42.900 & 1,8950 & 0,6392 & 0,1261 \\
\hline TOTAL & 98.327 & 8.369 & 106.696 & \multicolumn{1}{|c|}{} & $\mathbf{0 , 2 2 9 9}$ \\
\hline
\end{tabular}

Variável 20 - Saldo médio em c/c

\begin{tabular}{l||r|r|r|r|r|c}
\hline & Bons & Ruins & \multicolumn{1}{c|}{ Total } & $p b / p r$ & $\ln (p b / p r)$ & $V \boldsymbol{I}$ \\
\hline missing & 16.355 & 2.810 & 19.165 & 0,4954 & $-0,7024$ & 0,1190 \\
$(<-\mathrm{R} \$ 130)$ & 4.243 & 666 & 4.909 & 0,5423 & $-0,6119$ & 0,0223 \\
$(\geq-\mathrm{R} \$ 130 \mathrm{e}<\mathrm{R} \$ 30)$ & 37.903 & 4.276 & 42.179 & 0,7545 & $-0,2817$ & 0,0353 \\
$(\geq \mathrm{R} \$ 30 \mathrm{e}<\mathrm{R} \$ 70)$ & 10.672 & 283 & 10.955 & 3,2097 & 1,1662 & 0,0871 \\
$(\geq \mathrm{R} \$ 70 \mathrm{e}<\mathrm{R} \$ 100)$ & 5.620 & 81 & 5.701 & 5,9054 & 1,7759 & 0,0843 \\
$(\geq \mathrm{R} \$ 100 \mathrm{e}<\mathrm{R} \$ 160)$ & 6.935 & 79 & 7.014 & 7,4717 & 2,0111 & 0,1229 \\
$(\geq \mathrm{R} \$ 160)$ & 16.599 & 174 & 16.773 & 8,1196 & 2,0943 & 0,3100 \\
\hline TOTAL & 98.327 & 8.369 & 106.696 & & & 0,7810 \\
\hline
\end{tabular}


Variável 21 - Saldo médio em c/c e investimentos

\begin{tabular}{l||r|r|r|r|r|c}
\hline & \multicolumn{1}{|c|}{ Bons } & Ruins & \multicolumn{1}{c|}{ Total } & $p b / p r$ & $\ln (p b / p r)$ & \multicolumn{1}{c}{$\boldsymbol{V I}$} \\
\hline$(\geq \mathrm{R} \$ 0$ e $<\mathrm{R} \$ 40)$ & 5.159 & 1.507 & 6.666 & 0,2914 & $-1,2331$ & 0,1574 \\
missing & 13.966 & 2.527 & 16.493 & 0,4704 & $-0,7542$ & 0,1206 \\
$(<\mathrm{R} \$ 0)$ ou $(\geq \mathrm{R} \$ 40$ e $<\mathrm{R} \$ 100)$ & 22.475 & 2.918 & 25.393 & 0,6556 & $-0,4222$ & 0,0507 \\
$(\geq \mathrm{R} \$ 100 \mathrm{e}<\mathrm{R} \$ 200)$ & 5.467 & 458 & 5.925 & 1,0160 & 0,0159 & 0,0000 \\
$(\geq \mathrm{R} \$ 200 \mathrm{e}<\mathrm{R} \$ 500)$ & 10.349 & 468 & 10.817 & 1,8821 & 0,6324 & 0,0312 \\
$(\geq \mathrm{R} \$ 500)$ & 40.911 & 491 & 41.402 & 7,0918 & 1,9589 & 0,7001 \\
\hline TOTAL & 98.327 & 8.369 & 106.696 & & & $\mathbf{1 , 0 6 0 0}$ \\
\hline
\end{tabular}

Variável 22 - Saldo médio em c/c dividido pela renda

\begin{tabular}{l||r|r|r|r|r|c}
\hline & \multicolumn{1}{|c|}{ Bons } & Ruins & \multicolumn{1}{c|}{ Total } & $p b / p r$ & $\ln (p b / p r)$ & $V \boldsymbol{I}$ \\
\hline$(<-0,90)$ & 1.627 & 331 & 1.958 & 0,4184 & $-0,8713$ & 0,0200 \\
missing & 16.355 & 2.810 & 19.165 & 0,4954 & $-0,7024$ & 0,1190 \\
$(\geq-0,90 \mathrm{e}<-0,30)$ & 6.258 & 937 & 7.195 & 0,5685 & $-0,5648$ & 0,0273 \\
$(\geq-0,30 \mathrm{e}<0,20)$ & 37.464 & 3.628 & 41.092 & 0,8789 & $-0,1291$ & 0,0068 \\
$(\geq 0,20 \mathrm{e}<0,50)$ & 16.416 & 356 & 16.772 & 3,9248 & 1,3673 & 0,1701 \\
$(\geq 0,50)$ & 20.207 & 307 & 20.514 & 5,6023 & 1,7232 & 0,2909 \\
\hline TOTAL & 98.327 & 8.369 & 106.696 & & & $\mathbf{0 , 6 3 4 2}$ \\
\hline
\end{tabular}

Variável 23 - Saldo médio em c/c e investimentos dividido pela renda

\begin{tabular}{l||r|r|r|r|r|r}
\hline & \multicolumn{1}{|c|}{ Bons } & Ruins & \multicolumn{1}{c|}{ Total } & \multicolumn{1}{c}{$p b / p r$} & $\ln (p b / p r)$ & \multicolumn{1}{c}{$\boldsymbol{V I}$} \\
\hline missing ou $(<-0,90)$ & 15.272 & 2.813 & 18.085 & 0,4621 & $-0,7720$ & 0,1396 \\
$(\geq-0,90 \mathrm{e}<-0,30)$ & 4.949 & 0.826 & 5.775 & 0,51 & $-0,6733$ & 0,0326 \\
$(\geq-0,30 \mathrm{e}<0,30)$ & 33.479 & 3.951 & 37.430 & 0,7212 & $-0,3268$ & 0,043 \\
$(\geq 0,30 \mathrm{e}<0,70)$ & 11.646 & 0.379 & 12.025 & 2,6154 & 0,9614 & 0,0703 \\
$(\geq 0,70 \mathrm{e}<1,00)$ & 4.639 & 0.117 & 4.756 & 3,3747 & 1,2163 & 0,0404 \\
$(\geq 1,00)$ & 28.342 & 0.283 & 28.625 & 8,524 & 2,1429 & 0,5452 \\
\hline TOTAL & 98.327 & 8.369 & 106.696 & & & $\mathbf{0 , 8 7 1 1}$ \\
\hline
\end{tabular}


Variável 24 - Variação do saldo médio em c/c

\begin{tabular}{l||c|r|c|c|r|c}
\hline & Bons & Ruins & Total & $p b / p r$ & $\ln (p b / p r)$ & $\boldsymbol{V I}$ \\
\hline missing & 11.617 & 3.004 & 14.621 & 0,3292 & $-1,1111$ & 0,2676 \\
$(<0,25)$ & 10.756 & 1.636 & 12.392 & 0,5596 & $-0,5805$ & 0,0500 \\
$(\geq 0,25 \mathrm{e}<0,50)$ ou $(\geq 5,00)$ & 17.144 & 1.307 & 18.451 & 1,1164 & 0,1101 & 0,0020 \\
$(\geq 0,50 \mathrm{e}<1,00)$ ou $(\geq 2,25 \mathrm{e}<5,00)$ & 32.045 & 1.444 & 33.489 & 1,8888 & 0,6359 & 0,0975 \\
$(\geq 1,00 \mathrm{e}<2,25)$ & 26.765 & 978 & 27.743 & 2,3293 & 0,8456 & 0,1314 \\
\hline TOTAL & 98.327 & 8.369 & 106.696 & & & $\mathbf{0 , 5 4 8 5}$ \\
\hline
\end{tabular}

Variável 25 - Variação do saldo médio em c/c e investimentos

\begin{tabular}{l||c|r|r|r|r|c}
\hline & Bons & Ruins & Total & $p b / p r$ & $\ln (p b / p r)$ & $V \boldsymbol{V}$ \\
\hline missing ou $(<0,30)$ & 17.405 & 4.031 & 21.436 & 0,3675 & $-1,0010$ & 0,3050 \\
$(\geq 0,30$ e $<0,75)$ ou $(\geq 2,85)$ & 28.721 & 1.989 & 30.710 & 1,2290 & 0,2062 & 0,0112 \\
$(\geq 0,75$ e $<1,05)$ ou $(\geq 1,35$ e $<2,85)$ & 37.352 & 1.869 & 39.221 & 1,7010 & 0,5312 & 0,0832 \\
$(\geq 1,05$ e $<1,35)$ & 14.849 & 480 & 15.329 & 2,6330 & 0,9681 & 0,0907 \\
\hline TOTAL & 98.327 & 8.369 & 106.696 & & & $\mathbf{0 , 4 9 0 0}$ \\
\hline
\end{tabular}

Variável 26 - Entradas mais saídas dividido pelo saldo médio em c/c

\begin{tabular}{l||r|r|r|r|r|c}
\hline & Bons & Ruins & \multicolumn{1}{|c|}{ Total } & $p b / p r$ & $\ln (p b / p r)$ & \multicolumn{1}{c}{$\boldsymbol{I I}$} \\
\hline$(\geq 21,25)$ & 20.334 & 3.735 & 24.069 & 0,4634 & $-0,7692$ & 0,1842 \\
missing ou $(\geq 13,75$ e $<21,25)$ & 16.314 & 2.737 & 19.051 & 0,5073 & $-0,6787$ & 0,1093 \\
$(<1,25)$ ou $(\geq 10,00$ e $<13,75)$ & 7.330 & 414 & 7.744 & 1,5070 & 0,4101 & 0,0103 \\
$(\geq 6,25$ e $<10,00)$ & 20.058 & 847 & 20.905 & 2,0156 & 0,7009 & 0,0720 \\
$(\geq 3,75$ e $<6,25)$ & 14.324 & 347 & 14.671 & 3,5135 & 1,2566 & 0,1310 \\
$(\geq 1,25$ e $<3,75)$ & 19.967 & 289 & 20.256 & 5,8805 & 1,7716 & 0,2986 \\
\hline TOTAL & 98.327 & 8.369 & 106.696 & & & $\mathbf{0 , 8 0 5 4}$ \\
\hline
\end{tabular}

Variável 27 - Número de meses desde o menor saldo em c/c

\begin{tabular}{l||c|c|c|c|r|c}
\hline & Bons & Ruins & Total & $p b / p r$ & $\ln (p b / p r)$ & $\boldsymbol{V I}$ \\
\hline 0 meses & 10.582 & 1.064 & 11.646 & 0,8465 & $-0,1666$ & 0,0033 \\
missing ou 1 ou 2 meses & 36.436 & 3.458 & 39.894 & 0,8968 & $-0,1089$ & 0,0046 \\
3,4 ou 5 meses & 51.309 & 3.847 & 55.156 & 1,1352 & 0,1268 & 0,0079 \\
\hline TOTAL & 98.327 & 8.369 & 106.696 & & & $\mathbf{0 , 0 1 5 8}$ \\
\hline
\end{tabular}


Variável 28 - Número de meses do menor saldo em c/c e investimentos

\begin{tabular}{l||c|c|c|c|r|r}
\hline & Bons & Ruins & \multicolumn{1}{c|}{ Total } & $p b / p r$ & $\ln (p b / p r)$ & \multicolumn{1}{|c|}{$\boldsymbol{I}$} \\
\hline missing, 0, 1 ou 2 meses & 42.364 & 4.211 & 46.575 & 0,8563 & $-0,1551$ & 0,0112 \\
3,4 ou 5 meses & 55.963 & 4.158 & 60.121 & 1,1456 & 0,1359 & 0,0098 \\
\hline TOTAL & 98.327 & 8.369 & 106.696 & & & $\mathbf{0 , 0 2 1 0}$ \\
\hline
\end{tabular}

Variável 29 - Dias de excesso em c/c

\begin{tabular}{l||r|r|r|r|r|c}
\hline & Bons & Ruins & \multicolumn{1}{|c|}{ Total } & $p b / p r$ & $\ln (p b / p r)$ & $\boldsymbol{V I}$ \\
\hline missing ou ( $\geq 30$ dias) & 7.155 & 2.056 & 9.211 & 0,2962 & $-1,2167$ & 0,2104 \\
$(\geq 7$ e $<30$ dias) & 2.359 & 447 & 2.806 & 0,4492 & $-0,8003$ & 0,0235 \\
$(\geq 1$ e $<7$ dias $)$ & 1.349 & 202 & 1.551 & 0,5684 & $-0,5649$ & 0,0059 \\
$(<1$ dia $)$ & 87.464 & 5.664 & 93.128 & 1,3143 & 0,2733 & 0,0581 \\
\hline TOTAL & 98.327 & 8.369 & 106.696 & & & $\mathbf{0 , 2 9 8 0}$ \\
\hline
\end{tabular}

Variável 30 - Cheques devolvidos

\begin{tabular}{l||r|r|r|r|r|c}
\hline & Bons & Ruins & \multicolumn{1}{c|}{ Total } & $p b / p r$ & $\ln (p b / p r)$ & $\boldsymbol{V I}$ \\
\hline mais que 5 cheques & 2.987 & 1.657 & 4.644 & 0,1534 & $-1,8747$ & 0,3142 \\
missing & 5.838 & 1.651 & 7.489 & 0,3010 & $-1,2006$ & 0,1656 \\
3,4 ou 5 cheques & 3.625 & 621 & 4.246 & 0,4968 & $-0,6996$ & 0,0261 \\
1 ou 2 cheques & 8.778 & 876 & 9.654 & 0,8529 & $-0,1591$ & 0,0025 \\
nenhum cheque & 77.099 & 3.564 & 80.663 & 1,8412 & 0,6104 & 0,2187 \\
\hline TOTAL & 98.327 & 8.369 & 106.696 & \multicolumn{5}{|c}{} & $\mathbf{0 , 7 2 7 0}$ \\
\hline
\end{tabular}

Variável 31 - Dias de excesso em cheque especial

\begin{tabular}{l||r|r|r|r|r|c}
\hline & \multicolumn{1}{||}{ Bons } & Ruins & \multicolumn{1}{c|}{ Total } & $p b / p r$ & $\ln (p b / p r)$ & $\boldsymbol{V I}$ \\
\hline mais do que 29 dias & 2.528 & 1.104 & 3.632 & 0,1949 & $-1,6353$ & 0,1737 \\
missing & 23.103 & 4.890 & 27.993 & 0,4021 & $-0,9111$ & 0,3182 \\
de 15 a 29 dias & 2.962 & 505 & 3.467 & 0,4992 & $-0,6947$ & 0,0210 \\
de 8 a 14 dias & 3.323 & 387 & 3.710 & 0,7308 & $-0,3136$ & 0,0039 \\
de 2 a 7 dias & 7.123 & 505 & 7.628 & 1,2005 & 0,1827 & 0,0022 \\
1 dia & 3.256 & 193 & 3.449 & 1,4359 & 0,3618 & 0,0036 \\
nenhum dia & 56.032 & 785 & 56.817 & 6,0753 & 1,8042 & 0,8589 \\
\hline TOTAL & 98.327 & 8.369 & 106.696 & & & $\mathbf{1 , 3 8 1 6}$ \\
\hline
\end{tabular}


Variável 32 - Utilização máxima de cheque especial

\begin{tabular}{l||r|r|r|r|r|c}
\hline & Bons & Ruins & \multicolumn{1}{c|}{ Total } & $p b / p r$ & $\ln (p b / p r)$ & $V I$ \\
\hline missing ou $(\geq 0.85)$ & 30.194 & 6.678 & 36.872 & 0,3848 & $-0,9550$ & 0,4687 \\
$(\geq 0,60 \mathrm{e}<0,85)$ & 11.305 & 816 & 12.121 & 1,1792 & 0,1648 & 0,0029 \\
$(\geq 0,45 \mathrm{e}<0,60)$ & 6.424 & 255 & 6.679 & 2,1442 & 0,7628 & 0,0266 \\
$(\geq 0,30 \mathrm{e}<0,45)$ & 6.513 & 168 & 6.681 & 3,2997 & 1,1938 & 0,0551 \\
$(\geq 0,20 \mathrm{e}<0,30)$ & 5.137 & 95 & 5.232 & 4,6024 & 1,5266 & 0,0624 \\
$(\geq 0,10 \mathrm{e}<0,20)$ & 6.633 & 72 & 6.705 & 7,8411 & 2,0594 & 0,1212 \\
$(<0,10)$ & 32.121 & 285 & 32.406 & 9,5928 & 2,2610 & 0,6616 \\
\hline TOTAL & 98.327 & 8.369 & 106.696 & & & $\mathbf{1 , 3 9 8 6}$ \\
\hline
\end{tabular}

Variável 33 - Utilização média de cheque especial

\begin{tabular}{l||r|r|r|r|r|c}
\hline & \multicolumn{1}{|c|}{ Bons } & Ruins & \multicolumn{1}{c|}{ Total } & \multicolumn{1}{c}{$p b / p r$} & $\ln (p b / p r)$ & $\boldsymbol{V} \boldsymbol{I}$ \\
\hline missing ou $(\geq 0,70)$ & 26.944 & 6.070 & 33.014 & 0,3778 & $-0,9734$ & 0,4393 \\
$(\geq 0,50 \mathrm{e}<0,70)$ & 6.371 & 857 & 7.228 & 0,6327 & $-0,4578$ & 0,0172 \\
$(\geq 0,30 \mathrm{e}<0,50)$ & 9.125 & 651 & 9.776 & 1,1930 & 0,1765 & 0,0027 \\
$(\geq 0,15 \mathrm{e}<0,30)$ & 9.542 & 317 & 9.859 & 2,5620 & 0,9408 & 0,0557 \\
$(\geq 0,05 \mathrm{e}<0,15)$ & 10.760 & 182 & 10.942 & 5,0320 & 1,6158 & 0,1417 \\
$(<0,05)$ & 35.585 & 292 & 35.877 & 10,3725 & 2,3392 & 0,7649 \\
\hline TOTAL & 98.327 & 8.369 & 106.696 & & & $\mathbf{1 , 4 2 1 4}$ \\
\hline
\end{tabular}

Variável 34 - Número de meses da utilização de cheque

\begin{tabular}{l||r|r|r|r|r|c}
\hline & \multicolumn{1}{|c|}{ Bons } & Ruins & \multicolumn{1}{c|}{ Total } & $p b / p r$ & $\ln (p b / p r)$ & \multicolumn{1}{c}{$\boldsymbol{V} \boldsymbol{c}$} \\
\hline não utilizou nos últimos 6 meses & 36.862 & 5.027 & 41.889 & 0,6241 & $-0,4714$ & 0,1064 \\
mês corrente ou 5 meses atrás & 46.886 & 2.906 & 49.792 & 1,3732 & 0,3171 & 0,0411 \\
2,3 ou 4 meses atrás & 7.137 & 258 & 7.395 & 2,3545 & 0,8563 & 0,0358 \\
mês passado & 7.442 & 178 & 7.620 & 3,5585 & 1,2693 & 0,0691 \\
\hline TOTAL & 98.327 & 8.369 & 106.696 & & & $\mathbf{0 , 2 5 2 4}$ \\
\hline
\end{tabular}


Variável 35 - Valor médio de empréstimos

\begin{tabular}{l||r|r|r|r|r|c}
\hline & Bons & Ruins & \multicolumn{1}{c|}{ Total } & $p b / p r$ & $\ln (p b / p r)$ & $\boldsymbol{V I}$ \\
\hline$(\geq \mathrm{R} \$ 5.000)$ & 2.241 & 662 & 2.903 & 0,2881 & $-1,2444$ & 0,0701 \\
$(\geq \mathrm{R} \$ 410$ e $<\mathrm{R} \$ 5.000)$ & 17.405 & 2.884 & 20.289 & 0,5137 & $-0,6661$ & 0,1116 \\
$(\geq \mathrm{R} \$ 110$ e $<\mathrm{R} \$ 410)$ & 15.396 & 1.728 & 17.124 & 0,7583 & $-0,2767$ & 0,0138 \\
$(\geq \mathrm{R} \$ 30$ e $<\mathrm{R} \$ 110)$ ou missing & 26.843 & 2.299 & 29.142 & 0,9938 & $-0,0062$ & 0,0000 \\
$(<\mathrm{R} \$ 30)$ & 36.442 & 796 & 37.238 & 3,8966 & 1,3601 & 0,3747 \\
\hline TOTAL & 98.327 & 8.369 & 106.696 & \multicolumn{4}{|c|}{} & $\mathbf{0 , 5 7 0 3}$ \\
\hline
\end{tabular}

Variável 36 - Valor de empréstimos dividido pela renda

\begin{tabular}{l||r|r|r|r|r|c}
\hline & Bons & Ruins & \multicolumn{1}{c|}{ Total } & $p b / p r$ & $\ln (p b / p r)$ & $V \boldsymbol{I}$ \\
\hline$(\geq 14)$ & 572 & 264 & 836 & 0,1844 & $-1,6906$ & 0,0435 \\
$(\geq 1,05$ e $<14)$ & 5.817 & 1.684 & 7.501 & 0,2940 & $-1,2242$ & 0,1739 \\
$(\geq 0,55$ e $<1,05)$ & 5.352 & 1.148 & 6.500 & 0,3968 & $-0,9243$ & 0,0765 \\
$(\geq 0,10$ e $<0,55)$ ou missing & 39.069 & 4.168 & 43.237 & 0,7978 & $-0,2259$ & 0,0227 \\
$(\geq 0$ e $<0,10)$ & 20.496 & 0.695 & 21.191 & 2,5101 & 0,9203 & 0,1154 \\
(igual a zero) & 27.021 & 410 & 27.431 & 5,6094 & 1,7244 & 0,3894 \\
\hline TOTAL & 98.327 & 8.369 & 106.696 & & & 0,8214 \\
\hline
\end{tabular}

Variável 37 - Menor valor de saldo médio em c/c dividido por empréstimos

\begin{tabular}{l||r|r|r|r|r|c}
\hline & Bons & Ruins & \multicolumn{1}{c|}{ Total } & $p b / p r$ & $\ln (p b / p r)$ & $V I$ \\
\hline missing ou $(\geq 0 \mathrm{e}<0,60)$ & 22.503 & 4.161 & 26.664 & 0,4603 & $-0,7759$ & 0,2082 \\
$(<0)$ ou $(\geq 0,60 \mathrm{e}<6)$ & 47.757 & 3.840 & 51.597 & 1,0585 & 0,0569 & 0,0015 \\
$(\geq 6 \mathrm{e}<40)$ & 5.000 & 229 & 5.229 & 1,8584 & 0,6197 & 0,0146 \\
$(\geq 40 \mathrm{e}<70)$ & 1.503 & 32 & 1.535 & 3,9977 & 1,3857 & 0,0159 \\
$(\geq 70 \mathrm{e}<100)$ & 1.920 & 36 & 1.956 & 4,5394 & 1,5128 & 0,0230 \\
$(\geq 100 \mathrm{e}<500)$ & 9.876 & 58 & 9.934 & 14,4929 & 2,6737 & 0,2500 \\
$(\geq 500)$ & 9.768 & 13 & 9.781 & 63,9533 & 4,1582 & 0,4066 \\
\hline TOTAL & 98.327 & 8.369 & 106.696 & & & $\mathbf{0 , 9 1 9 8}$ \\
\hline
\end{tabular}


Variável 38 - Menor valor de saldo médio em c/c e investimentos dividido por empréstimos

\begin{tabular}{l||r|r|r|c|r|c}
\hline & Bons & Ruins & Total & $p b / p r$ & $\ln (p b / p r)$ & \multicolumn{1}{c}{$\boldsymbol{I}$} \\
\hline missing ou $(\geq 0$ e $<0,10)$ & 16.826 & 3.819 & 20.645 & 0,3750 & $-0,9808$ & 0,2797 \\
$(\geq 0,10$ e $<0,30)$ ou $(\geq-6$ e $<0)$ & 23.069 & 2.739 & 25.808 & 0,7169 & $-0,3328$ & 0,0308 \\
$(\geq 0,30$ e $<1,25)$ ou $(\geq-30$ e $<-6)$ & 7.210 & 513 & 7.723 & 1,1962 & 0,1791 & 0,0022 \\
$(\geq 1,25$ e $<2,50)$ ou $(<-30)$ & 11.888 & 690 & 12.578 & 1,4664 & 0,3828 & 0,0147 \\
$(\geq 2,50$ e $<10)$ & 5.182 & 218 & 5.400 & 2,0232 & 0,7047 & 0,0188 \\
$(\geq 10)$ & 34.152 & 390 & 34.542 & 7,4534 & 2,0087 & 0,6041 \\
\hline TOTAL & 98.327 & 8.369 & 106.696 & & & $\mathbf{0 , 9 5 0 3}$ \\
\hline
\end{tabular}




\section{Apêndice $\mathrm{C}$}

\section{Escolha dos Parâmetros do REAL}

Tabela C.1: Tamanho das amostras

\begin{tabular}{c||r|r|r}
\hline \hline Amostra & Qtde.Bons & Qtde.Ruins & Total \\
\hline \hline 1 & 848 & 825 & 1.673 \\
\hline 2 & 809 & 864 & 1.673 \\
\hline 3 & 846 & 827 & 1.673 \\
\hline 4 & 858 & 815 & 1.673 \\
\hline 5 & 829 & 844 & 1.673 \\
\hline 6 & 839 & 834 & 1.673 \\
\hline 7 & 851 & 822 & 1.673 \\
\hline 8 & 808 & 865 & 1.673 \\
\hline 9 & 863 & 810 & 1.673 \\
\hline 10 & 818 & 863 & 1.681 \\
\hline Total & 8.369 & 8.369 & 16.738 \\
\hline
\end{tabular}


Tabela C.2: $\quad r=2,0 ; c l=0,10$

\begin{tabular}{c||c|c|c}
\hline \hline Amostra & TAR & TAB & TAT \\
\hline \hline 1 & 0,6764 & 0,8278 & 0,7531 \\
\hline 2 & 0,6528 & 0,8245 & 0,7358 \\
\hline 3 & 0,6759 & 0,8180 & 0,7478 \\
\hline 4 & 0,6699 & 0,8403 & 0,7573 \\
\hline 5 & 0,6528 & 0,8384 & 0,7448 \\
\hline 6 & 0,6847 & 0,8069 & 0,7460 \\
\hline 7 & 0,6983 & 0,8249 & 0,7627 \\
\hline 8 & 0,6566 & 0,8391 & 0,7448 \\
\hline 9 & 0,6790 & 0,8134 & 0,7484 \\
\hline 10 & 0,6860 & 0,7946 & 0,7388 \\
\hline \hline Média & 0,6732 & 0,8228 & 0,7479 \\
\hline D.P. & 0,0152 & 0,0149 & 0,0081 \\
\hline \hline
\end{tabular}

Tabela C.3: $\quad r=2,0 ; c l=0,30$

\begin{tabular}{c||c|c|c}
\hline \hline Amostra & TAR & TAB & TAT \\
\hline \hline 1 & 0,7152 & 0,8774 & 0,7974 \\
\hline 2 & 0,6759 & 0,8912 & 0,7800 \\
\hline 3 & 0,7098 & 0,8948 & 0,8033 \\
\hline 4 & 0,7043 & 0,8904 & 0,7998 \\
\hline 5 & 0,6943 & 0,9119 & 0,8022 \\
\hline 6 & 0,7182 & 0,8892 & 0,8039 \\
\hline 7 & 0,7360 & 0,8872 & 0,8129 \\
\hline 8 & 0,8763 & 0,7785 & 0,8290 \\
\hline 9 & 0,7272 & 0,8934 & 0,8129 \\
\hline 10 & 0,8413 & 0,8020 & 0,8221 \\
\hline \hline Média & 0,7398 & 0,8716 & 0,8064 \\
\hline D.P. & 0,0654 & 0,0441 & 0,0137 \\
\hline \hline
\end{tabular}


Tabela C.4: $\quad r=2,0 ; c l=0,50$

\begin{tabular}{c||c|c|c}
\hline \hline Amostra & TAR & TAB & TAT \\
\hline \hline 1 & 0,8097 & 0,8290 & 0,8195 \\
\hline 2 & 0,7731 & 0,8504 & 0,8105 \\
\hline 3 & 0,7944 & 0,8203 & 0,8075 \\
\hline 4 & 0,8098 & 0,8403 & 0,8255 \\
\hline 5 & 0,8270 & 0,8359 & 0,8314 \\
\hline 6 & 0,7974 & 0,8415 & 0,8195 \\
\hline 7 & 0,8285 & 0,8261 & 0,8273 \\
\hline 8 & 0,8104 & 0,8601 & 0,8344 \\
\hline 9 & 0,8247 & 0,8192 & 0,8219 \\
\hline 10 & 0,8146 & 0,8264 & 0,8203 \\
\hline \hline Média & 0,8090 & 0,8349 & 0,8218 \\
\hline D.P. & 0,0171 & 0,0133 & 0,0084 \\
\hline \hline
\end{tabular}

Tabela C.5: $\quad r=3,0 ; c l=0,10$

\begin{tabular}{c||c|c|c}
\hline \hline Amostra & TAR & TAB & TAT \\
\hline \hline 1 & 0,6764 & 0,8278 & 0,7531 \\
\hline 2 & 0,6528 & 0,8245 & 0,7358 \\
\hline 3 & 0,6759 & 0,8180 & 0,7478 \\
\hline 4 & 0,6699 & 0,8403 & 0,7573 \\
\hline 5 & 0,6528 & 0,8384 & 0,7448 \\
\hline 6 & 0,6847 & 0,8069 & 0,7460 \\
\hline 7 & 0,6983 & 0,8249 & 0,7627 \\
\hline 8 & 0,6566 & 0,8391 & 0,7448 \\
\hline 9 & 0,6790 & 0,8134 & 0,7484 \\
\hline 10 & 0,6860 & 0,7946 & 0,7388 \\
\hline \hline Média & 0,6732 & 0,8228 & 0,7479 \\
\hline D.P. & 0,0152 & 0,0149 & 0,0081 \\
\hline \hline
\end{tabular}


Tabela C.6: $\quad r=3,0 ; c l=0,30$

\begin{tabular}{c||c|c|c}
\hline \hline Amostra & TAR & TAB & TAT \\
\hline \hline 1 & 0,7212 & 0,8502 & 0,7866 \\
\hline 2 & 0,6771 & 0,8554 & 0,7633 \\
\hline 3 & 0,7050 & 0,8830 & 0,7950 \\
\hline 4 & 0,7018 & 0,8869 & 0,7968 \\
\hline 5 & 0,7026 & 0,8914 & 0,7962 \\
\hline 6 & 0,7098 & 0,8701 & 0,7902 \\
\hline 7 & 0,7348 & 0,8707 & 0,8039 \\
\hline 8 & 0,8694 & 0,7512 & 0,8123 \\
\hline 9 & 0,7148 & 0,8911 & 0,8057 \\
\hline 10 & 0,8343 & 0,7641 & 0,8001 \\
\hline \hline Média & 0,7371 & 0,8514 & 0,7950 \\
\hline D.P. & 0,0628 & 0,0515 & 0,0134 \\
\hline \hline
\end{tabular}

Tabela C.7: $\quad r=3,0 ; c l=0,50$

\begin{tabular}{c||c|c|c}
\hline \hline Amostra & TAR & TAB & TAT \\
\hline \hline 1 & 0,7952 & 0,8373 & 0,8165 \\
\hline 2 & 0,7905 & 0,8504 & 0,8195 \\
\hline 3 & 0,7944 & 0,8203 & 0,8075 \\
\hline 4 & 0,7828 & 0,8636 & 0,8243 \\
\hline 5 & 0,6943 & 0,9119 & 0,8022 \\
\hline 6 & 0,7878 & 0,8403 & 0,8141 \\
\hline 7 & 0,8285 & 0,8261 & 0,8273 \\
\hline 8 & 0,7896 & 0,8787 & 0,8326 \\
\hline 9 & 0,8247 & 0,8192 & 0,8219 \\
\hline 10 & 0,8146 & 0,8289 & 0,8215 \\
\hline \hline Média & 0,7902 & 0,8477 & 0,8187 \\
\hline D.P. & 0,0373 & 0,0296 & 0,0091 \\
\hline \hline
\end{tabular}


Tabela C.8: $\quad r=4,0 ; c l=0,10$

\begin{tabular}{c||c|c|c}
\hline \hline Amostra & TAL & TAB & TAT \\
\hline \hline 1 & 0,6764 & 0,8278 & 0,7531 \\
\hline 2 & 0,6528 & 0,8245 & 0,7358 \\
\hline 3 & 0,6759 & 0,8180 & 0,7478 \\
\hline 4 & 0,6699 & 0,8403 & 0,7573 \\
\hline 5 & 0,6528 & 0,8384 & 0,7448 \\
\hline 6 & 0,6847 & 0,8069 & 0,7460 \\
\hline 7 & 0,6983 & 0,8249 & 0,7627 \\
\hline 8 & 0,6566 & 0,8391 & 0,7448 \\
\hline 9 & 0,6790 & 0,8134 & 0,7484 \\
\hline 10 & 0,6860 & 0,7946 & 0,7388 \\
\hline \hline Média & 0,6732 & 0,8228 & 0,7479 \\
\hline D.P. & 0,0152 & 0,0149 & 0,0081 \\
\hline \hline
\end{tabular}

Tabela C.9: $\quad r=4,0 ; c l=0,30$

\begin{tabular}{c||c|c|c}
\hline \hline Amostra & TAR & TAB & TAT \\
\hline \hline 1 & 0,7273 & 0,8738 & 0,8016 \\
\hline 2 & 0,8310 & 0,7862 & 0,8093 \\
\hline 3 & 0,7098 & 0,8948 & 0,8033 \\
\hline 4 & 0,7043 & 0,8904 & 0,7998 \\
\hline 5 & 0,7026 & 0,9059 & 0,8033 \\
\hline 6 & 0,7182 & 0,8903 & 0,8045 \\
\hline 7 & 0,7360 & 0,8872 & 0,8129 \\
\hline 8 & 0,8763 & 0,7785 & 0,8290 \\
\hline 9 & 0,7272 & 0,8934 & 0,8129 \\
\hline 10 & 0,8494 & 0,7763 & 0,8138 \\
\hline \hline Média & 0,7582 & 0,8577 & 0,8091 \\
\hline D.P. & 0,0666 & 0,0540 & 0,0087 \\
\hline \hline \multicolumn{4}{|c}{}
\end{tabular}


Tabela C.10: $\quad r=4,0 ; c l=0,50$

\begin{tabular}{c||c|c|c}
\hline \hline Amostra & TAR & TAB & TAT \\
\hline \hline 1 & 0,7200 & 0,8691 & 0,7956 \\
\hline 2 & 0,8044 & 0,8269 & 0,8153 \\
\hline 3 & 0,7944 & 0,8203 & 0,8075 \\
\hline 4 & 0,6982 & 0,8974 & 0,8004 \\
\hline 5 & 0,6955 & 0,9131 & 0,8033 \\
\hline 6 & 0,7866 & 0,8403 & 0,8135 \\
\hline 7 & 0,7299 & 0,8954 & 0,8141 \\
\hline 8 & 0,8012 & 0,8688 & 0,8338 \\
\hline 9 & 0,7148 & 0,9038 & 0,8123 \\
\hline 10 & 0,8239 & 0,8130 & 0,8186 \\
\hline \hline Média & 0,7569 & 0,8648 & 0,8114 \\
\hline D.P. & 0,0495 & 0,0374 & 0,0107 \\
\hline \hline
\end{tabular}

Tabela C.11: $\quad r=5,0 ; c l=0,10$

\begin{tabular}{c||c|c|c}
\hline \hline Amostra & TAR & TAB & TAT \\
\hline \hline 1 & 0,6764 & 0,8278 & 0,7531 \\
\hline 2 & 0,6528 & 0,8245 & 0,7358 \\
\hline 3 & 0,6759 & 0,8180 & 0,7478 \\
\hline 4 & 0,6699 & 0,8403 & 0,7573 \\
\hline 5 & 0,6528 & 0,8384 & 0,7448 \\
\hline 6 & 0,6847 & 0,8069 & 0,7460 \\
\hline 7 & 0,6983 & 0,8249 & 0,7627 \\
\hline 8 & 0,6566 & 0,8391 & 0,7448 \\
\hline 9 & 0,6790 & 0,8134 & 0,7484 \\
\hline 10 & 0,6860 & 0,7946 & 0,7388 \\
\hline \hline Média & 0,6732 & 0,8228 & 0,7479 \\
\hline D.P. & 0,0152 & 0,0149 & 0,0081 \\
\hline \hline
\end{tabular}


Tabela C.12: $\quad r=5,0 ; c l=0,30$

\begin{tabular}{c||c|c|c}
\hline \hline Amostra & TAR & TAB & TAT \\
\hline \hline 1 & 0,7273 & 0,8738 & 0,8016 \\
\hline 2 & 0,8310 & 0,7862 & 0,8093 \\
\hline 3 & 0,7098 & 0,8948 & 0,8033 \\
\hline 4 & 0,7043 & 0,8904 & 0,7998 \\
\hline 5 & 0,8614 & 0,7973 & 0,8296 \\
\hline 6 & 0,7182 & 0,8903 & 0,8045 \\
\hline 7 & 0,8625 & 0,7767 & 0,8189 \\
\hline 8 & 0,8763 & 0,7785 & 0,8290 \\
\hline 9 & 0,7272 & 0,8934 & 0,8129 \\
\hline 10 & 0,8494 & 0,7763 & 0,8138 \\
\hline \hline Média & 0,7867 & 0,8358 & 0,8123 \\
\hline D.P. & 0,0743 & 0,0562 & 0,0108 \\
\hline \hline
\end{tabular}

Tabela C.13: $\quad r=5,0 ; c l=0,50$

\begin{tabular}{c||c|c|c}
\hline \hline Amostra & TAR & TAB & TAT \\
\hline \hline 1 & 0,7200 & 0,8738 & 0,7980 \\
\hline 2 & 0,7731 & 0,8591 & 0,8147 \\
\hline 3 & 0,8089 & 0,8038 & 0,8063 \\
\hline 4 & 0,6957 & 0,8998 & 0,8004 \\
\hline 5 & 0,8235 & 0,8408 & 0,8320 \\
\hline 6 & 0,7074 & 0,8987 & 0,8033 \\
\hline 7 & 0,8431 & 0,8120 & 0,8273 \\
\hline 8 & 0,8520 & 0,8230 & 0,8380 \\
\hline 9 & 0,7148 & 0,9038 & 0,8123 \\
\hline 10 & 0,8239 & 0,8130 & 0,8186 \\
\hline \hline Média & 0,7762 & 0,8528 & 0,8151 \\
\hline D.P. & 0,0614 & 0,0396 & 0,0138 \\
\hline \hline
\end{tabular}




\section{Bibliografia}

[1] Anderson, J.A.; Rosenfeld, E. (1988). Neurocomputing: Foundations of Research. MIT Press, Cambridge.

[2] Bishop, C. M. (1995). Neural Networks for Pattern Recognition. University Press, Oxford.

[3] Breiman, L.; Friedman, J.H.; Olshen, R.A. and Stone, C.H. (1984). Classificaction and regression trees. Warsworth International, California.

[4] Broomhead, D.S. and Lowe, D. (1988). Multivariable Functional Interpolation and Adaptive Networks. Complex Systems, 2, 321-355.

[5] Cox, D.R. (1970). The Analysis of Binary Data. Methuen \& Co. Ltd., London.

[6] Desai, V. S.; Crook, J. N. and Overstreet Jr., G. A. (1996). A comparison of neural networks and linear scoring models in the credit union environment. European Journal of Operational Research, 95, 24-37.

[7] Fahlman, S.E. (1988). Faster-learning variations on back-propagation: an empirical study. In D. Touretzky, G.E. Hinton e T.J. Sejnowski Eds.), Proceedings of the 1988 Connectionist Models Summer School, 38-51, Morgan Kaufmann, San Mateo.

[8] Fausett, L. (1994). Fundamentals of Neural Networks. Prentice Hall, New York.

[9] Ferreira, C.A. (1999). Comparação da Capacidade Preditiva da Regressão Loística, CART e Redes Neurais. Dissertação de Mestrado. Departamento de Estatística. Universidade Federal de Minas Gerais. 
[10] Hand, D.J. and Henley, W.E. (1997). Statistical Classification Methods in Consumer Credit Scoring: a Review. Journal of the Royal Statistical; Society A, 160, 523-541.

[11] Haykin, S. (1994). Neural Networks : A Comprehensive Foundation. Macmillan Publishing, New York.

[12] Hopfield, J.J. (1984). Neurons with Graded Response Have Collective Computational Properties like Those of Two-state Neurons. Proceedings of the National Academy of Sciences, 81, 3088-3092. Reprinted in Anderson \& Rosenfeld (1988).

[13] Hosmer, Jr. D. W and Lemeshow, S. (1989). Applied Logistic Regression. John Wiley \& Sons, New York.

[14] Jacobs, R.A. (1988). Increased Rates of Convergence Through Learning Rate Adaptation. Neural Networks, 1(4), 295-307.

[15] Kohonen, T. (1982). Self-organized Formation of Topologically Correct Feature Maps. Biological Cybernetics, 43, 59-69.

[16] McCullagh, P. and Nelder, J.A. (1989). Generalized Linear Models (The Monographs on Statistics and Applied Probability), Vol 37, 2. Ed., Chapman and Hall.

[17] McCulloch, W.S.; Pitts, W. (1943). A Logical Calculus of the Ideas Immanent in Nervous Activity. Bulletin of Mathematical Biophysics, 5, 115-133. Reprinted in Anderson \& Rosenfeld (1988).

[18] Moody, J.; Darken, C.J. (1989). Fast Learning in Networks of Locally Tuned Processing Units. Neural Computation, 1, 281-294.

[19] Morgan, J.N.; Sonquist, J.A. (1963). Problems in the Analysis of Survey Data, and a Proposal. Journal of the Amarican Statistical Association, 58, 514-435.

[20] Neter, J.; Kutner, M.H.; Nachtschiem, C.J.; Wasserman, W. (1996). Applied Linear Statistical Models. Irwin, Boston. 
[21] Oliveira, R.B.S. (2000). Deteç̧ão de Problemas em Instituiçôes Financeiras Utilizando Modelos Estatísticos. Dissertação de Mestrado. Departamento de Estatística. Universidade de São Paulo.

[22] Parzen, E. (1962). On Estimation of a Probability Density Function and Mòde. Annals of Mathematical Statistics, 33, 1065-1076.

[23] Patterson, D. (1996). Artificial Neural Networks. Prentice Hall, Singapore.

[24] Paula, G. A. (1997). Modelos de Regressão. Instituto de Matemática e Estatística - Universidade de São Paulo.

[25] Pregibon, D. (1981). Logistic Regression Diagostics. The Annals of Statistics, 9, 705-724.

[26] Rao, C.R. (1973). Linear Statistical Inference and Its Applications. 2. Ed., John Wiley \& Sons, New York.

[27] Rosa, P.T.M. (2000). Modelos de "Credit Scoring": Regressão Logística, CHAID e REAL. Dissertação de Mestrado. Departamento de Estatística. Universidade de São Paulo.

[28] Rosenblatt, F. (1958). The Perceptron: a Probabilistic Model for Information Storage and Organization in the Brain. Psychological Review, 65, 386-408. Reprinted in Anderson \& Rosenfeld (1988).

[29] Rumelhart, D.E. and McClelland, J. (1986). Parallel Distributed Processing : Explorations in the Microstructure of Cognition, Vol 1., MIT Press, Cambridge.

[30] Sanda, R. (1990). Análise Discriminante com Mistura de Variáveis Categóricas e Contínuas. Dissertação de Mestrado. Departamento de Estatística. Universidade de São Paulo.

[31] SAS Institute Inc, SAS/Language: Reference, Version 6, First Edition, Cary, NC: SAS Institute Inc., 1990.

[32] SAS Institute Inc., SAS/Guide to Macro Processing, Version 6, Second Edition, Cary, NC: SAS Institute Inc., 1990. 
[33] SAS Institute Inc., SAS/Procedures Guide, Release V.03 Edition. Cary, NC: SAS Institute Inc., 1988.

[34] SAS Institute Inc., SAS/STAT User's Guide, Version 6, Fourth Edition, Volume 1, Cary, NC: SAS Institute Inc., 1989.

[35] SAS Institute Inc., SAS/STAT User's Guide, Version 6, Fourth Edition, Volume 2, Cary, NC: SAS Institute Inc., 1989.

[36] Shepherd, A.J. (1997). Second-Order Methods for Neural Networks. Springer, New York.

[37] Specht, D.F. (1990). Probabilistic Neural Networks. Neural Networks, 3(1), 109-118.

[38] SPSS Inc., AnswerTree 2.0 User's Guide, Chicago, IL: SPSS Inc., 1998.

[39] StatSoft Inc., STATISTIC Neural Networks User's Guide, Addendum for Version 4, Tulsa, OK: StatSoft Inc., 1998.

[40] StatSoft Inc., STATISTIC Neural Networks User's Guide, Tulsa, OK: StatSoft Inc., 1998.

[41] Stern, J.M.; Nakano, F. e Lauretto, M. (1996).REAL: Real Attribute Learning for Strategic Market Operation., Tech.Report RT-MAC-9606, Instituto de Matemática e Estatística - Universidade de São Paulo.

[42] Thomas, L.C.; Edelman, D.B. and Crook, J.N. (2002). Credit Scoring and Its Applications. SIAM monographs on mathematical modeling and computation.

[43] Walker, S.H.; Duncan, D.B. (1967). Estimation of the Probability of an Event as a Function of Several Independent Variables. Biometrika,6, 568-576. 